\title{
Riding the Biotechnology Wave: A Mixed-Methods Analysis of
}

\section{Malaysia's emerging Biotechnology industry}

by

\author{
Melvyn Wei Ming Loh
}

\author{
A thesis \\ submitted to the Victoria University of Wellington \\ in fulfilment of the \\ requirements for the degree of \\ Master of Commerce and Administration \\ in Management
}

Victoria University of Wellington

2009 


\begin{abstract}
Building a sustainable bioeconomy requires strategic alliances, intellectual property, funding and talent. The research focus of this empirical study was to assess Malaysian biotechnology companies regarding their opinions on priorities and capabilities necessary to establish a thriving bioeconomy. The research questions that form the basis of this paper explore the extent to which initial factor endowments affect the trajectory of biotechnology industry development and how Malaysia should prioritise, mobilise and coordinate resources to build a bioeconomy. A mixed methods approach using qualitative interviews and case studies, as well as a quantitative survey, indicated that respondents advocated a resource-based-view in terms of resource allocation and agglomeration towards building Malaysia's bioecnomy. That is, there was strong support to leverage Malaysia's existing capabilities in agriculture and biofuels to derive value-added products towards gaining leadership positions in these respective biotechnology sectors globally. Access to funding and talent emerged as the highest priority capabilities necessary for commercialising discoveries, conducting research and development and accelerating innovation. Respondents perceived the government as having a 'very important' role in building and accelerating the Malaysian biotechnology industry. The gap between required capabilities and strategic priorities provides a framework within which the government may play a central role in coordinate, accelerating and resourcing Malaysia's nascent bioeconomy.
\end{abstract}




\section{Acknowledgements}

I would like to thank my supervisor, Professor Mark Ahn during this MCA programme. His guidance, patience and expertise assisted me to complete this paper successfully and with great pride.

I would also like to thank the management team of Malaysia Biotechnology Corporation for the opportunity to cooperate on this successful research project. I also hope the results and recommendations will greatly assist Malaysia's bid to establish their own bioeconomy.

I thank the journal reviewers on reviewing and considering this paper for future publications and their inputs on editing this paper.

Lastly I would like to thank my parents for their financial and mental support of my studies and their endless love. 


\section{Table of Contents}

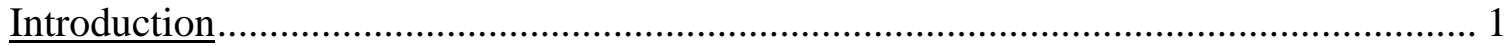

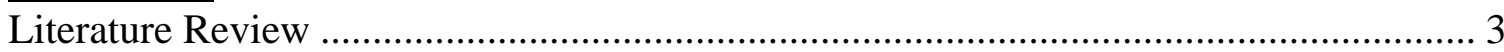

Global Biotech Industry .................................................................................. 3

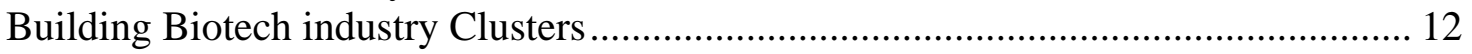

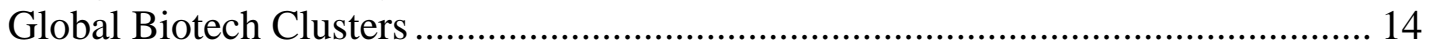

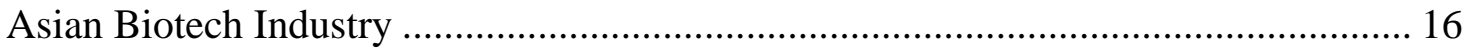

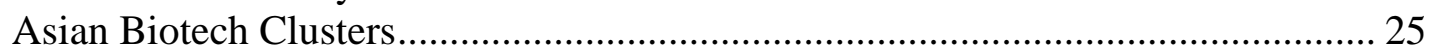

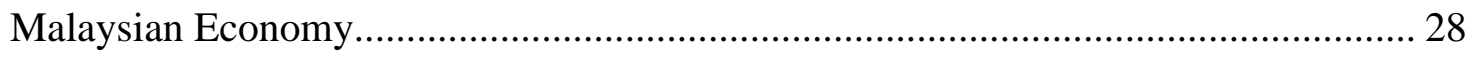

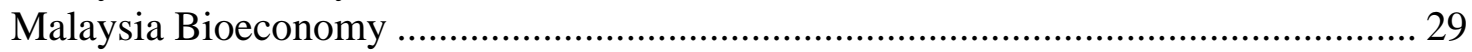

Malaysian Government Strategies for biotech sector growth.............................. 33

Malaysian Biotech Fund and Venture Capital ........................................................ 38

Malaysia Intellectual Property Competitiveness ................................................ 43

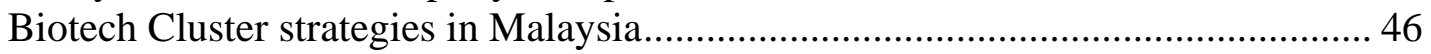

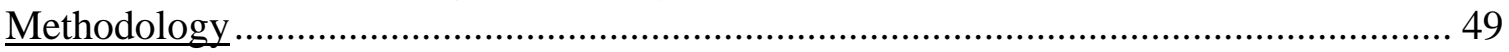

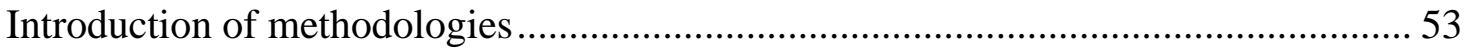

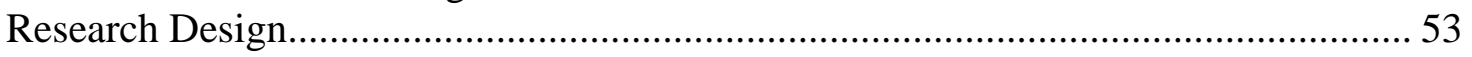

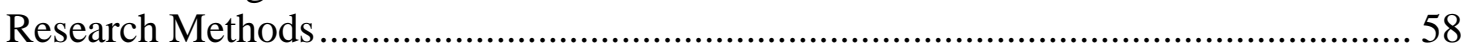

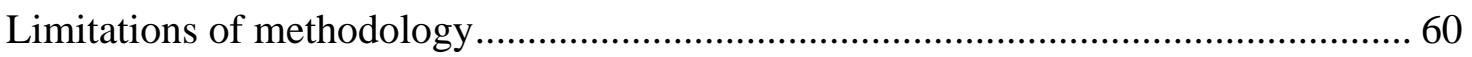

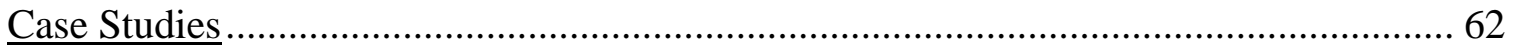

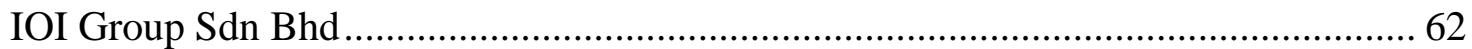

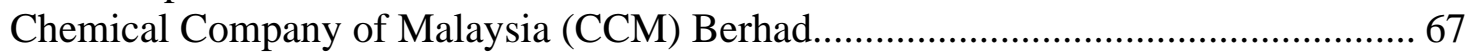

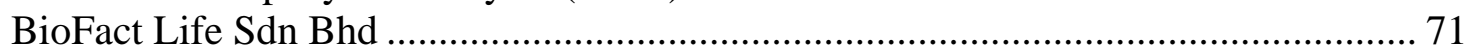

Malaysian Bio-Diagnostics Research (MBDR) Sdn Bhd ....................................... 75

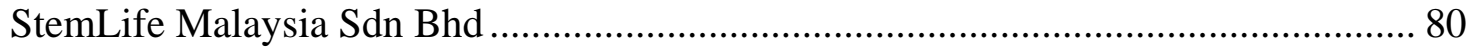

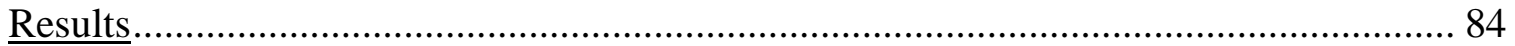

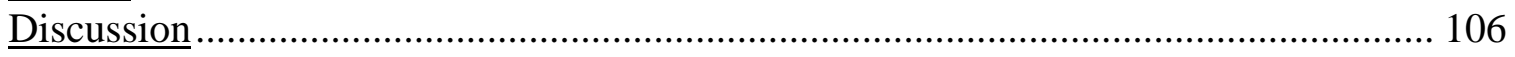

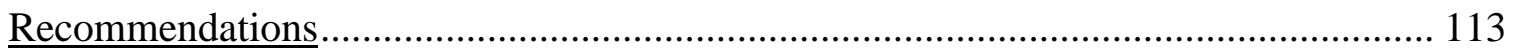

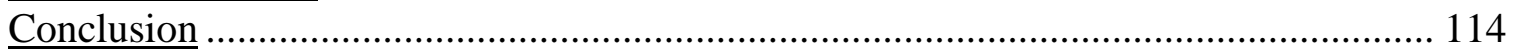

References

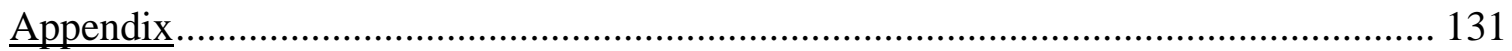

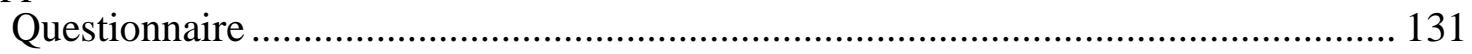




\section{Figure}

\section{List of Figures}

1: Global Biotechnology Clusters Map......................................... 15

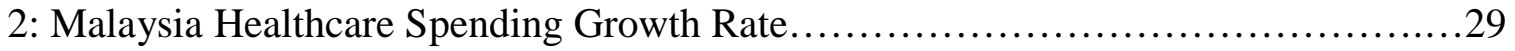

3: Biotechnology Focus Areas.................................................. 31

4: Stages of Understanding in Case studies......................................55

5: Business Processes and Valued Added Activities................................63

6: Roles of Participants........................................................ 84

7: Years of Experience....................................................... 85

8: Malaysian Bioeconomy - Priority Sectors vs. Competitiveness.....................87

9: Malaysian Bioeconomy - Priority Capabilities vs. Competitiveness..................88

10: Access to Funding ........................................................ 90

11: Cronbach's Alpha on Access to Funding ....................................... 90

12: Access to Talent..............................................................93

13: Cronbach's Alpha on Access to Talent........................................93

14: Malaysian Bioeconomy Ecosystem........................................ 95

15: Proximity to Research centres............................................ 97

16: Quality of Life Factors................................................... 99

17: Lab and Office Space..................................................... 100

18: Entrepreneurial Environment............................................... 101

19: Access to patients and Markets............................................. 103

20: Favourable incentives and tax treatment.................................... 105 


\section{List of Tables}

\section{Table}

1: Global Biotechnology Clusters by Region.................................... 15

2: Application and Registration of Patents...................................... 45

3: Patents Based on Field of Technologies......................................45

4: Case-studies Company Profiles............................................... 54 


\section{Introduction}

Biotechnology, information technology, and the globalisation of capital markets are entrepreneurial mega-force multipliers for future economic development and productivity. The biotechnology industry has similarities to the innovation and diffusion patterns of the information technology era. To date, the biotechnology industry and market has evolved from a technologically-advanced and highly specialised area to an increasingly common and enabling technology with vast commercial applications and entrepreneurial opportunities throughout all sectors of the global economy. This can be attributed to advancements in biologic insights, decreasing costs of new discoveries and widespread availability of research tools. Even though the biotechnology industry can be termed as an 'emerging' after only three decades of scientific and entrepreneurial resolve, there is great potential in addressing significant challenges in developed and developing nations like healthcare, security, substitute or renewable energy sources, environment rehabilitation and agricultural productivity (BIO,2007; Burrill 2007; CHI, 2006; Ernst \& Young, 2008).

Public and private stakeholders wanting to create and increase bioeconomy competitiveness and reduce the effect of distance face enabling trends such as increasing numbers of science graduates, accelerating pace of scientific advancement leading to greater public-private sector collaboration enabled by globalisation, democratising forces of the internet and the relentless competitive pressure to innovate (Furman et al, 2002; Iammarino and McCann, 2006; Casper, 2007). Earlier studies on multinational biotechnology leaders, has shown that the number of strategic alliances has twice the performance impact compared to geographic proximity to partners (Ahn and Meeks, 2007; Ahn et al, 2008). Even though dyads or formal networks of related parties such as public sector research and private investment capital are critical, formation of regional capabilities have depended on local context (Stuart and Sorenson, 2003; Andersson et al, 2004; Casper, 2007). 
Global trends and with Malaysia's biotechnology industry in its early stages of development; identification of key sector priorities and developing capabilities required to achieve global competitiveness is crucial. This study examines the development process of building a sustainable bioeconomy by analysing the perceptions and attitudes of industry participants concerning the key attributes and priorities in Malaysia. We explored growth patterns, industry platforms and networks; and enabling factors that support entrepreneurial activity, innovation, productivity, sustainability and research development. Questions explored include: Do initial factor endowments affect the trajectory of a biotechnology industry? How should Malaysia prioritise, mobilise and coordinate resources to build a sustainable bioeconomy?

Case studies, confidential interviews and an online-survey were conducted to collect data from Malaysian biotechnology companies that are part of the Bionexus Network. This network is an exclusive group of promising companies that have been targeted by Biotech Corporation Malaysia as potential future industry leaders. Multiple case studies were done to capture a rich set of secondary data and an online survey of Malaysia's Bionexus network participants to provide insights and directions on biotech sector priorities, capabilities and competitiveness. A summary of conclusions and recommendations for policy makers, practitioners and academics was considered. 


\section{Literature Review}

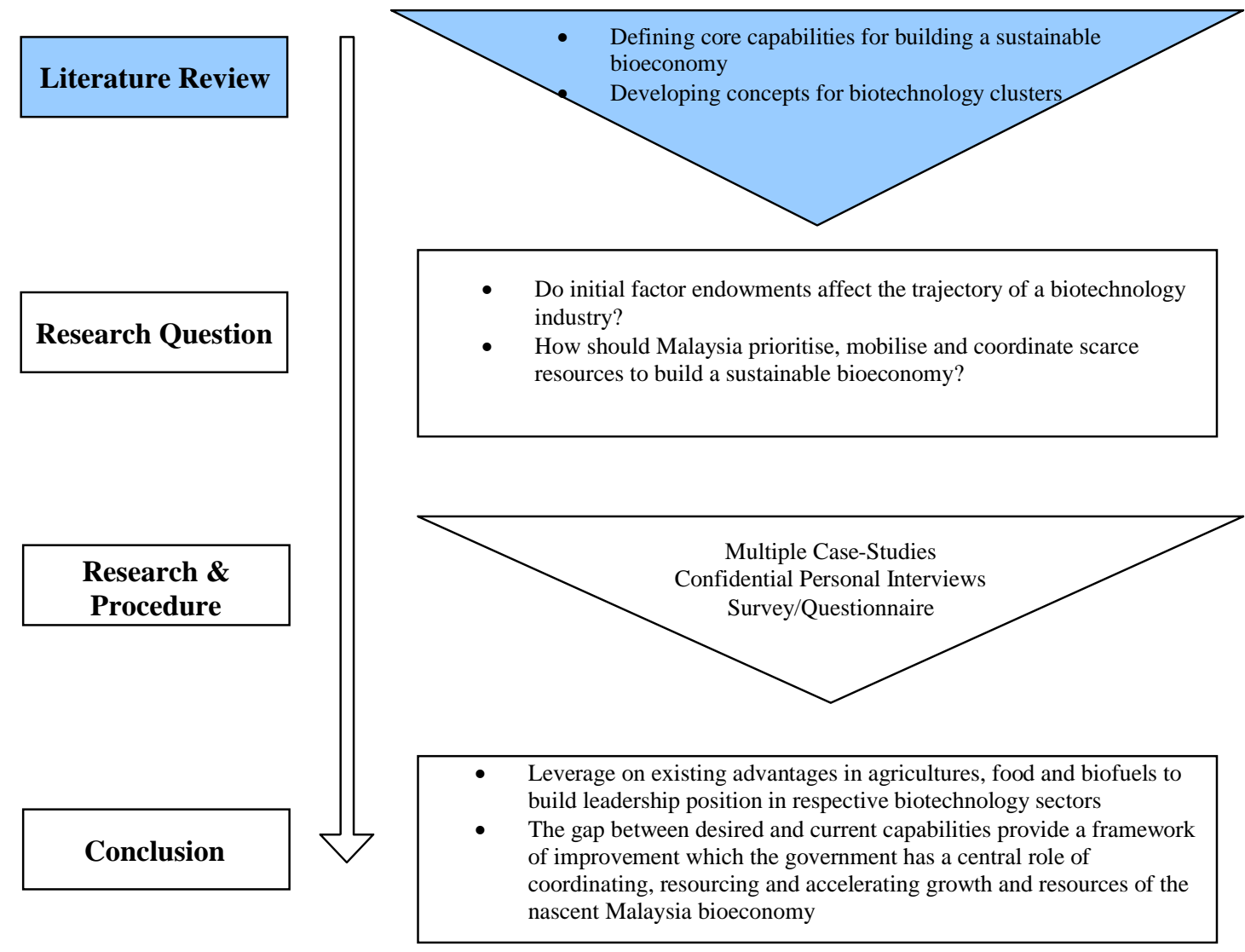

\section{Global Biotech Industry}

Biotechnology is the process of applying "biological knowledge and techniques to develop products and services... [with] any technique that uses living organisms to make [or] modify products, improve plants or animals, or develop micro-organisms for a specific use" (BIO, 2006; Goetz and Morgan, 1995). The biotechnology industry consists of key sectors: biofuels, molecular diagnostics, agriculture and nutraceuticals; and biopharmaceuticals.

\section{Biofuels}

Biofuels are a type of renewable resource that is derived from organic plant matter or animal origin, widely-distributed compared to fossil and nuclear resources and has the 
potential to provide energy (Demirbas, 2007; Frost \& Sullivan 2007). Currently biofuels are blended with ethanol and diesel to power petrol and diesel-driven engines respectively. Biofuels have received increased media and scientific attention after initial research had identified a decrease in carbon dioxide emissions when used as fuel and possible links to decrease overall greenhouse gas emissions. Biofuels have also been linked to contribute positive social and economic benefits to countries like Germany, Brazil, United States and the United Kingdom (Frost \& Sullivan, 2007a; Demirbas, 2006). The biofuels industry has developed rapidly in regions like the Asia-Pacific especially in developing countries like India and China. To date, China and India are ranked top-consumers globally in terms of energy needs and consumption. Their dependence on scarce fossil fuels and need for more sources of fuel, mirror developed countries that have invested in biofuel research and production facilities. Nevertheless, this demand has opened up potential export markets for biofuel producers. From 20002007, statistics by the International Energy Agency (IEA) has shown a steady increase in biofuel production from 2 billion gallons to 17 billion gallons $(1$ gallon $=3.785$ litres) (Coyle, 2007). The United States, Brazil, China and India are the top producers of bioethanol, with the United States producing approximately 16.2 billion litres of ethanol in 2005 (Frost \& Sullivan, 2007b; Coyle, 2007; Burrill 2007).

An illustrative example is Neste Oil, established since 1948, a Finland-based oil-refining and renewable diesel company with an annual turnover of EURO $\$ 12.103$ billion ( US $\$ 16.1$ billion) and more than 4,800 employees (NesteOil, 2009). Neste Oil has established refining facilities from Edmonton, Canada to St. Petersburg, Russia and Bahrain to Singapore. Key products manufactured are petroleum, oil-component lubricants and solvents. Prior to 2005, Neste Oil mainly refines crude-oil for export and sale and producing other petroleum-related products. In 2005 Neste Oil started research and development (R\&D) on renewable fuels and establishing biodiesel plants in Finland which is available for export since 2007. Meanwhile Neste Oil has commenced building biodiesel plants in Singapore by 2010 and Rotterdam in 2011 in order to increase production capacity and be the world's leading biodiesel manufacturer. This can be seen as a strategic move by Neste Oil since both ports have a combined processed handling of 
over 800-million tons of cargo-tonnage and are ranked as the top 3 busiest sea-ports in the world in 2006. Establishing a biodiesel plant in areas which have heavy shippingtraffic gives Neste Oil an advantage of being closer to potential target markets like refuelling or selling biodiesel to shipping containers and tankers. Currently Neste Oil's biodiesel is manufactured from vegetable oils and animal fats. Neste Oil has begun initiatives on $R \& D$ towards cultivation of existing crops that do not compete with food production nor has no food-value.

The Kyoto Protocol was ratified in 1997 and countries that were signatories are committed to reducing greenhouse gas emissions by 2012. This is a significant market driver for the biofuels industry as participating governments are likely to have increased research incentives to biotechnology companies and research institutes and pushed forth policies and legislations. The market drivers for biofuels appear to be volatile oil prices, compatibility with existing fuel infrastructures, production facilities and capabilities and availability of biomass or feedstock. Market restraints are capital investments for production facilities, skilled scientist and workers and government incentive programs.

\section{Biopharmaceuticals}

Biopharmaceuticals are classified as drugs and drug therapies which are produced through the use of living cells that treat, control and cure medical conditions such as AIDs, cancers and others (Gurau, 2004; Gwyne, 2004; Burrill 2008). Biopharmaceuticals represent the largest area of investment and revenue, with over $\$ 70$ billion in sales in 2007. Since the approval of the first biotechnology drug by US FDA (Food and Drug Administration) in 1982, the total number of drugs has increased to 254 with 385 applications. Furthermore with another 300 drugs under clinical developments, targeting over 200 diseases, this represents over $\$ 20$ billion in annual research and development. Consequently the pharmaceutical industry has emerged as a significant source of new venture creation with over 700 public-listed firms reporting double-digit growth in North America, Europe and Asia-Pacific. 
An emerging trend in biopharmaceuticals is human therapeutics. This has been the largest segment of the biopharmaceuticals industry, with technology spill-over effects into highgrowth markets like molecular diagnostics (\$3.5 billion), nutraceuticals and functional foods ( $\$ 50$ billion), environment ( $\$ 30$ billion), biosecurity ( $\$ 7$ billion) and biofuels ( $\$ 6$ billion) (BIO, 2007; Burrill, 2007; Kalorama, 2006).

An illustrative example is Amgen, established in 1980, US-based Fortune 500 human therapeutics company situated in Thousand Oaks, California, with more than 20,000 employees and annual turnover of US\$14.3 billion. With over 25 years experience in biopharmaceuticals, Amgen uses DNA and molecular biology to pioneer new drug developments aimed at treating rheumatoid arthritis, anaemia, cancers and kidney diseases. Global estimates suggest that close to 5 million people world-wide are longterm chronic sufferers of rheumatoid arthritis with 1.3 million people in the United States. In New Zealand, rheumatoid arthritis occurs in one to two out of a 100 people and women are three time more susceptible than men; which puts the overall figure at 44,000 sufferers (ArthritisNZ, 2009).

Symptoms may range from painful or stiff joints to more severe cases like tendon inflammation and swelling of joints. This disease occurs at any age and is not hereditary. It is also long-term, chronic, and incurable and might recur any time. Prior to medication, exercise and rest were the main methods of managing this disease. However due to the recurring nature and inflammatory symptoms, medication has emerged to be the main source of managing this disease. Through intensive R\&D with a team of chemists and scientists, Amgen pioneered ENBREL, a drug which lowers the amount of tumour necrosis factor (TNF) created by the immune system. Research in rheumatoid arthritis pin-pointed the immune system for over-producing amounts of TNF which causes this disease. Therefore ENBREL should reduce the amount of TNF in the body to normal levels. At this current point in time, there is no cure for rheumatoid arthritis. However biopharmaceutical companies have been experimenting with 'regenerative tissues and medicines' as a possible cure. 


\section{Nutraceuticals}

Nutraceuticals was coined in 1989 by Stephen Defelice as a food or part of a food that contains or provides nutritional value beyond normal levels and is able to offer medical and health benefits (DeFelice, 1995; Andlauer \& Furst, 2002; Belem, 1999; Ekta, 2003). Nutraceuticals are the fastest-growing segment in the food industry with estimates of the market being between US\$30-60 billion (Andlauer \& Furst, 2002; Belem, 1999; Hard, 2000; Thompson \& Moughan, 2008).

The nutraceutical interest started in the early 1980s when the actual or potential benefits of calcium, fiber and fish oil commonly found in food were supported by clinical studies in distinguished medical journals (DeFelice, 1995). The popularity for nutraceuticals can be attributed to two reasons: one being the growing awareness of the importance of good health and secondly the lack of viable alternatives.

In affluent nations, there are a variety of health issues that are currently affecting the people. Obesity, cancers, and a lack of exercise are some issues that affect these people. Nutritionists have advised the benefits of a balanced diet with adequate amounts of protein, fibre and exercise. However these dietary reference values do not take into account the diverse types of consumers who are impacted by different health issues at different stages in their lives by virtue of differing circumstances. Though the consumption of certain foods may improve health and well-being, however the idea of food proving more than just the basic nutritional values is apparently not new as in 400BC, Hippocrates was reported to have said 'Let food be your medicine and medicine be your food' (Thompson \& Moughan, 2008).

Currently companies involved in investigating and developing nutraceutical products belong mainly to food technology companies at 55\% and pharmaceutical companies at $35 \%$, with a steadily growing amount of strategic alliances in place between these two types of competitors (Belem, 1999). Products in nutraceuticals are also increasingly converging with other foods as a result of functional ingredients being added to more 
products in order to satisfy consumers' different needs in one transaction (DeFelice, 1995; Ekta, 2003; Thompson \& Moughan, 2008).

An illustrative example is Kraft Foods, established in 1903, a US-based Fortune 500 company with more than 103,000 employees and annual sales of US\$37.2 billion (Kraft, 2009). Kraft Foods is a heavily-diversified food and beverage company which have added a line of healthy-alternative food-products. Termed as "Health \& Wellness", this range of healthy-alternatives are pushed-forth by Kraft to target the health-conscious consumers. By promoting healthy living and eating-choices, Kraft advertises their products to help consumers manage their weight, and add fibre or calcium into their diet.

The driver for this health-range is due to the company's vision and strategy of making their products more contemporary and relevant through identifying key consumer-trends and being able to cater to their ever-changing needs. Kraft has established strategic alliances with various pharmaceutical companies to cooperate on food and nutrition $R \& D$ and have engaged an international panel of advisors and scientists to head a council which monitors their functional health food-products and nutritional-values. The scientists come from Malaysia, United States and United Kingdom. With an international team of advisors, Kraft is able to package, label and include relevant nutritional and dietary information for consumers world-wide. An example is the "100-Calorie Packs" commonly-sold in the United States and Canada, which caters to health-conscious consumers who want to snack but stay on track with their healthy and balanced eating routine. To date, this product-category has grown into a US\$100 million brand with new products routinely added.

\section{Agriculture}

Agriculture biotech utilises biotechnology to supplement traditional methods of agriculture to increase yields per land ratio and disease-resistant crops. A widelyaccepted definition is the utilisation of biotechnology to understand and manipulate the genetic make-up of organisms for use in production or processing of agriculture products 
(GreenFacts, 2004). To date, the common applications of agriculture biotechnology include crops, livestock, forestry and fisheries (Frost \& Sullivan, 2004). There are two major segments in the agriculture-biotech sector. One being the genetically-modified (GM) crop market and the other is the 'value-added agriculture' which involves the agricultural production of proteins that includes pharmaceutical and industrial applications in crops (Frost \& Sullivan, 2003). Biopharmaceuticals have teamed up with agriculture-biotech companies to cultivate and produce crops with pharmaceutical properties to treat diseases.

For agriculture, GM crops have increased in popularity and the global market is estimated at US $\$ 7.5$ billion (Frost \& Sullivan, 2003). The common GM crops are cotton, corn, rice and soybean. These crops are often genetically-modified to increase disease-resistance, enhanced taste, nutritional values and economies of scales. Other than cotton, the rest are important as they form part of staple-diets of most people around the world.

According to population estimates by the United Nations, the total global population will reach 9.3 billion people in year 2020 and food production needs to be doubled to feed everyone. Difficulties like reduction of arable land for housing and increased competition for water resources are some of the factors affecting agriculture and food production. Thus there is a current pressing need to increase agriculture productivity within existing arable lands, increase crop-yields and increase food production methods.

To illustrate an example, Monsanto, established in 1901, a US-based Fortune 500 agriculture company with more than 22,000 employees and annual sales of US $\$ 11.4$ billion (Monsanto, 2009). Monsanto produces seeds for large-acre crops like corn, cotton, soybeans, wheat and canola, and small-acre crops like vegetables. Their seeds are biotechnologically-engineered to increase crop-yields, disease-resistant crops to reduce usage of pesticides and increased nutritional values. Monsanto also offers crop protection products like herbicides to increase agricultural productivity. Through extensive $R \& D$, Monsanto has formulated their herbicides to reduce or not impact crops which are sprayed on and contain no harmful substances that might kill other forms of wildlife or 
pollute nearby streams or rivers through surface-runoffs. For 2009, Monsanto has included R\&D projects into developing drough-tolerant corn crops for drought-prone and water-scarce areas and countries; higher-yielding soybeans and second-generation herbicides.

\section{Medical Diagnostics and Devices}

Medical diagnostics, sensors and biosensors are medical equipment built with the purpose of detecting diseases, illnesses and other bodily fluids. A formal definition of such technology dictates a compact analytical device incorporated with biological sensitive material that will form a biochemical reaction after contact with body fluid (Owen, 1985; Albinson, 1987; Smith, 2005). This, in most cases, is a colour band to indicate positive or negative results.

To date, the medical diagnostics industry is estimated at least US\$ 15-29 billion and with annual growth rates of 10-15\% (Smith, 2005; Batchelder \& Miller, 2006). This encompasses clinical chemistry, advanced instrumentation and medical imaging like Magnetic Resonance Imaging (MRI). The diagnostics market is still dominated by wellestablished companies like Roche Diagnostics, Abbott Diagnostics, Johnson \& Johnson Diagnostics and Bayer Diagnostics which amount to majority of total revenue generated (Baker, 2006). Advancements and merging of different technologies has created a wide variety of device (Rowley, 2002; Burrill 2008).

Diagnostic kits are increasingly popular as these products have the potential to reduce lengthy clinical trails in which a drug company has to conduct experiments or trials to ensure the product is safe for human consumption. An emerging feature of this industry is due to the Baby Boomers Generation, as they are knowledgeable about healthcare and treatment options and willing to monitor their health. Therefore life-science companies are responding with new product offerings that are less invasive, painless, convenient and increasingly affordable (Newman et al, 2001; Eselius et al, 2008). 
An illustrative example of such merging technologies is Boston Scientific, a US-based Fortune 500 medical diagnostics company with more than 25 years experience is the world's largest company dedicated to less-invasive medical devices. The company employs more than 25,000 employees and distributes more than 13,000 products in over 45 countries with an annual sales turnover of US\$8.1 billion (Boston Scientific, 2009). Boston Scientific has an innovative product, LATITUDE $360^{\circ}$ of care - Remote Patient Management System. This is a home-monitoring machine/system offered to cardiac device patients and families. It allows cardiac patients with implanted cardiac devices to receive medical consultation and check-ups at home and reduce clinic visits. The devices collect information and transmit data to the monitoring system which utilises a standard phone line to transmit data to a secure website hosted by Boston Scientific. The monitoring doctor is able to make diagnosis, dispense medication and monitor patientprogress. The implanted cardiac devices monitor abnormal heart rhythms and heart failures. Any major heart failure triggers the alarm on the monitoring system which prompts the monitoring doctor to take medical action and rescue the patient from home. Patients are also advised to conduct their own medical check-ups twice a day, each lasting 2-3 minutes.

Biotechnology firms operate globally from inception due to their reliance on intellectual property (IP) exclusivity. Strategic alliances with other research institutes and smaller biotech companies offer another way of organising and controlling a firm's value chain and preferred compared to vertical integration (Trigeorgis, 1996; McGrath, 1997; Vassolo et al, 2004). Barriers to entry have rapidly decreased and innovation is becoming increasingly 'balkanised' into smaller firms and research institutes therefore business models in biotech are constantly evolving and appear similar to the process of project management in movie production in contrast to their historic pharmaceutical parentage.

Moreover globalisation and advance information systems networks enhance the possibility of virtual operations and teams; and accessibility to the biotech ecosystem open to contract manufacturers for process developments, research organisations with 
unique testing capabilities, patent lawyers, venture capitalists, and others who enable start-up formation and development (Burrill, 2007; Pisano, 2006).

The next section will analyse the concept of biotechnology clusters within the context of industry development trends and capacity building.

\section{Building Biotech industry Clusters}

Clusters are concentrations of competing and cooperating companies, suppliers, service providers and associated institutions (Rinaldi, 2006). This is a concept based on the definition by Michael Porter (1990) Competitive Advantage of Nations. According to Porter's definition, clusters are geographic concentrations of interrelated individuals, firms and institutions which compete and collaborate by accumulating knowledge and intellectual capital (Ahn et al., 2009). Clusters can be a concentration of any industry and are not limited to only the biotechnology sector. The aim of establishing clusters is to enhance levels of productivity and innovation through increased proximity of players. This proximity reduces institutional boundaries and allows knowledge to flow freely. One example is the development of Euro BioCluster, a meta-cluster which is a formation of participating biotech clusters from Germany to Spain to form a 'super'-cluster (Rinaldi, 2006). Established since 1996, it houses 400 biotechnology companies, more than 150 academic and research institutions and $40 \%$ of the world's pharmaceutical companies have established a presence in the BioCluster (Byrum, 2004).

The economies of agglomeration build on Porter's cluster theory by suggesting a firm's performance is influenced by the presence of other firms within the boundaries. These advantages are attributed to knowledge, skilled labour; innovation and input spill-over (Ahn, Meeks, Ross, Dalziel \& Bednarek, 2008).

Cluster approaches may be viewed in the theoretical context of the Resource-Based View (RBV). According to Barney (1991), the definition of RBV suggests that rare, valuable firm resources and capabilities that are hard to duplicate provide a firm with competitive 
advantage (Hart, 1995). Such resources may range from a variety of categories from financial, organisational, and physical; and the competitive advantages derived are based on the value and rareness.

The underlying assumption of the RBV perspective is that resources and capabilities are heterogeneous across firms (Peteraf, 1992). Therefore when firms are endowed with such resources, they are able to produce more economically and better satisfy customer wants. Thus if a competing firm is unable to imitate, create or develop the same resources, the time-lag in between is classified as a source of competitive advantage for the firm which is able to acquire the set of resources. However the premise of sustained competitive advantage cease to exist once there are equivalent substitutes in a competitive situation. (Barney, 2001) Thus to establish a sustainable competitive advantage, a firm needs to evaluate, find and protect that resource; either physical or intangible through intellectual property protection, trade secrets or trademarks.

In the strategic management field of study, the match between internal and external circumstances should produce competitive advantages (Hart, 1995). Thus competitive advantage will depend on the match between organisational capabilities (internal) and environmental (environmental) circumstances. Makadok (2001) states that capabilities are a type of resource, which is organisation-specific, unique and an inherent quality which is designed to combine all the other resources possessed by the firm and produce economic return. Thus capabilities in Makadok's view is firm specific, non-transferable and can be seen as an important quality to harness all the other resources to achieve an economic rate of return.

Makadok views capabilities as being acquired over time and not purchased, but they must be built. According to Makadok, this is termed as "capabilities building". In order to build capabilities, some essential drivers necessary to be developed and nurtured might be knowledge, skills and behaviours. Utilising cluster approaches can be a source of "capabilities building", since companies in the cluster may cooperate together in strategic alliances and decrease any potential asymmetries in research and development or 
production. Companies which realise the strategic importance of identifying, managing and leveraging core competencies from partner-firms are in an advantageous position to reap benefits in research and development or production.

Firms have to position themselves in an advantageous situation to establish leadership in their respective industries. In order to achieve this, firms would have to pick an optimal capability trajectory that will sustain first-mover advantages and an equally efficient resource trajectory that is unique (Miller, 2003). From firms to national industries, applying RBV is interesting once competitive advantage is adapted from an organisational level to a national focus.

Developing national industries is often costly, time-intensive and requires extensive planning. Utilising the RBV is useful as traditional factor resources can be mapped onto physical, financial and human resources. Thus if a firm or country makes an early move into an industry, it is possible to pre-empt competitors by applying RBV to identify critical raw material, locations and production processes (Hart, 1995). First-mover advantage will provide firms with a market niche and establish strong barriers against potential competitors. Likewise acquiring and managing an efficient resource trajectory is important especially when resources or initial factor endowments will greatly impact first-mover potential for firms and countries.

With adapting the RBV model to a national level, it may help to answer the global competitiveness question and provide useful insight in understanding how to develop new industries and inject new resources into current industries.

\section{Global Biotech Clusters}

Biotechnology communities have increasingly emerged in recent years, especially in developed and developing countries like India and China. This shows global acknowledgment of the benefits offered by biotechnology. Prior to this current global 
trend, biotechnology leaders by revenue, net income and market capitalisation were mostly in the United States of America. To date, most developed countries have biotechnology companies operating within its borders and these firms have established links with other biotechnology companies globally. As seen below in (Figure 1) countries coloured in brown rank highly in the Growth Competitiveness Index 2004-2005, World Economic Forum. Black circles represent select biotechnology and life sciences clusters.

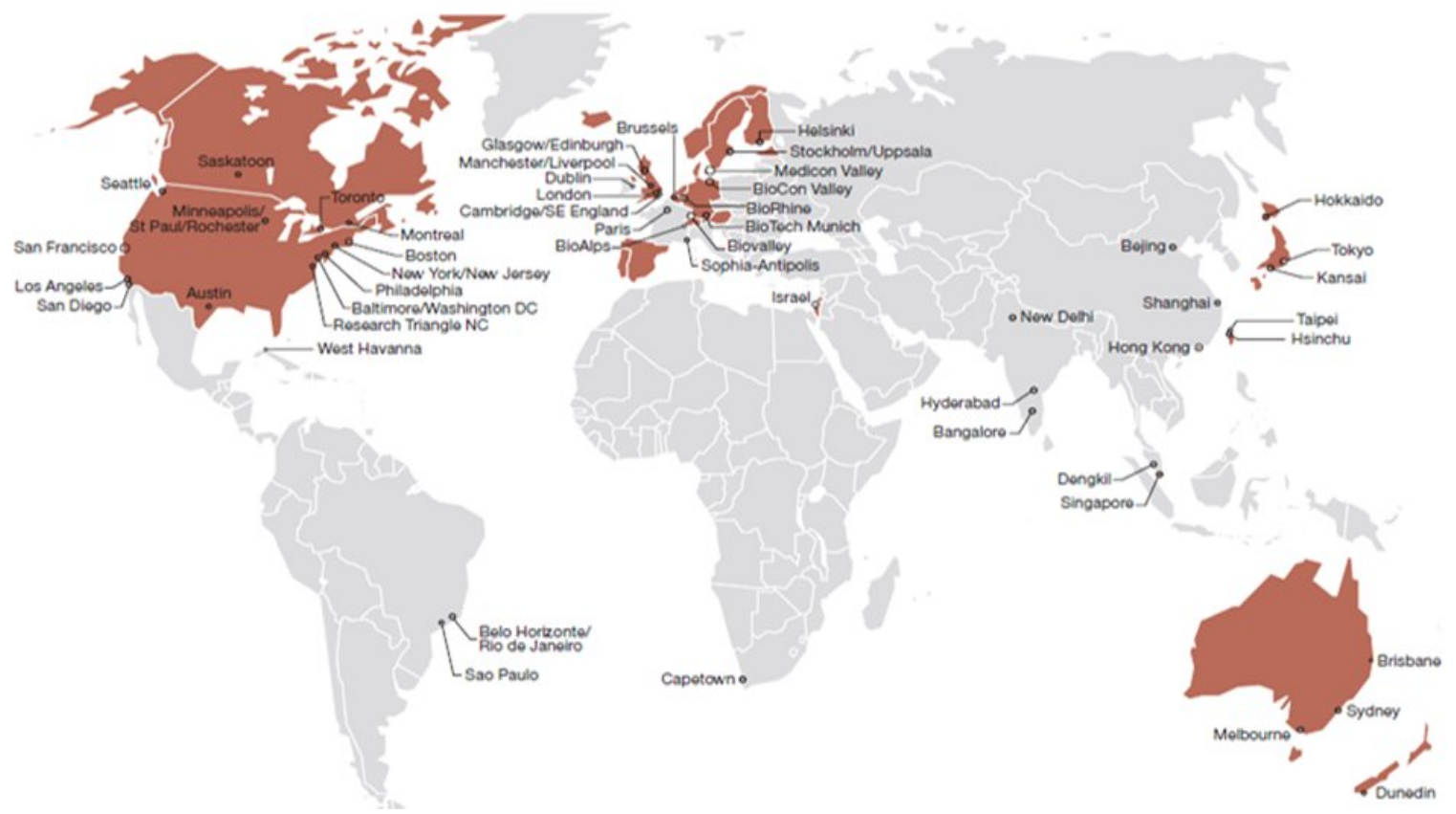

Figure 1: Global Biotechnology Clusters Map

(MBBNet, 2009)

\begin{tabular}{ll}
\multicolumn{1}{c}{ United Kingdom/ Ireland } & \multicolumn{1}{c}{ Continental Europe } \\
Glasgow-Edinburgh, Scotland & Brussels, Belgium \\
Manchester-Liverpool, England & Medicon Valley, Denmark/Sweden \\
London, England & Stockholm/Uppsala, Sweden \\
Cambridge-SE England & Helsinki, Finland \\
Dublin, Republic of Ireland & Paris, France \\
& Biovalley, France/Germany/Switzerland \\
& BioAlps, France/Switzerland \\
& Sophia-Antipolis, France \\
& BioRhine, Germany \\
& BioTech Munich, Germany \\
& BioCon Valley, Germany
\end{tabular}

\begin{tabular}{|c|c|c|c|}
\hline $\begin{array}{l}\text { Middle-East } \\
\text { Israel }\end{array}$ & $\begin{array}{c}\text { Africa } \\
\text { Capetown, South Africa }\end{array}$ & $\begin{array}{l}\quad \text { Asia } \\
\text { Beijing, China } \\
\text { Shanghai, China } \\
\text { Shenzhen, China } \\
\text { Hong Kong, China } \\
\text { Tokyo-Kanto, Japan } \\
\text { Kansai, Japan } \\
\text { Hokkaido, Japan } \\
\text { Taipei, Taiwan } \\
\text { Hsinchu, Taiwan } \\
\text { Singapore } \\
\text { Dengkil, Malaysia } \\
\text { New Delhi, India } \\
\text { Hyderabad, India } \\
\text { Bangalore, India }\end{array}$ & \begin{tabular}{l}
\multicolumn{1}{c}{ Oceania } \\
Brisbane, Australia \\
Sydney, Australia \\
Melbourne, Australia \\
Dunedin, New Zealand
\end{tabular} \\
\hline
\end{tabular}

\section{Table 1: Global Biotechnology Clusters by Region}

(MBBNet, 2009) 
Several examples of biotech clusters are clearly depicted in the picture above are Medicon Valley in Denmark/Sweden; Biopolis in Singapore and US bioscience clusters in Cambridge, LaJolla, Research Triangle Park and the San Francisco Bay Area. These are some examples that demonstrated the transformational commercial and economic development opportunities which biotechnology represent.

Medicon Valley has emerged as one of Europe's strongest biotechnology regions with a dense cluster of universities, hospitals and research institutes in pharmaceuticals and medical diagnostics (Burrill, 2008). Established in 1997, Medicon spans the Greater Copenhagen area in Demark and the Skåne region of southern Sweden with many universities, hospitals and companies within life sciences and medical technology. There are 100 biotechnology companies, 70 pharmaceutical companies, 130 medical technology and 15 clinical research organisations (CROs) (Medicon, 2009). With a diverse set of companies in the cluster, synergies in $\mathrm{R} \& \mathrm{D}$, clinical research, production and sales and distribution are some examples of realised benefits. Biotechnology clusters are usually supported by government grants, subsidies, available laboratory-space, tax rebates and a favourable business environment (Ahn et al., 2008) to ensure growth and a thriving biotechnology industry. Companies in Medicon Valley are supported by low corporate taw, R\&D expenses which are reimbursable and personal tax schemes for key biotechnology personnel (Medicon, 2009).

\section{Asian Biotech Industry}

This section will analyse the Asian biotechnology industry and gather insights on the industry, developments and aid overall understanding in the biotechnology business.

\section{Biofuels}

The Asian biofuel industry has emerged and started rapid development in recent years. Attracting foreign direct investments by overseas companies, issuing government licenses and approvals and development of biofuel plants are some growth initiatives undertaken by Asian countries to develop their own biofuel industry (Frost \& Sullivan, 2007). The 
Asian biofuel market can be segmented into supply and manufacturing components. The supply-side provides feedstock to manufacturers to mix with diesel to produce biodiesel or petroleum to produce bioethanol.

Feedstock is the single largest cost component in biofuel production as the crop needs to be sown, cultivated, harvested and processed before being produced as biofuel. However Asia has ready access to low-cost feedstocks, lower labour costs and operations which gives them a comparative advantage over other global producers like the United States and Brazil (Frost \& Sullivan, 2007). To acknowledge this advantage and potential export revenues, governments in countries like Malaysia, Thailand, Singapore and Indonesia have approved licenses and provided investment incentives to firms establishing biofuel production capabilities in their countries. It is significant now that the biofuel industry have grown into a main-stream industry and strategic source of income for respective governments.

Demand for biofuel by countries in the European Union has increased export revenue potential as producers in the Asia region are able to offer their products at a lower cost. Countries that produce in excess of domestic demand are likely to export to other countries. The two largest biofuel manufacturers in Asia are China and India, in terms of market size, China has the third largest biofuel market globally after US and Brazil (Frost \& Sullivan, 2009).

The Asian biofuel industry has faced several challenges that have impacted growth to this industry. Issues of debate have raised concerns over the "food versus fuel", this means should edible vegetable crops be used for fuel or food; burning and clearing of native forests for more arable land and replacing current food crops like rice, fruits or vegetables with cash crops like palm oil and rapeseed for biofuels.

An illustrative example is Gushan Environmental Energy Limited, a China-based company founded in 2001 and listed on the New York Stock Exchange in 2007 with annual revenue of over US\$140 million and 350 employees (Gushan, 2008). Gushan is a 
leader producer of biodiesel and related products in China with current annual production capacity of 400,000 tons of biodiesel. Through economic transformation of China's economy, urban households are one example that has managed to experience an increase in income and their spending expenditure has grown. Vehicle-ownership is one of the key drivers of energy-consumption, vehicles in China has increased from 11.5 million in 1994 to 41.8 million in 2004 .

In view of China's expanding economy and corresponding demand for energy; and increase in Europe and United States biodiesel consumption, producers like Gushan will continue to experience growth and if their prices remain competitive and scientific discoveries continue to prove biofuels are a useful interim alternative to reduce carbon dioxide emissions. China's economy, measured through Gross Domestic Product (GDP) has expanded at an annual rate of $11 \%$ especially in the last 10 years. Gushan has its own R\&D department which developed their current biodiesel manufacturing technology. This process is currently protected under patent on Intellectual Property Rights. This process utilises vegetable oil, used cooking oil and offal which are easily available in China and at low costs. This helps Gushan maintain cost-competitive and able to compete in distant markets.

\section{Biopharmaceuticals}

Asia's biopharmaceutical industry has been growing and making significant progress in recent years ever since their local governments perceived life sciences as a driver of economic development. However they are latecomers to commercial life sciences as compared to the United States and European Union (Gwynne, 2004; Ernst \& Young, 2004). Nevertheless many foreign companies are attracted to Asia. Some reasons for growth are government financial incentives like tax-cuts/breaks, lower overheads and close geographical proximity to neighbouring countries like China and India which have human population of over 1 billion people. 
One advantage of being latecomers to life sciences is that for an expensive venture with high failure rates, the risk which is extremely high. This is minimised to a certain extent because of returning expatriates with experience in the Western biopharma industry and they bring knowledge of its standards and processes, new ideas and money when they return to their respective homelands (Ernst \& Young, 2004). The ongoing developments of new medicines require extensive screening of initial candidate substances and require long periods of time (Gurau, 2004).Therefore playing catch-up by Asia's numerous biopharmaceutical contenders is a positive first-step forward.

The South-East Asian market is emerging as a growing market for biopharmaceuticals and a research-driven environment for R\&D. Thailand, Malaysia and Singapore are examples of how biopharmaceuticals have experienced constant annual growth averaging 5-6\% (Espicom, 2008). The respective governments have acknowledged biopharmaceuticals and biomedical sciences as an integral driver of future wealth creation and to promote investment. Key initiatives undertaken and pursued range from strategies to develop a bioeconomy, demonstrate government-led commitment, policies to regulate biotechnology-business environment, infrastructure to support companies and $\mathrm{R} \& \mathrm{D}$; and provide funding or tax incentives to attract foreign investment.

Biopharmaceuticals in other parts of Asia like India and Japan are established as the biggest biotechnology sector. Biopharmaceuticals comprise more than $70 \%$ of India and Japan's biotechnology industry. To date, Japan's biopharmaceuticals industry is the world's second largest market valued at US\$64 billion. The growth in Japan's biopharmaceuticals comes from a rapidly-aging population, declining birth-rates, longer life-spans, and increasing costs for providing healthcare to the elderly.

An illustrative example is Japan's largest biopharmaceutical company Takeda Pharmaceutical Company Limited, established since 1781 as a traditional medicines company and became in 1925 with R\&D facilities, manufacturing plants and various business operations. Takeda has R\&D facilities in Japan, United States, Singapore and the United Kingdom; production facilities in Japan, Italy, China and Indonesia, hiring a 
total of 15,717 employees with annual revenue of US\$13.748 billion (Takeda, 2009). Takeda's mainstay product is Actos, a drug targeted at Type 2 Diabetes, a disease which reduces insulin sensitivity in the body and requires injected insulin. Diabetes is an increasing problem in Japan as estimates by the Ministry of Health puts the amount of diabetic patients at $7 \%$ of the total population of 127 million people. Diabetes is a disease which causes poor healing of wounds, nerve damage, double-risk of cardiovascular diseases and retinal dysfunction or failure (US FDA, 2009). Diabetes is classified as a life-style disease and factors like obesity, limited exercise, smoking and poor diet are some factors that result in the disease. This disease is increasingly prevalent amongst developed nations as Takeda sales revenue in Actos, have experienced compound annual growth between 10-15\% since 2001, annual revenue is worth US\$326 million in Europe, US\$2.8 billion in the United States and US\$420 million in Japan (Takeda, 2008).

\section{Nutraceuticals}

The Asian nutraceutical product market showed that the region accounted for $44 \%$ of global sales and is the single largest market, exceeding North America and Europe (Food \& Drink, 2006; Frost \& Sullivan, 2004). Japan was the largest market in Asia, worth US\$11.4 billion and the second-largest globally after the United States; and China, second-largest in Asia and third-largest globally, was worth US\$5.9 billion. Including countries like South Korea and Taiwan, both valued at US\$1.9 billion and US\$1.3 billion respectively, the Asia market is worth at least US\$20.5 billion.

Asia's perception of nutraceuticals have shifted in recent decades vis-à-vis changing lifestyles and increased awareness of a balance and nutritious diet. The general population in Asia are aware of healthcare costs, lack of nutrition in processed foods and increased public-education and awareness of healthy living. Numerous companies have targeted this change in consumer preference and offer nutraceuticals in various forms from vitamins, health supplements and fortified foods. 
The general Asian diet is considered to be naturally healthy due to dietary intakes of fish, fresh vegetables and chicken. However increased westernisation of diets has resulted in more red-meat, dairy and processed-food consumption, which raises the need for nutritional supplements. Nutraceuticals in Asia are dominated by nutritional supplements such as herbal products since the region has a long history of traditional and herbal medicines or cures. According to a study in 2004 by Frost \& Sullivan, vitamins and natural supplements make up $70 \%$ of the Asian nutraceuticals market as compared to $35 \%$ to North America and the European market. This view is supported as tonics account for US\$4 billion in sales in 2006 and is the single most popular nutraceutical category (Food \& Drink, 2006).

An illustrative example is Cerebos Pacific Limited, with history dating back to 1892 but modern history from 1981, is a Singapore-based diversified-nutraceutical company with annual turnover of US\$540 million and over 2,478 employees (Cerebos, 2009). Cerebos has corporate headquarters based in Singapore and provides management services to subsidiaries in the region. The mainstay product of Cerebos is BRAND's liquid which are herbal soups packaged into bottles that can be drank either chilled or heated. This product has established market-share in Asian markets like China, Singapore, Taiwan, Thailand, Malaysia and Hong Kong which Cerebos earns over US\$282 million annually. This product also makes up almost $52 \%$ of Cerebos annual turnover and has an annual compound growth rate of 5.6\%. BRAND's product range targets children, school-going children, working adults and the elderly. Well-known Asian herbs like cordyceps, ginseng and bird's nests are some main ingredients of BRAND's liquid health supplements. Other herbs also form part of the product range which caters to varying tastes and attractive packaging to market the product. The inclusion of such herbs into modern applications like bottling, customise flavours and attractive packaging demonstrates the evolving nature of consumer taste and preference and how a nutraceutical company like Cerebos has to keep up with times. 


\section{Agriculture}

A 2007 United States Department of State study (USINFO, 2007) of the Asian agriculture biotechnology industry proposes that there will be more research to improve crops to improve growing needs for food and fuel to feed rising populations and energy requirements. Genetically modified or transgenic crops are increasingly approved by Asian countries and extensive cultivation has commenced in countries such as China, India, Pakistan, Japan, Thailand, Philippines and Vietnam. Commercial adoption of transgenic crops is one of the main driving factors of the rapid adoption and diffusion of biotechnology in the Asian region (AgBioWorld, 2000; Asian Development Bank; 2001; USINFO, 2007).

Asian leaders of agriculture-biotech are India and China with the highest number of hectares planted with transgenic crops. India and China have a combined total of 7.1 million hectares of cultivated transgenic crops but are significantly lesser as compared to the United States of 54.6 million hectares or Argentina at 18 million hectares (USINFO, 2007). Transgenic crops that have been cultivated are rice, cotton, corn, oil palm and canola; of which cotton, corn and canola have been planted in significant areas of Asia. These crops have an important role in Asia as a food and fuel source.

Countries like China, Philippines, Malaysia and India have invested heavily to develop their agriculture industries through utilising biotechnology to improve yields, reduce pesticides and increase nutrition in crops. Government initiatives have helped developed agriculture biotechnology through establishment of research institutions, biotech clusters, strategic alliances between neighbouring countries to co-develop a particular vaccine or cash-crop and guidelines for a regulatory framework to commercialise transgenic crops for import and export (Teng, 2008; Bar Chronicle, 2000; Asian Development Bank; 2001).

An illustrative example is Yasheng Group, China's leading biotech enterprise, established since 1970 s with annual revenue of US\$656 million and employing more than 15,000 
workers in regional offices in China and the United States (Yasheng, 2009). Yasheng's 51 products are sold in China and other regional markets like Europe, Canada, Australia and Pakistan, with major brands like Tsingtao Beer and MacDonalds as their strong customers (Yasheng, 2009). Yasheng capitalised on biotechnology in 1998 to supplement their current capabilities in agriculture and developed superior crops like cotton which yield more and require lesser water and nutrition; and hybrid seeds that are disease-resistant and able to be cultivated in high altitudes. Strategic alliances with Mexico's leading Wheat and Corn Improvement centre in 1999 has resulted in R\&D success with over 2178 varieties of wheat, barley, corn and other related field crops developed. This change in direction and development of biotechnology has been flowed over to the creation of support services like a high-tech agricultural park that has been fully-operational since 2005. The company has also established two educational institutes with more than 200 teachers and lecturers and approximately 2,000 students. Subjects taught in these institutes focus on technology and agriculture, acting as a R\&D facility for Yasheng's commercial operations and as a training resource for potential employees. The macro outlook for Yasheng's activities appears sustainable as China's growing population, increasing demand for food and fuel and favourable policies from the central government has created a favourable environment to grow its operations and businesses. Long-term growth plans is to capitalise on Yasheng's market leadership in China's agriculture industry to fund global acquisition or mergers and acquisitions.

\section{Medical Devices \& Diagnostics}

Asia's diagnostic and medical devices industry has grown rapidly in past years, and has attracted numerous American and European companies to outsource manufacturing of medical devices and a potential export market (Gross, 2007; Delporte, 2006). Factors like lack of domestic competition in Asia, major disease outbreaks, and increasing health awareness are cited as drivers of a growing diagnostics industry (Chigullapalli \& Tadulwadikar, 2007; Frost \& Sullivan, 2008; Frost \& Sullivan, 2007c). 
The single largest market is Japan, estimated value at US\$10 billion, with China, estimated at US\$ 6 billion, India at US\$1.5 billion and South Korea at US\$1.4 billion. An interesting phenomenon discovered was Asian medical device producers from Japan, China and South Korea have started to move into Latin America markets (Frost \& Sullivan, 2008a). These producers have focused largely on patient monitoring and ultrasound, which are both essential components of healthcare. Asian manufactured products are often associated as low-cost solutions with reasonable quality. This perception is due to years of outsourcing by European and American companies which have enabled these Asian producers to manufacture similar products at heavily-reduced costs.

An illustrative example is Olympus, Japan-based heavily-diversified consumer, medical and industrial company, established since 1919 with annual revenue of US\$10.75 billion and 35,772 employees (Olympus, 2008). Olympus started producing cameras and gradually progressed onto microscopes, endoscopes and diagnostic systems. Olympus recently acquired Gyrus Group PLC in February 2008, with approximately 1,400 employees in 13 world-wide locations. Gyrus is a medical equipment company based in the United Kingdom, listed on the London Stock Exchange with annual net sales worth US\$323 million. This recent acquisition is part of Olympus' basic strategy of adding new capabilities in its Medical Systems Business. Gyrus specialises in endoscopes, which is used in minimally invasive procedures without opening the abdominal cavity. This process is increasingly popular as it contributes to easing physical stress on patients and reduces hospital stays. To date, endoscopes are used in general surgeries, gynaecology and urology.

This acquisition opens up product and regional transition synergies for Olympus. The regional strategy by Olympus is to use Gyrus' established reputation in the North American market which amounts to $80 \%$ of annual turnover to sell Olympus products and sell Gyrus' products. Utilising Gyrus' capabilities in endoscopes will increase Olympus' surgical business scope and add to new products line-ups. This will aid Olympus' bid to establish a leadership position in the urological and gynaecological 
fields, along with tapping Gyrus' established relationships with doctors, hospitals and other research institutes. Olympus estimates after the acquisition with Gyrus, Olympus will have over $50 \%$ share of the global market share for urological endoscopes, spanning across Japan, United States and Europe.

\section{Asian Biotech Clusters}

This section will analyse three Asian biotechnology clusters within the context of cluster theory and understand how these clusters function and support the companies.

\section{Japan}

The Hokkaido biotechnology cluster is situated in Japan established in 1999 with 34 companies initially; and has grown to 94 companies in 2006. Annual turnover is estimated at US\$263 million with 938 employees across member companies (HokkaidoBIO, 2008). The Hokkaido biotechnology cluster consists mostly of agriculture and food, and medical care and pharmaceutical industries. Both industries account for $70 \%$ of the cluster. The cluster was launched by the Hokkaido Bureau of Economy, Trade and Industry with the aim of promoting the formation of an information and biotechnology industry cluster.

The cluster focuses on growing and developing university-launched ventures and aiding small to medium enterprises. Companies within the cluster have established mutual relationships with one another on transaction and joint research and merging various capabilities together for new product development. The number of university-launched ventures average 40 new ventures per annum.

Numerous efforts have been undertaken to collaborate with other institutions like trading firms, venture companies and manufacturers. The notion is without these support providers, lack of funding or manufacturing capabilities might limit growth. Therefore the Hokkaido cluster has a formal platform which seeks to attract investments by 
promoting the cluster nationally and internationally and establish multi-layered networks with universities, research institutions and biotechnology clusters.

\section{Singapore}

The Biopolis is a custom-built biomedical research and development cluster situated in Singapore. Construction began in 2003 and planned to be completed in 4 phases (Biopolis, 2007). The Biopolis is situated next to the National University of Singapore (NUS), a globally-renowned institute and other education and service providers like polytechnics, ministry of education and hospitals. There are nearby clusters like the Singapore Science Park and Fusionopolis, which is a R\&D centre for electronics and technology. Locating the Biopolis close to other creative clusters allows synergies like agglomeration, tapping into capabilities from other industries and collaborating to develop products.

Biopolis is an initiative to provide space for biomedical research and offer a platform for collaboration between the private sector and public research institutes. Phases 1 and 2 are completed with nine buildings. These buildings house public sector research institutes and private companies like GlaxoSmithKline and Novartis. Current research is on neurology and immunology and Biopolis is also self-contained with accommodation for over 2,000 personnel.

\section{Hong Kong}

The biotechnology industry in Hong Kong is an emerging sector with an estimated 400 companies. Healthcare companies with businesses in pharmaceuticals, nutraceuticals and medical diagnostics form the majority of companies in Hong Kong. Most of Hong Kong's biotechnology companies have substantial business dealings in mainland China and perceives it to be their largest export destination (ITC, 2009).

The main biotechnology cluster, Hong Kong Science Park, completed in 2005, is a dedicated commercial area for more than 200 biotechnology companies where a 
Bioinformatics Centre provides R\&D facilities in therapeutics, medical diagnostics and other biopharmaceutical-rated research (HKSTP, 2009). Other current tenants in the cluster are companies in electronics, precision engineering, information-technology, business consulting and law. These tenants provide support services to biotechnology firms in the cluster through manufacturing, accounting, marketing, business advisory, intellectual property protection, $R \& D$ and other value-added services. New start-up benefits like access to university resources, technology, aid reimbursement or expense subsidisation up to US\$110,000 for a period of 4 years and rent-free occupancy for 4 years are available to assist biotechnology companies. These benefits are made available to assist biotechnology companies to achieve R\&D to commercialisation success. 


\section{Malaysian Economy}

This section will analyse Malaysia's overall economy within the context of existing capabilities and capacity building.

Malaysia is a former British colonial settlement situated in South-East Asia and shares borders with Thailand, Indonesia and Brunei. The country first gained independence in 1957 and formed the Federation of Malaysia which consisted of various Malaysian states.

Malaysia has a population of 27.7 million people living in both East and West Peninsular Malaysia (MIDA, 2008). The major ethnic groups are 50.4\% Malay, 23.7\% Chinese, 11\% Indigenous, 7.1\% Indian and 7.8\% others (CIA World Fact Book, 2008). Malaysia has transformed itself gradually from a raw materials producer of agriculture and primary commodities to a multi-sector economy spurred on by technology, knowledge and capital-intensive industries.

The government has launched economic initiatives like the Ninth Malaysia Plan (20062010), National Biotechnology Policy and Third Industrial Master Plan (2006-2020) to propel and grow Malaysia's economy and provide more value-added products and services. Such policies give emphasis, directives and targets for long-term growth and progress, which will be covered later on in this paper.

The Gross Domestic Product - composition by sector shows agriculture at $9.9 \%$, industry at $45.3 \%$ and services at $44.8 \%$ (CIA World Fact Book, 2008). Major exports by Malaysia are manufactured electrical and electronic products, chemicals, machinery, palm oil and rubber (CIA World Fact Book, 2008; MIDA, 2008). Major imports are vehicles, iron and steel products, petroleum, plastics, processed food and beverages and industrial supplies (CIA World Fact Book, 2008; MIDA, 2008).

Malaysia is currently the world's largest producer of rubber and tin and is a leading exporter of semiconductor devices, computer hard disks and other electronic products. 
This is a direct result of growth in its manufacturing sector which accounted for $30.3 \%$ of Malaysia's GDP in 2007 (MIDA, 2008). Malaysia's rapid industrialisation is a result of policies encouraging foreign direct investments (FDI), an educated multilingual workforce and beneficial economic policies.

Malaysia's GDP per capita increased rapidly from 1990-2005, and is currently classified as an upper-middle income economy by the World Bank (World Bank, 2009). From 1990-2005, Malaysia's average income increased from US\$5,284 to \$10,318 with an annual growth rate of $4.6 \%$. An important thing of note, a study conducted by Frost \& Sullivan in 2006 showed that Malaysia's healthcare spending ranks the $5^{\text {th }}$ highest in Asia and this has led to new demand for healthcare products and services (Figure 2).

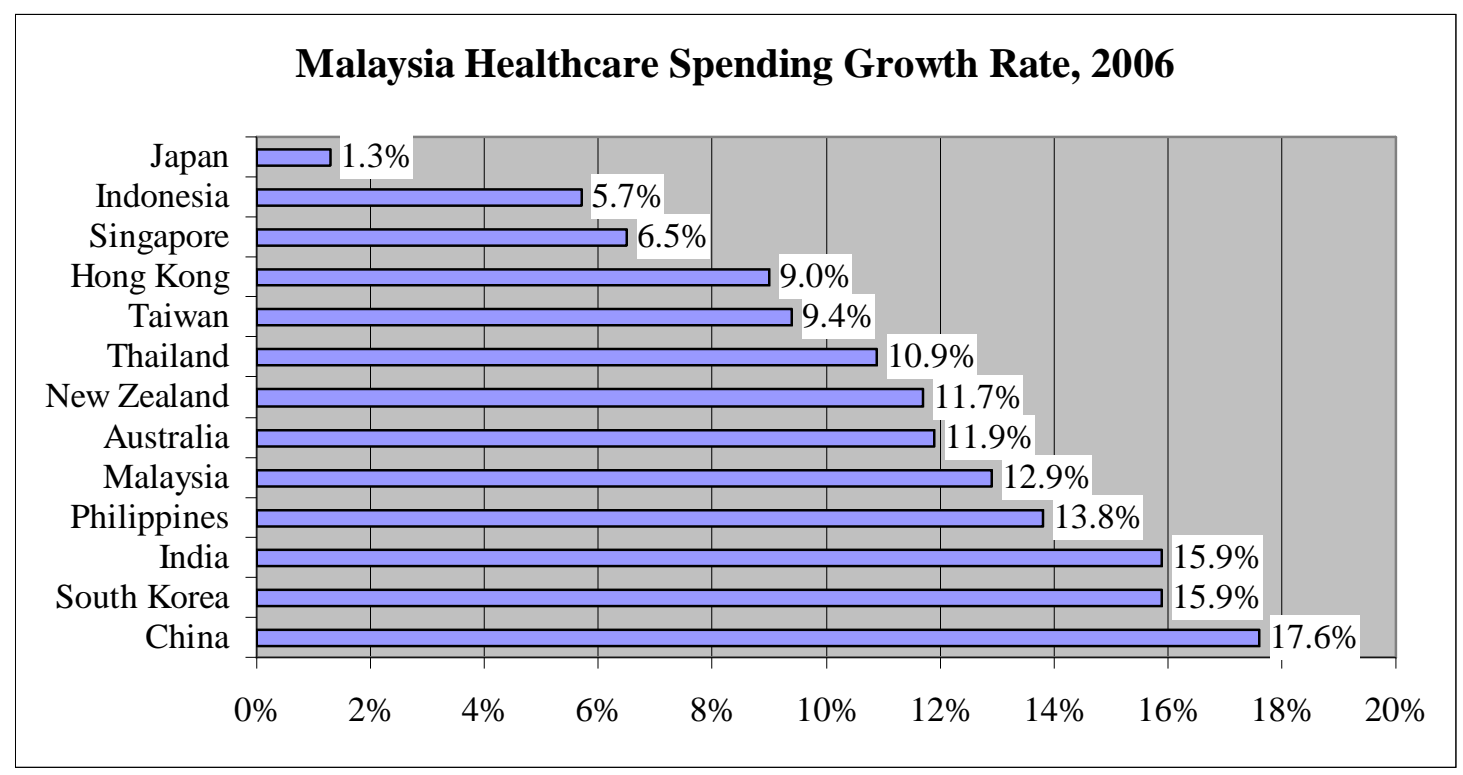

Figure 2: Malaysia Healthcare Spending Growth Rate

(Frost \& Sullivan, 2006)

\section{Malaysia Bioeconomy}

Malaysia has prioritised biotechnology and its benefits to bring progress to its people financially and socially. South-East Asia has been developing biotechnology industries and capabilities rapidly in the last few years. Researches have started on areas of 
significance to the Asia culture and region. For example, agro-biotechnology has focused on rice, and other tropical crops for the herbal medicine industry. Biomedical research has also focused on diseases common to Asian people in tropical regions like Malaria, Typhoid and Dengue (Frost \& Sullivan, 2001). Throughout South-East Asia, the trend has been to strengthen research facilities, biotech parks and seeking foreign investments to enhance growth in the bioeconomy.

The Prime Minister of Malaysia Abdullah Badawi made a speech in 2006: "It is not about placing big companies here to operate. Our approach has to be different and we have to develop our unique strengths and capitalise on them with products that have comparative advantages" (Fierce Biotech, 2006).

The Malaysian government has announced the $9^{\text {th }}$ Malaysia Plan, with an allocation of Ringgit $\$ 2$ billion (US\$553 million) for the biotechnology and life sciences for research and development and industry development. This allocation complements current private sector funding in the biotechnology industry as the government has set it out to be a new driver of economic growth in Malaysia. A life-sciences fund has been started up as venture capital to fund pioneering biotechnology companies. Numerous initiatives have also been underway to formulate institutions and companies. Malaysia Biotech Corporation (BiotechCorp), a government-linked company with key roles in developing the biotechnology industry and providing financial aid to biotechnology companies to assist them with commercialising discoveries (BIOTEK, 2009).

Biotech Corporation has targeted specific growth areas in Malaysia. The three focus areas are Agriculture, Healthcare and Industrial (refer to Figure3). These specific areas are crucial to Malaysia's long-term growth in terms of comparative advantage and increasing global demands like renewable energy sources, drug-resistant diseases and healthier lifestyles. 


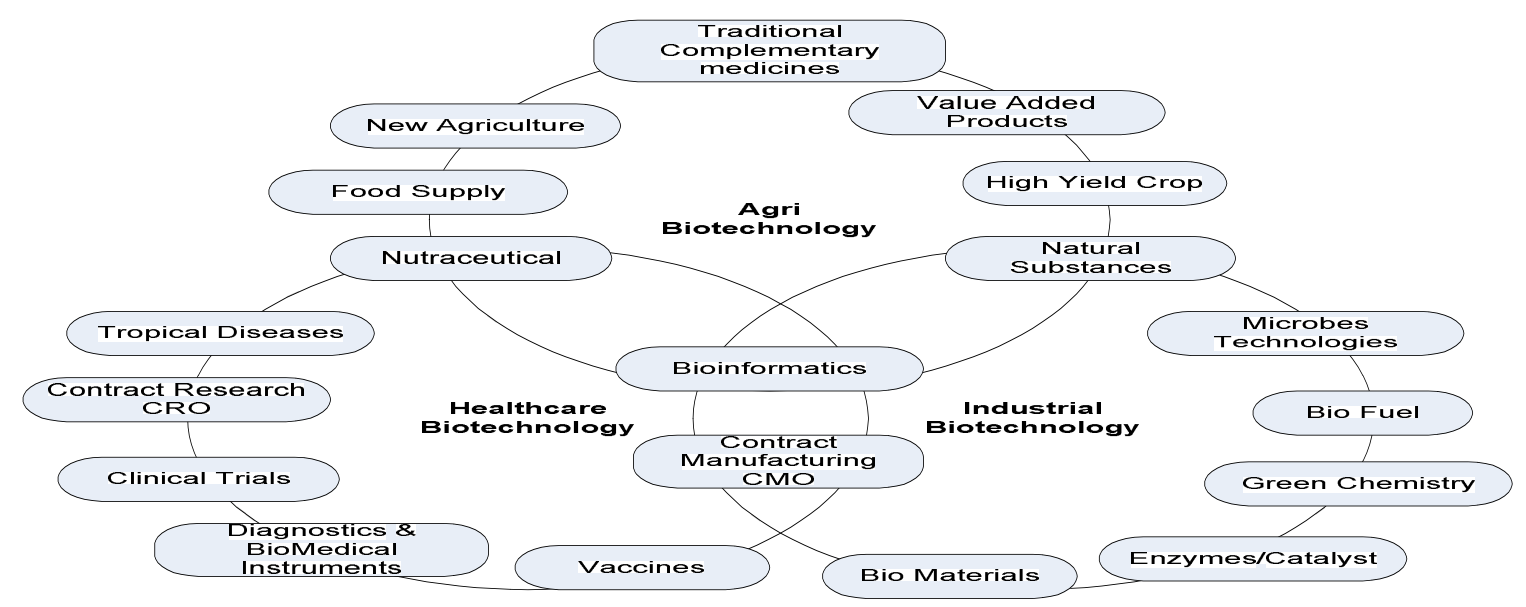

Figure 3: Biotechnology Focus Areas

(Biotechcorp, 2009)

Malaysia is largely an agricultural-based country with primary produce, for example: vegetables, rice, meat and fruits. Therefore agricultural and food biotechnology have emerged as the main biotechnology focus of government and private sector. Agriculture biotechnology has impacted industrial and food crops. Crops like oil palm are increasingly cultivated by Malaysia as a food source with industrial purposes such as renewable fuel, chemicals and in pharmaceutical products. Oil palm is produced in estates owned by plantation companies. The fruit bunches are harvested by hand and the oil extraction process is done at mills often located nearby the plantation. Investing in oil palm cultivation is a long-term commitment as the oil palm tree will take at least thirty months to mature in order to produce sufficient fruit for harvesting (Basiron, 2007). An oil palm has an economic life-span of 25-30 years, of which due to intensive research over the years have ensured consistent high yields and agronomy best practices (Basiron, 2007). Today's major palm oil producing countries are Indonesia and Malaysia which account for over $85 \%$ of the global oil palm output. The oil palm can only survive in tropical climates.

According to Frost \& Sullivan (2008), the Malaysian Pharmaceutical outlook, Malaysia is likely to grow to be a leader in the global pharmaceutical industry. Key reasons that were given are an increased reputation as a medical provider and supplier; in medical tourism, Malaysia offers low-cost and good quality medical treatment; and the generic 
medicines market which Malaysia has been focusing on is a booming industry globally (Biospectrum, 2008). According to a study done in 2005 in the United States, the generic medicines industry represented more than 56 percent of prescriptions dispensed (Jaeger, 2006). This percentage leads to annual sales of US $\$ 22$ Billion in the generic pharmaceutical industry. Research in other areas of medical biotechnology has resulted in development of diagnostic kits for Dengue Fever and several other tropical diseases.

The National Biotechnology Division (BIOTEK) was established in 2005, a division under the Ministry of Science and Innovation (MOSTI). BIOTEK's roles are to lead the biotechnology development and establish biotechnology in Malaysia (BIOTEK, 2009a). Other roles include $\mathrm{R} \& \mathrm{D}$, developing international linkages between the domestic and international biotechnology industry, research funding and; providing relevant education and training to human capital for biotechnology growth.

In other Malaysian states, there has been development of research institutions, in part of the government's numerous grants but also to attract foreign investment into their regions. An example of this would be Malaysian state of Melaka, which created a biotechnology institute, Malacca Biotech, in 2005 to focus on farming and seafood aquaculture. Chief Minister of Melaka Mohd Ali Rustam commented: "After the initial focus on agriculture and food biotechnology, the institute will produce plant extracts for usage in nutraceuticals" (Daily Express, 2005).

The Malaysian state, Sabah, in 2006 formulated a ten-year action plan from 2006-2015; drawn up with policies and strategies to develop a biotechnology hub in the state. Chief Minister of Sabah Musa Aman commented "biotechnology will accelerate the state's transition to a bioeconomic region, exporting value-added products instead of raw or semi-processed ones... a viable bio-industry enterprises can be established with Sabah's factor endowments." Strategies for the state will include private sector participation to commercialise innovations, allocate agro-technology parks and clusters (Daily Express, 2005; Daily Express, 2007). The Chief Minister, Musa Aman also assured various stakeholders like government agencies, research institutions and the private sector; of the 
state's ambitions and determination to succeed and will provide support and necessary assistance to develop the biotechnology sector in Sabah.

For Malaysia, there are a series of plans to develop their bioeconomy. During BIO 2007, Malaysia signed a deal with France-based Nanobiotix for an exclusive worldwide license in nanotechnology platform for non-cancer purposes. Also at BIO 2008 in Malaysia, six biotech contracts worth Ringgit\$1 billion (US\$276.5 million) was signed. Foreign companies from the United States of America, Italy, India, France and South Korea were involved. Domestic company like Malacca Biotech, mentioned earlier is one of the six companies to strike a contract with a foreign company like Vivo Biotech (India) to commercialise biotherapeutics, to produce drugs for diseases such as diabetes and cancer (The Star Online, 2008). To date, Malacca has attracted close to Ringgit\$2.5 billion (US\$691 million) in foreign biotechnology investments.

\section{Malaysian Government Strategies for biotech sector growth}

This section will analyse Malaysia's strategies to develop a bioeconomy within the context of economic policies and growth schemes; and will assist in overall understanding.

\section{Ninth Malaysia Plan}

"In the context of building our prosperity, the Ninth Malaysia Plan represents one of the most significant Malaysia Plans in our country's history”

YAB Dato’ Seri Abullah Ahmad Badawi

Prime Minister of Malaysia

At the tabling of the motion on the

Ninth Malaysia Plan 2006-2010

$31^{\text {st }}$ March, 2006

In March 2006, the Ninth Malaysia Plan which is the first of three Malaysia Plans to achieve Vision 2020 (EPU, 2008). This phase of developments represent Malaysia's 
ambition to become a developed nation by 2020 . The Plan which runs from 2006-2010 consists of policies and key programmes that will be essential for Malaysia to attain and accomplish in order to fulfil the Plan's objectives during this time frame. There are several thrusts or steps to be achieved in order to realise this dream. They are:

\section{$9^{\text {th }}$ Malaysia Plan}

- Thrust 1 - To move the economy up the value chain

- Thrust 2 - To raise the capacity for knowledge and innovation and nurture 'First Class Mentality'

- Thrust 3 - To address persistent socio-economic inequalities constructively and productively

- Thrust 4 - To improve the standard and sustainability of quality of life

- Thrust 5 - To strengthen the institutional and implementation capacity

In these thrusts, there are several initiatives. Firstly, the government had realised there was a need to establish new sources of wealth-generation; namely through biotechnology and information-communication technology. Given the changing domestic and global economic landscapes, a plan is needed to enhance national competitiveness and resilience. Effort and support will be given to develop the biotechnology industry as a new driver of economic growth.

The government has also ear-marked several aspects of necessary improvements like the investment regulatory framework, development of relevant infrastructure, improve access to funding, increase rate of research and development (R\&D) commercialisation, increasing the number of skilled biotechnology workers and researchers and attract foreign research partners and institutes (EPU, 2006). The Malaysian government will allocate Ringgit $\$ 2$ billion (US\$553 million) to aid the development of biotechnology and to complement private sector funding. The focus in the biotechnology industry will be in agriculture, health care, industrial, bio-informatics and diagnostics. 
The government is also committed to strengthening R\&D, science and technology as another front to further the pursuit of biotechnology. The realisation that Malaysia needs to acquire significant capabilities in science and technology has led to increase in the public sector budget allocation to Ringgit $\$ 3.9$ billion (US $\$ 1.08$ billion), twice the amount allocation under the previous Eighth Malaysia Plan (EPU, 2006). By 2010, the government aims to eventually spend $1.5 \%$ of the country's GDP on R\&D and encourage research as the basis of developing and deepening knowledge. The Science and Techno Funds will be established to ensure expenditure of $R \& D$ will be maximised through prioritising and focusing on specific and promising $R \& D$ efforts and pursue commercialisation of successful R\&D discoveries.

\section{National Biotechnology Policy}

"If the 20th century was the age of chemistry and physics, the 21st century will be known in history as the era of life sciences. Man has, of course, explored and utilised biological processes for centuries."

YAB Dato’ Seri Abullah Ahmad Badawi

Prime Minister of Malaysia

At the launch of BioMalaysia 2005

$28^{\text {th }}$ April 2005

(Biotechcorp, 2005)

The biotechnology industry has expanded at a rapid pace due to various government initiatives and policies. The Malaysian government recognises that biotechnology can bring improvements in Malaysians' quality of life, propel knowledge creation and innovation and is a crucial element in the country's quest to ascend the economic valuechain. With the application of biotechnology, additional value can be unravelled in traditionally strong sectors especially in its agricultural industry. This potentially can create spill-over effects in new and upcoming sectors such as healthcare, nutraceuticals and industrial bio-progressing (NBP, 2005). The government view Malaysia is endowed with a wealth of resources that is essential to the development of biotechnology. Varied 
biodiversity can be found throughout Malaysia and the country has developed its resource-based industries.

This landmark policy contains nine thrusts which outline the direction and measures offered by the government towards developing biotechnology for wealth creation and national well-being (NBP, 2005).

They are:

\section{National Biotechnology Policy 2005}

- Thrust 1 - Agriculture Biotechnology Development

- Thrust 2 - Healthcare Biotechnology Development

- Thrust 3 - Industrial Biotechnology Development

- Thrust $4-\mathrm{R} \& \mathrm{D}$ and Technology Acquisition

- Thrust 5 - Human Capital Development

- Thrust 6 - Financial Infrastructure Development

- Thrust 7 - Legislative and Regulatory Framework Development

- Thrust 8 - Strategic Positioning

- Thrust 9 - Government Commitment

Thrust 1 of the Biotechnology Policy seeks to transform and enhance the value creation of the agricultural sector through biotechnology. Thrust 2 seeks to capitalise on strengths of Malaysia's biodiversity by commercialising discoveries in health-related natural products and bio-generic drugs in nutraceuticals and biopharmaceuticals. Thrust 3 will leverage through Malaysia's current strong manufacturing sector by increasing the current opportunities in bio-processing and bio-manufacturing. These thrusts epitomises one of the main principles behind the Biotechnology Policy, which is to leverage Malaysia's existing capabilities and to add value to aid the country's ascension up the economic value-chain (NBP, 2005). These initial biotechnology developments will grow the country's agriculture, healthcare and manufacturing to a higher stage.

Thrust 4 seeks to establish biotechnology centres of excellence throughout the country where research teams of various disciplines can cooperate in coordinated initiatives. 
Resources have been channelled into developing centres of excellence such as Mardi and Universiti Putra Malaysia for agricultural technology, Universiti Kebangsaan Malaysia for genomics and molecular biology and Biovalley in Dengkil for pharmaceuticals and nutraceuticals (BM, 2005). In Thrust 5, the plan is to build the nation's human capital in biotechnology via education and training. As outlined earlier in the Ninth Malaysia Plan, there will be a boost in the education sector. This is also known as the National Education Blueprint 2006-2010.

According to a press release by Education Minister Datuk Seri Hishammuddin Tun Hussein on a new curriculum to be released into primary schools "We need changes in curriculum to bring about changes...therefore new areas of focus will be on literacy in science and technology” (The Star Online, 2007). In Malaysia's institutes of higher learning, 13 universities offer biotechnology programs and 12 universities offer chemical engineering programs. This amounts to about 3,000 undergraduates studying biotechnology and related courses annually. The government estimates over the next five years, there will be an estimated 23,000 research personnel and more than 5,000 R\&D scientists ready to be employed into the biotechnology industry (MIDA, 2006)

Thrust 6 is all about applying funding to commercialise discoveries from 'lab to market'. Incentives are also given to encourage participation from academia and private sector institutes. The Malaysian government intends to participate in every sector of the biotechnology value-chain, thus giving balanced attention to all ventures and avenues of interests. As mentioned earlier, the key areas were to increase R\&D and participation from academia and the private sector. To achieve these targets, the Malaysian government intends to establish dedicated matching grants for biotechnology R\&D and commercialisation ventures. Financial support will also be given to companies trying to apply for patents. To further encourage private sector participation, tax reductions or relief of up to $100 \%$ on qualifying biotechnology investments will be granted. Biotechnology companies will also enjoy tax incentives prepared by the government. 
Thrust 7 of the policy is to improve Malaysia's innovation system. This takes into consideration of reviewing the legal and regulatory framework on intellectual protection. Intellectual protection gives researchers a share in the ownership of their discoveries and in any monetary rewards derived from their work (NBP, 2005). This will be covered in detail in later segments.

Thrust 8 sets out to establish a global reputation for Malaysia's biotechnology industry. Biotechnology has developed into global commerce as firms do not operate in only one country but often cooperate with other firms globally for $R \& D$ and production. Therefore to build its reputation, the Malaysian government has two tie-up programs with the Massachusetts Institute of Technology (MIT) and the California Institute for Quantitative Biomedical Research (QB3). The former, a 5-year research collaboration known as the Malaysia-MIT Biotechnology Partnership program, will bring together 200 researchers in Malaysian institutes and 27 researchers from MIT to focus on medicinal plants and palm oil (Biobusiness Channel, 2007). The latter is an advanced training program at QB3 for senior Malaysian scientists and administrators and students are also given opportunities to pursue their thesis or postdoctoral research at the institute.

The Malaysian Biotechnology Corporation (Biotech Corp) was setup as part of the government's commitment in Thrust 9. Biotech Corp is under instruction by the Implementation Council headed by Malaysia's Prime Minister Abdullah Badawi. Biotech Corp is also tasked with identifying worthwhile ventures in biotechnology R\&D and commerce, assisting start-ups with financial and developmental services. The corporation will work closely with all relevant agencies in order to grow Malaysia's biotechnology industry.

\section{Malaysian Biotech Fund and Venture Capital}

Funding is provided by Malaysian Biotechnology Corporation (BiotechCorp) and Malaysia Technology Development Corporation (MTDC). MTDC is an agency under the Ministry of Science, Technology and Innovation (MOSTI), started by the Malaysian Government in 1992 to lead development of technological businesses in Malaysia. Its 
original roles were to promote and assist commercialisation of local research and invest in new ventures to bring in new technologies (Biotech, 2009). MTDC has since become a leading venture capital outfit and spearheading the venture capital market in Malaysia. To date, MTDC has established six private equity funds with a combined funding of RM\$202 million (US\$56.07 million). These private equity funds are targeted at growth areas in technology, agriculture, timber and economic growth in East Malaysia (MTDC, 2009).

There are five sources of funding made available by BiotechCorp and provided for biotechnology companies in Malaysia. They are as mentioned:

\section{- Technology Acquisition Programme}

- Biotechnology Commercialisation Grants

- Biotechnology Entrepreneurs Development Fund

- Intellectual Property (IP) Research and Management Programme

- Venture Capital, co-share with Malaysian Technology Development Corporation

Technology Acquisition Programme provides financing for biotechnology companies and individuals intending to purchase present and emerging products or process technologies for use in biotechnology. The criteria to qualify for such funding includes the direct expenditure incurred for acquiring the product or process technology.

Biotechnology Commercialisation Grants provide funding to priority biotechnology areas and seeks to bridge gaps between public and private sector funding. Under this grant, there are three types of funding available. Firstly, Seed Fund is for financing startup costs in setting up biotechnology companies. This funding also aids commercialisation and development of biotechnology projects and R\&D findings in priority and core areas. Secondly, $R \& D$ Matching Fund provides matching funds for current or new $\mathrm{R} \& \mathrm{D}$ initiatives to develop new or improve existing products, processes and technologies to enable further development and future commercialisation. Lastly, the International Business Development Matching Fund promotes the expansion of companies with 
Bionexus status into entering the global market. This fund also provides to support Bionexus firms internationally and efforts to compete globally.

Biotechnology Entrepreneurs Development Fund provides biotechnology individuals especially entrepreneurs with the necessary skill sets and knowledge to start-up new biotechnology ventures. Potential entrepreneurs are also supported on how to seek funding and business management. Typically all new ventures will be supported especially the establishment of start-ups and development of small to medium enterprises (SMEs). Other aims of this fund include enhancing the competitiveness of entrepreneurs and their enterprises, business sustainability and training serial entrepreneurs.

Intellectual Property (IP) Research and Management Programme is introduced to educate and increase awareness of existing IP networks and channels. Such information is disseminated through seminars, workshops and conferences on IP management. IP protection has proven to be an integral part of the biotechnology industry. IP protection grants the research or company temporary monopoly over their R\&D discoveries and allows commercialisation and future product development. This will be covered in later sections of this paper.

Venture Capital has become an important source of financing for technology-intensive companies and the Malaysian government has developed a list of government-backed and private venture capital companies to support start-ups. An example would be the Malaysian Life Sciences Fund which is a cooperative effort between the Malaysian Technology Development Corporation Sdn Bhd (MTDC) and Burrill \& Co.; an American life sciences bank based in San Francisco, California (MTDC, 2008). It was first launched late 2005 and specialised in early stage investments in various areas of biotechnology like agriculture, biopharmaceuticals, diagnostics and biofuels. MTDC will acquire a maximum of $30 \%$ equity stake for a period of up to 5 years to allow the investee company to retain majority control to manage their company later on. Maximum funding is limited to US\$8 million per company and the entire fund is valued at US\$150 million (Biotechcorp, 2009a). Various biotechnology firms have been the fortunate 
recipients, like the Malaysian Bio-Diagnostics Research Sdn Bhd (MBDR) which will be covered in case studies later on in the paper.

The Commercialisation Research and Development Fund (CRDF) is a grant established towards assisting commercialisation efforts of local R\&D activities. This grant provides partial grants to R\&D projects that fulfil several criteria. Firstly, SMEs that conduct their own $R \& D$ in Malaysia can gain assistance from this grant to commercialise their discoveries. Secondly, biotechnology companies interested to undertake feasibility studies on public sector research institutes $R \& D$ results can gain assistance from this grant. Thirdly, commercial spin-off companies and subsidiaries affiliated with public sector research institutes and universities can get access to funding. Lastly public sector institutes that desire to commercialise their discoveries can apply for this fund to finance their new start-ups. The maximum amount of funding is capped at RM $\$ 4$ million or $70 \%$ of the project cost. The funding also aims to increase leverages on science, technology and innovation for national development (BIOTEK, 2009b).

The Technology Acquisition Fund is a grant established to manage acquisitions of strategic and relevant technologies by the Malaysian Industrial Sector. The private sector is also provided partial funding to acquire new technologies and to improve their current technology and production processes. Local Malaysian companies intending to acquire foreign technologies need to incorporate the new capabilities into their existing systems immediately in order to qualify for the grant. Failure to do so will prevent them from receiving assistance from the grant. Acquisitions of foreign technologies cover these following aspects: technology know-how, patent rights, prototypes, design licensing and outright purchase of technology (BIOTEK, 2009b). Funding from this grant also covers eligible women entrepreneurs and given the additional option of acquiring equipment and machinery.

Apart from BiotechCorp and MTDC's commercialisation grants and private equity funds, biotechnology companies and entrepreneurs may secure funding for projects and start-ups through other government companies and agencies. 
The list is as follow:

- Malaysian Debt Ventures (MDV)

- Bank Perusahaan Kecil \& Sederhana Malaysia Berhad (SME Bank)

- Ministry of Science, Technology and Innovation (MOSTI)

MDV, incorporated on April $23^{\text {rd }} 2002$ is a wholly-owned subsidiary of the Ministry of Finance. MDV's starting role was to manage financing and development of the Information and Communications Technology (ICT) industry and other high-growth sectors in Malaysia. This fund has an equity size of RM\$1.6 billion or US\$420 million, which is sourced from the government of Japan through the Japan Bank for International Cooperation (JBIC) (MDV, 2009). Currently MDV is tasked with securing funding and becoming another funding source for the biotechnology sector and include the industry in its high-growth sector portfolio. Alternative sources of financing are crucial for knowledge-intensive and technology-intensive start-up enterprises as intangible collateral such as ideas and R\&D discoveries are its principal assets (MDV, 2009). MDV will contribute to finance biotechnology companies in Malaysia on acquisitions of equipment and infrastructure, and contracts/ projects; up to RM\$120 million each. Working capital is financed up to RM\$50 million. The grant is currently estimated at RM\$2.5 billion.

SME Bank, incorporated on October $3^{\text {rd }} 2005$ is a government-linked financing and business development institute. The bank's main role is to finance SMEs and support or improve their business sustainability through advisory services when necessary. A fund was established to function as a business loan to eligible SMEs for an amount of up to RM\$5 million per company with the purpose of funding working capital, licensing of technologies and fixed assets financing. The total fund size is valued at RM\$15 million.

MOSTI, first established in 1973 and restructured in 2004 is the leading agency of Malaysia for science, technology and innovation. The ministry has six conditional grants to finance and assist the biotechnology industry. These grants are open for applications by individuals or companies and cover technological, scientific, innovation and various biotechnological processes involving agro-biotechnology, genomic and molecular and 
pharmaceuticals (Biotechcorp, 2009a). Funding amounts differ from various grants but the common aim is to assist the commercialisation process and aid the individual or company.

\section{Malaysia Intellectual Property Competitiveness}

"It cannot be denied that intellectual property has been identified as one of the nation's most valuable assets. Intellectual property rights play a significant role in the growth of supporting industries in particular, the small and medium enterprises".

Datuk Hj. Mohd. Shafie Bin Hj. Apdal Minister of Domestic Trade \& Consumer Affairs Foreword by Intellectual Property Corporation of Malaysia Annual Report 2007

Intellectual Property Corporation of Malaysia (MyIPO), established since 1983, is a government agency primarily responsible of enforcing intellectual property rights in Malaysia. This agency provides advisory services on intellectual property (IP) to individuals and companies, conduct training programs and initiatives to increase current numbers of IP managers; and provide statistical data on IP programs and information.

Intellectual property protection in Malaysia covers patents, trademarks, industrial designs, copyright, geographical indications and layout designs of integrated circuits (MIDA, 2009). Malaysia is also part of the World Intellectual Property Organisation (WIPO) and signatory to the Paris and Berne Convention which governs intellectual property rights. Patents in Malaysia are governed by legislation and an invention is patentable if it is a new process, or inventive step and applicable for industrial usage. The Patents Act in Malaysia follows TRIPS (Trade Related Aspects of Intellectual Property Rights) and awards a compulsory protection period of 20 years from date of application. The patent owner also has the right to assign, transmit and include a licensed contract. 
The benefits of having a patent are to assist in company marketing purposes, rights of revenue source over the invention, bargaining chip to raise funds through venture capitalists or stock exchanges and creating a defensive market niche through temporary monopolistic rights. A quote by a CEO of a Malaysian biotechnology company: "A quick look at Fortune's Global 500 Rankings shows the dominance of American multinational companies comprising of 153 followed by Japanese companies at 64. Japan is a patenthungry nation as are the many European nations that figure strongly on the list. Looking at the Malaysian scenario...patents must spur national competitiveness that will make Malaysia into a developed nation".

Datuk Dr Rajen M CEO, Holista Biotech Sdn Bhd

There has been an annual increase in the applications for patents, trade marks and industrial designs. Malaysia also consistently ranked among the top-ten list of countries with the most number of patents' application received, increasing from 206 to 3420 approved patents from the year 2000 to 2007 (MyIPO, 2007).

Despite Malaysia's developing biotechnology industry, current progress has shown positive results. Furthermore there will be opportunities for Malaysia to increase to world-class levels as their biotechnology industry develops further.

Malaysia has compiled statistics from 1986-2008 in the table shown in Table 2. There is a drop in patent applications in 2008. MyIPO Director General's comment is as follows "Though the number of patents in 2007 increased 4\%, the number of applications dropped 50.6\% in 2008 after Malaysia joined the Patent Cooperation Treaty (PCT). The PCT system allows applicants to file their respective applications through Bureau of WIPO in Geneva instead of the respective country's IP office". 


\begin{tabular}{|c|c|c|c|c|c|c|}
\hline \multicolumn{7}{|c|}{ Application and Registration of Patent and Utility Innovations from 1986 to 2008} \\
\hline \multirow[t]{2}{*}{ Year } & \multicolumn{3}{|c|}{ Application Received } & \multicolumn{3}{|c|}{ Registration } \\
\hline & Malaysia & Foreign & Total & Malaysia & Foreign & Total \\
\hline 1986-1998 & 1,805 & 41,014 & 42,819 & 286 & 10,380 & 10,666 \\
\hline 1999 & 218 & 5,621 & 5,842 & 39 & 682 & 721 \\
\hline 2000 & 206 & 6,021 & 6,227 & 24 & 381 & 405 \\
\hline 2001 & 271 & 5,663 & 5,934 & 18 & 1,452 & 1,470 \\
\hline 2002 & 322 & 4,615 & 4,937 & 32 & 1,460 & 1,492 \\
\hline 2003 & 376 & 4,686 & 5,062 & 31 & 1,547 & 1,578 \\
\hline 2004 & 522 & 4,920 & 5,442 & 24 & 2,323 & 2,347 \\
\hline 2005 & 522 & 5,764 & 6,286 & 37 & 2,471 & 2,508 \\
\hline 2006 & 531 & 4,269 & 4,800 & 187 & 6,562 & 6,749 \\
\hline 2007 & 670 & 1,702 & 2,372 & 338 & 6,645 & 6,983 \\
\hline 2008 & 864 & 4,539 & 5,403 & 198 & 2,044 & 2,242 \\
\hline Total & 6,307 & 88,814 & 95,124 & 1,214 & 35,947 & 37,161 \\
\hline
\end{tabular}

\section{Table 2: Application and Registration of Patents}

(MyIPO, 2009)

\begin{tabular}{|c|c|c|c|c|c|c|c|c|c|c|}
\hline \multicolumn{11}{|c|}{ Malaysia Patent Based on Field of Technology From year 2000 to 2008} \\
\hline SECTION & 2000 & 2001 & 2002 & 2003 & 2004 & 2005 & 2006 & 2007 & 2008 & TOTAL \\
\hline A & 61 & 155 & 206 & 224 & 325 & 333 & 948 & 1,179 & 423 & 3,711 \\
\hline B & 59 & 233 & 236 & 242 & 377 & 452 & 1,155 & 1,213 & 421 & 4,258 \\
\hline C & 110 & 288 & 334 & 396 & 625 & 600 & 1,275 & 1,748 & 451 & 5,662 \\
\hline D & 8 & 18 & 19 & 28 & 25 & 30 & 101 & 109 & 33 & 360 \\
\hline $\mathbf{E}$ & 19 & 44 & 42 & 38 & 50 & 82 & 197 & 221 & 98 & 761 \\
\hline $\mathbf{F}$ & 42 & 102 & 104 & 119 & 132 & 164 & 448 & 407 & 159 & 1,625 \\
\hline G & 36 & 231 & 228 & 190 & 321 & 316 & 1,042 & 883 & 293 & 3,449 \\
\hline $\mathbf{H}$ & 70 & 399 & 323 & 341 & 492 & 531 & 1,583 & 1,223 & 364 & 5,218 \\
\hline TOTAL & 405 & 1,470 & 1,492 & 1,578 & 2,347 & 2,508 & 6,749 & 6,983 & 2,242 & 25,044 \\
\hline Section A: & \multicolumn{10}{|c|}{ Human Necessities } \\
\hline Section B: & \multicolumn{10}{|c|}{ Performing Operations; Transporting } \\
\hline Section C: & \multicolumn{10}{|c|}{ Chemistry; Metallurgy } \\
\hline Section D: & \multicolumn{10}{|c|}{ Textiles; Paper } \\
\hline $\begin{array}{l}\text { Section } \mathrm{E}: \\
\text { Section } \mathrm{F} \text { : }\end{array}$ & \multicolumn{10}{|c|}{$\begin{array}{l}\text { Fixed Constructions } \\
\text { Mechanical Engineering; Lighting; Heating; } \\
\text { Weapons }\end{array}$} \\
\hline Section G: & \multicolumn{10}{|l|}{ Physics } \\
\hline Section $\mathrm{H}$ : & \multicolumn{10}{|l|}{ Electricity } \\
\hline
\end{tabular}

Table 3: Patents Based on Field of Technologies

(MyIPO, 2009) 


\section{Biotech Cluster strategies in Malaysia}

\section{Bionexus Network}

Initiated by Malaysian Prime Minister, Abdullah Badawai on $7^{\text {th }}$ September 2006, the BioNexus network was started to aid and assist Malaysian and international biotechnology companies (Biotechcorp, 2008). The vision of the BioNexus Network is a creative cluster of biotechnology companies and organisations that can cooperate; enable transfers of technologies and develop new products. Universities and research institutions like centres of excellence play a major role in this cluster through the promotion and support of research and development in the biotechnology areas. To date there are three established centres of excellence throughout Malaysia, the Institute of Agricultural Biotechnology, the Malaysian Genome Institute and the National Pharmaceutical and Nutraceutical Institute. These are government linked and funded institutions; and are tasked to provide extensive research support through cooperative research programs with other research and development departments of biotechnology companies.

The Bionexus network is an exclusive cluster of biotechnology companies that has been targeted by BiotechCorp as industry leaders of their field and with internationalisation potential. These companies are supported by a variety of organisations like universities and research institutions throughout Malaysia. According to a press release by BiotechCorp, the number of Bionexus companies stands at 56 as of $31^{\text {st }}$ March 2008 with total investments total US\$383.6 million and R\&D expenditure US\$17.0 million. There is a set of Bills of Guarantees (BOG) that entitles Bionexus companies to several privileges like assistance for international accreditations and standards, access to supportive information network linking research institutes and assistance from BiotechCorp. 
Centres of Excellence are government research institutes with the aim of undertaking world-class research and providing research facilities to biotechnology companies. There are at least three such institutes at this current point in time.

They are: $\rightarrow$ Institute of Agricultural Biotechnology (ABI)

$\rightarrow$ Malaysian Genome institute (GENOMalaysia) $\rightarrow$ National Pharmaceutical \& Nutraceutical Institute (IPHARM)

\begin{abstract}
ABI, founded on June $6^{\text {th }} 2006$, undertakes R\&D and assists in project commercialisation related to agro-biotechnology. ABI relies on strategic links established with domestic and foreign universities, research institutes and other biotechnology firms (BIOTEK, 2009b).
\end{abstract}

GENOMalaysia is a network-based, not-for-profit organisation involved in R\&D on tropical bioresources. The R\&D projects range from genome sequencing, comparative and functional genomics and structural biology. An official forum/platform for gene discovery was established for the research and biotechnology business community to allow access to facilities in the institute and assist in difficulties faced. This is a result of a Memorandum of Understanding (MOU) between GENOMalaysia and the Department of Genetics, Stanford University (GENO, 2009). A new initiative to emerge was The National Biotechnology and Bioinformatics Network (NBBnet - Malaysia). It is a network of resources and infrastructure available for the Malaysian biological research community to learn and share within. Other functional roles of this network is to provide results of R\&D processes, conduct research and training, maintain databases and onlinesharing with other related industries.

IPHARM is a research institute that conducts $R \& D$ on new drug discoveries and development. It has strategic links with other global research institutes to add onto its current capabilities. Development and commercialisation of new pharmaceuticals and nutraceuticals are one of the long-term goals of the institute (IPHARM, 2009). Short courses are available for interested scientists and academics wanting to improve their knowledge of current or newly-discovered processes. 


\section{Triple Helix}

The Triple Helix is an online initiative by BiotechCorp to enhance the biotechnology industry in Malaysia. Launched by Malaysia's Prime Minister YAB Dato' Seri Abdullah bin Haji Badawai during BioMalaysia 2008, the main aim of this program is to encourage cooperation between researchers, biotechnology companies and the government. The portal contains information on current projects and products developed by researchers and aims to achieve commercialisation through partnerships with Bionexus companies or government institutes. Access and information on services, equipment and facilities offered by research institutes, technology parks and affiliated universities are available through the portal. Bionexus companies are entitled to enquire to share research facilities and engage in R\&D. 


\section{Methodology}
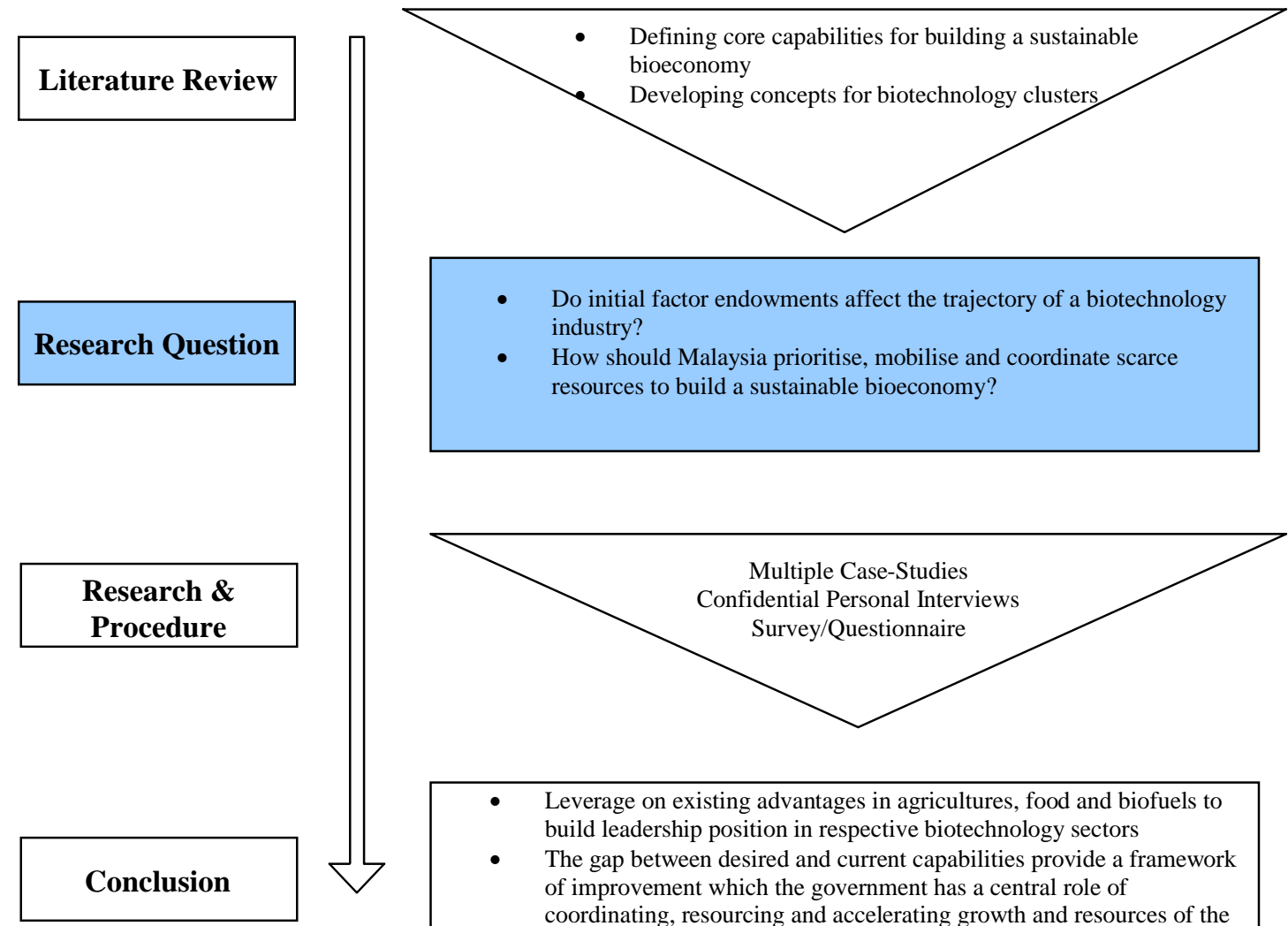

- $\quad$ Leverage on existing advantages in agricultures, food and biofuels to build leadership position in respective biotechnology sectors

- $\quad$ The gap between desired and current capabilities provide a framework of improvement which the government has a central role of coordinating, resourcing and accelerating growth and resources of the nascent Malaysia bioeconomy

\section{Overview}

This study focuses on investigating key priorities and capabilities for building a globally competitive and commercially-viable biotechnology industry and sector. Malaysia was chosen as it is an emerging player in the global and Asian biotechnology industry. As seen earlier, the Malaysian government and various governmental departments have identified the development and growth of a fledgling biotechnology and bioeconomy as a national priority to wealth creation and social well-being for all Malaysians in the country.

In order to gather intimate knowledge of the Malaysian biotechnology industry, sampling was focused on companies and industry experts in the Bionexus network. Collaboration 
was done with Biotech Corporation Sdn Bhd of Malaysia in order to gain access to the companies and encourage increased participation of the survey in view of Biotech Corporation's endorsement of the study. Information on the Malaysian Bionexus database reflected a total of approximately 80 participants. Biotech Corporation sent each member company an email to notify and endorse the study. This was to encourage recipient-participation to make the study a success. A $\$ 10$ donation was given to the local cancer society for every response received.

Research objectives are: to explore growth patterns, industry platforms and networks, enabling factors that support entrepreneurial activity, innovation, productivity, sustainability and research development. Questions explored are: do initial factor endowments affect the trajectory of a biotechnology industry, and how should Malaysia prioritise, mobilise and coordinate resources to build a sustainable bioeconomy.

This study utilizes an online-survey, confidential interviews and case-studies. The survey was formulated with a triangulated design that involved interviews and five firms in a multiple-case studies approach (Jick, 1979; Sackett and Larson, 1990; Scandura and Williams, 2000; Yin, 1984). The five case studies consist of local companies in Malaysia operating in diverse biotechnology applications (e.g. diagnostics, biofuels, therapeutics, nutraceuticals, and devices) and have been compiled in order to capture a rich set of data relevant to the study.

The triangulation design synthesizes two research approaches: an inductive grounded theory analysis (Glaser and Strauss, 1967; Corbin and Strauss, 1990), and a hypotheticodeductive scale development and testing methodology (Cook and Campbell, 1979; Popper, 1968; Stinchcombe, 1962; Salmon, 1971). The inductive approach utilizes theoretical sampling, collecting data from key informants, and coding, sorting and data comparison (Corbin and Strauss, 1990). The hypothetico-deductive approach utilizes interviews and a comprehensive literature review to identify specific antecedents to a viable and competitive bioeconomy. This is followed up by an online survey to validate these factors and generate an emergent grounded theory. 
A multiple-case study approach was done to enhance replication (Eisenhardt and Graebner, 2007; Yin, 1984). Five cases were chosen, designed and written for analysis and as independent experiments to record any emerging or current issues occurring in the Malaysian biotechnology industry. These Malaysian biotechnology firms operate in biofuels, nutraceuticals, biopharmaceuticals, diagnostics and devices; which allowed an adequate representation of the industry. Case study information was taken from company reports, publications, newspaper articles and scientific journals. Each case-study gave different viewpoints and a variety of potential variables necessary to build a bioeconomy. These were duly recorded and used for validation in interviews with Bionexus companies' executives.

Raw data for the survey was collected in a rigorous and thorough process, employing theoretical sampling (Glaser and Strauss, 1967; Charmaz, 1983) with Bionexus industry executives, founders, entrepreneurs and scientists. These individuals were invited to provide data through personal but confidential face-to-face interviews. The participants were tasked to identify and evidence survey variables (Merton and Kendall, 1946). This was a crucial step in constructing and structuring the survey.

For the first part of the interviews, open-ended questions were also asked to allow respondents' freedom to express their views and opinions on their specific roles in biotechnology and bioeconomy, and their expertise on the various essential factors to build a sustainable world-class biotechnology hub. In the second-part of interviews, validation of raw data from earlier case-studies was crucial and needed to be tested with these industry experts and practitioners. They were asked to chose and rate a set of variables which they felt were 'relevant' when assessing the current state of their biotechnology industry, current and emerging issues; and essential factors to develop a competitive bioeconomy.

Participants were asked to rate the items and variables identified in the literature research. This again gave validation and proof of relevance to the content and context on how the survey will be constructed. Therefore with the rated results, data collected from case 
studies and interviews; the information was used to design and purpose-built the survey. These steps were necessary to ensure the survey itself would be understandable to practitioners and rigorous for academics to trust the derived data sets and allow replication in future studies.

Based on the interviews and multiple case-studies, an online survey of 17 items was developed to validate findings related to the current state of the biotechnology industry, factors to innovation (Van de Ven et al., 1999) and perceived priorities and capabilities required to building a sustainable bioeconomy. There are 16 scaled items (importance, cross-validated, and ranked-order) which participants had to rank and answer. An openended question was added at the end of the survey to capture a richer understanding of responses and identify possible omissions. The survey was posted online at surveymonkey.com as a third-party host in order to guarantee full or conceal anonymity of participants. 


\section{Introduction of methodologies}

\section{Research Design}

\section{Triangulation}

Triangulation is a common and well-known approach in mixed-methods research. The purpose is to obtain data on the same topic through different techniques, in order to increase understanding of the research problem (Creswell \& Clark, 2007). The aim of this methodology is to combine both quantitative and qualitative methods of datacollection and reduce weaknesses in each individual method. Both data-collection methods are conducted concurrently, with each data-set separately analysed. The researcher can compare and contrast findings from both data-sets, combine both data-sets and write an overall integrated analysis and or validate one set of data from the other. Grounded-theory, attempts to analyse the data and identify key themes, patterns and categories from the data (Lancaster, 2003; Creswell \& Clark, 2007). The benefit of grounded-theory is it offers explanations relevant to a particular set of circumstances and situations (Lancaster, 2003).

For this study, a two-phase data collection research design is used. In the first phase, qualitative data-collection through multiple case-studies and a literature review will be undertaken to identify potential key concepts and variables. The findings will be validated with confidential face-to-face interviews with participants from the Bionexus network. The interviews will give a rich set of data that will provide insights into the necessary capabilities and priorities required to building a bioeconomy in Malaysia. After cross-validating data from the case-studies and literature review, new information derived from the interviews will be combined together with the cross-validated data to formulate a questionnaire. This questionnaire will survey the entire Bionexus network of companies to ascertain level of generalisability in results. 


\section{Case Studies}

A case represents an existing phenomenon that is observed at a single point or over a period of time (Gerring, 2007) and later portrayed through a study which simulates the situation that is put into context through a verbal representation of reality (Ellet, 2007). Thus a case-study can be referred to as an intensive study of a single case in order to understand a population sample. The inclusion of five cases in this paper was to form part of a multiple-case study, and is commonly referred to as cross-case since the assumption is that at a certain point it will not be feasible to study these cases intensively (Gerring, 2007). The cases selected were representative of the biotechnology companies in Malaysia and of the Bionexus network. The number of case-studies is influenced by the research problem and the research objectives. As this paper is an exploratory study into Malaysia's emerging biotechnology industry, it will be necessary to study at least one firm per biotech segment.

\begin{tabular}{|ccc|}
\hline Company & $\underline{\text { Type }}$ & $\underline{\text { Biotech Sector }}$ \\
Industrial Oxygen Incorporated (IOI) & Private & Biofuels \\
Chemical Company of Malaysia (CCM) & Private & BioPharmaceuticals \\
BioFact Life & Bionexus, Private & Nutraceuticals \\
Malaysian Bio-Diagnostcs Research (MBDR) & Bionexus, Private & Diagnostics \\
StemLife & Bionexus, Private & Stem Cell Banking \\
\hline
\end{tabular}

Table 4: Case-studies Company Profiles

Typically a cross-case study aims to explain the phenomena superficially, whereas a case study will have in-depth analysis. Thus for each individual cases covered in this paper, initial analysis is conducted such as collecting data from the internet regarding the corporation, company websites, publications and newspapers. The data is recorded and paraphrased to explain the company's activities, strategies and responsibilities. With these details of the company and further analysis is explained with knowledge from secondary sources like academic journals and corporate publications. 


\section{Preparing for a case study}

This process goes through four stages: 'drift', 'design', 'prediction' and 'disconfirmation'. According to a figure provided by Bonoma in 1985 by (Ghauri \& Gronhaug, 2005), these four stages are graphically depicted below.

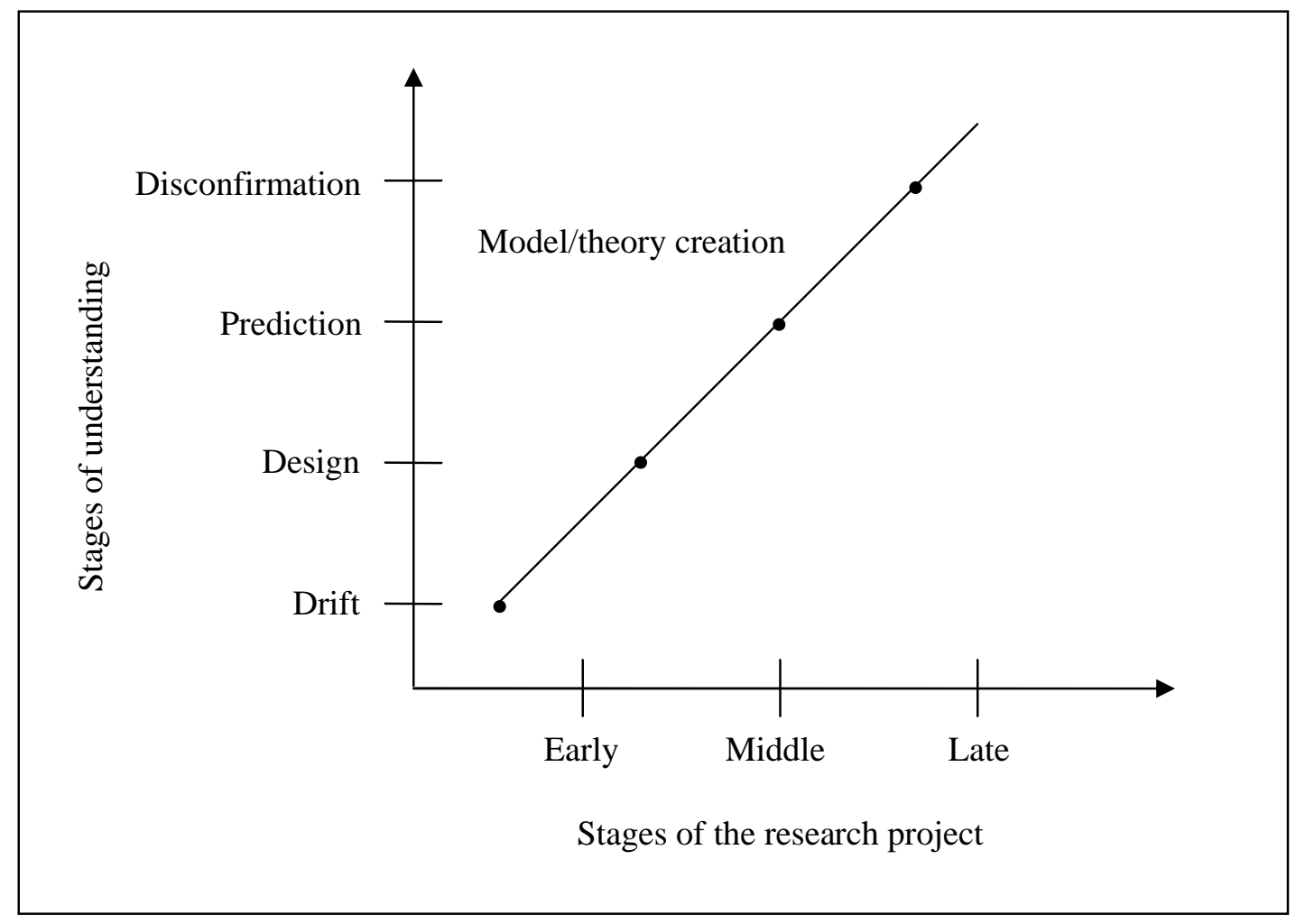

Figure 4: Stages of Understanding in Case studies

In the initial stages, the researcher is in a 'drift' stage as he/she is trying to learn the area of research, varying concepts and terminologies used (Ghauri \& Gronhaug, 2005). During this process, the researcher acquires basic knowledge about the subject and constructs themes surrounding the areas of interest. It is also during this stage that the researcher tends to restructure the research questions and knows where to find more data. In the second or 'design' stage, the researcher formulates a method to collect data to explain the research questions and establishing theoretical rigour in the case study. Later in the third or 'prediction' stage, with an advanced understanding of the case and 
necessary factors, the researcher compiles and constructs the case to draw meaningful conclusions. Concepts and variables derived from this exercise will be validated by the interview-participants. This is also known as the final stage 'disconfirmation', to test the generalisability of results.

\section{Interviews}

Interviews are acknowledged as one of the most effective ways of data-collection in social science research (Lancaster, 2005; Ghauri \& Gronhaug, 2005). Face-to-face interviews will be conducted to collect data, and complex issues can be explained and unclear issues clarified. Interviews are useful as the researcher is able to adapt the line of questioning to suit the circumstances and ensure the questions will be properly answered and explain meanings behind the concepts. In order to plan and conduct the interviews, data objectives and discussion topics were derived from the literature review and multiple case-studies.

The first-half of interviews will be unstructured as the questions are open-ended to initiate conversation with the participant and gather insight on their views. The secondhalf of interviews require participants to rate variables and concepts from the case-studies and literature reviews. This will be semi-structured as questions will be asked and validated against participants' answers. Interview participants will be selected from Malaysia's prestigious Bionexus network of biotechnology companies. Malaysia Biotechnology Corporation will send these companies an email and phone-call notifying them of this study and request their participation to make this study a success. These biotechnology companies are high-growth with internationalisation potential and are aided by the Malaysian government to spearhead growth of the bioeconomy. Interviews will be arranged directly through electronic-mail and phone-call communications with the researcher. This is to conceal their identities and maintain anonymity. The researcher will conduct the interviews at the participant's office or otherwise planned. 


\section{Questionnaire}

A questionnaire is a pre-formulated set of questions to which respondents record their answers within closely defined boundaries and alternatives (Cavana et al, 2001; Ghauri \& Gronhaug, 2005). The questions for this survey were derived from key concepts and variables identified from the first-phase of qualitative data-collection. For this paper, closed questions were used in the survey to Bionexus participants. With closed questions, respondents would need to make a choice among a set of alternatives or choices provided. Respondents were also asked to rank or indicate their preference or opinions. Closed questions aid participants' decision-making and researcher data-analysis. This limits the statistical methods and scope possible for analysis. The actual questionnaire is provided in the appendix at the end of this paper for review.

Survey questions were kept extremely brief to avoid several things like phrasing words negatively or positively, biases in questions or leading questions; and to keep the survey as short as possible. An issue of awareness highlighted was the difference in languagemedium in Malaysia as Bahasa Melayu is the predominant language with English, a second language. Demographic data like years of experience, role in the company and principal residence were the kind of questions used to capture insights on the characteristics of respondents. The questionnaire also included an open-ended question which gave respondents the freedom to comment on any areas of interest and provide further insights to enrich the data collected.

The questionnaire was planned for online distribution to Bionexus companies. Malaysia Biotechnology Corporation volunteered to send participant-companies an electronic-mail and a phone-call notifying them of this survey study and request for their participation.

Some benefits of online-distribution are; for example to provide fast access to computerliterate respondents, rapid data-collection, visual aids may be used to aid partcipants' response, participants feel anonymous and it is often the lowest-cost option (Cooper \& Schindler, 2008). The questions in the survey were structured with ordinal and 
categorical scales. Ordinal scales categorises variables to denote differences among various categories, and allows ranking of variables. However the ordinal scale does not provide an indication of magnitude in differences between each variable (Cavana et al, 2001; Creswell \& Clark, 2007). The graphs will be analysed using descriptive statistics.

For validity and consistency of findings, the Cronbach's Alpha will be used to statistically test the reliability of results from the top two priority capabilities identified by respondents. This test gives significance to the reliability of results and measurement instruments (Cavana et al, 2001).

Application for Human Ethics Commission (HEC) through Victoria University of Wellington was necessary to gain approval for the confidential interviews and anonymous questionnaire. This ensured a $3^{\text {rd }}$-party, i.e. Victoria University; was made aware of the researcher's data-collection and that the survey would not cause harm or offend any potential participants. Gaining approval is essential as it gives respondents further assurance of their anonymity. The HEC forms were filled out by the researcher and discussed with the supervisor and school HEC representative. Once the forms were filled out appropriately, they were sent to the HEC Committee for formal approval of data-collection.

\section{Research Methods}

Data sources for the case-studies were through secondary data. The researcher started with a literature search on topics specific to each case and progressed onto other areas of interest. For example, if one of the biotechnology companies was involved in biofuels, then the research would be on the topic of biofuels, definition of biofuels, specifics and history of biofuels, global and local market growth and demand; and other underlying issues directly or indirectly affecting the company or industry. Therefore the list of secondary data sources includes books, journal articles, newspapers, government webpages and company websites. The advantage of using secondary data is the reduction in time and money spent to gather data. The researcher can commence research through 
the internet or at the library. The researcher may draw conclusions or hypotheses rapidly once he/she validates the data sources and reliability of data. Through this exercise, the researcher managed to construct a background picture of each company and their respective business operations. Founding members and leading scientists were some of the people researched upon and highlighted to be responsible for the company's growth and success. Further research was done to shed insight on their respective biotechnology sector and issues affecting their industries for example global events like an oil-crisis, Kyoto Protocol over carbon emissions, new international regulations restricting crossborder stem-cell transfers and ethical dimensions on usage of regenerative medicine. Findings from the case studies were used to enrich questionnaire results. This was to provide an additional perspective as mentioned previously.

Confidential interviews were conducted after contact with the researcher was made. The researcher arranged and conducted the interviews in Malaysia. Interviews were conducted in the participants' office and at their convenience. The researcher was present to explain or clarify any uncertainties regarding questions or confidentiality issues. The conducted interview pattern was listening, questioning, paraphrasing and probing in order to elicit answers and viewpoints by participants. Responses were written down and tape-recorded by the researcher for further analysis. Tape-recorded interviews do not contain any participant information in order to conceal anonymity.

The questionnaire was administered through an online website, www.surveymonkey.com. The web address containing the survey was provided to BiotechCorp for dissemination to Bionexus companies, along with a note requesting their participation in the survey. This survey was opened to all participants for a period of three months, from September to November 2008. The measurement scales used in the survey were categorical and rating scales used were ordinal. 


\section{Data Analysis}

The raw data was downloaded from www.surveymonkey.com which hosted the onlinequestionnaire. The website tabulates and presents all responses in the raw data-set according to the questions answered. For example, if each respondent has to select 7 out of 10 options and there are 34 respondents, the total count of responses should be 238 . If there are lesser than that amount, there will be a 'missing response' section which will tabulate the amount. Missing and blank responses will be depicted in the graphs when necessary. The researcher is also aware that if a substantial amount of questions are left unanswered, there might be a problem with the questionnaire and the data-set is unsuitable for analysis. Since the survey was partially derived from interview responses, this may minimise the problem of editing and handling missing or blank responses. The raw data-set was entered into Microsoft Excel for data analysis. Frequency distributions were tabulated to obtain information on demographic variables like occupation, work experience and principal residence. Descriptive statistics was undertaken for the rest of this paper and results were shown in bar-graphs through the Results section.

\section{Limitations of methodology}

Online questionnaires are a useful way to distribute results and gather responses. However it could also be generalised that computer-savvy respondents are more likely to participate than non computer-savvy participants. Utilising close-questions in the questionnaire aids meaningful analysis in some way but limits statistical testing. The time frame of this research is limited to 12 months and potential research-methods and researcher's capabilities needed to be taken into account when choosing the appropriate methodologies for data-collection. Cross-case studies are practical for an informative insight into a large sample population; however deriving meaningful insights might be limited. Using only the Bionexus network of companies might give a narrow opinion or response since the unit under special focus is not perfectly representative of the population. However a perfect homogeneity across the sample and population is impossible to be assured (Gerring, 2007). 


\section{Limitations of Study}

Replicating social science research may provide a different answer from this study therefore a mixed-methods approach was adopted to increase credibility. Acknowledgement is given on limitations of this study's time-frame, researcher's capabilities, sources of funding and support. The hope is for this study to provide grounds for further and future research. Also it is acknowledged that there are too many variables to be considered and covered in a questionnaire that is designed to be brief and easy for respondents. 


\section{Case Studies}

\section{IOI Group Sdn Bhd}

\section{Company Background:}

Industrial Oxygen Incorporated (IOI) Sdn Bhd is a Malaysian company formed on the $31^{\text {st }}$ of October, 1969 with the principal business in distribution of industrial gas. IOI

converted to public status on the $29^{\text {th }}$ of September, 1972 and was listed in the Kuala Lumpur Stock Exchange of Malaysia on $29^{\text {th }}$ July, 1980 (IOI Group, 2008a). IOI Group started out in the real-estate market in Malaysia when it ventured into property development in 1984 and later delved into oil-palm plantations in 1985. Today, IOI is internationally renowned as a leading global integrated palm oil player with operations encompassing the entire oil-palm value chain from seedlings to plantations to crop-oil extraction and to diverse value-added manufacturing across more than 65 different countries. IOI also employs more than 30,000 workers of more than 23 different nationalities in 15 countries (IOI Group, 2008b)

\subsection{Company Major Products/Technology:}

IOI is currently involved in three different segments; Plantation, Resource-Based Manufacturing and Property. IOI view its product and service offerings as complementary in terms of internal usage for further value-add activities before reaching consumers and or being offered externally. The graph (refer to Figure 5) was provided by IOI to show how consumers could benefit from the eventual product or from a product anywhere in along its value-chain 


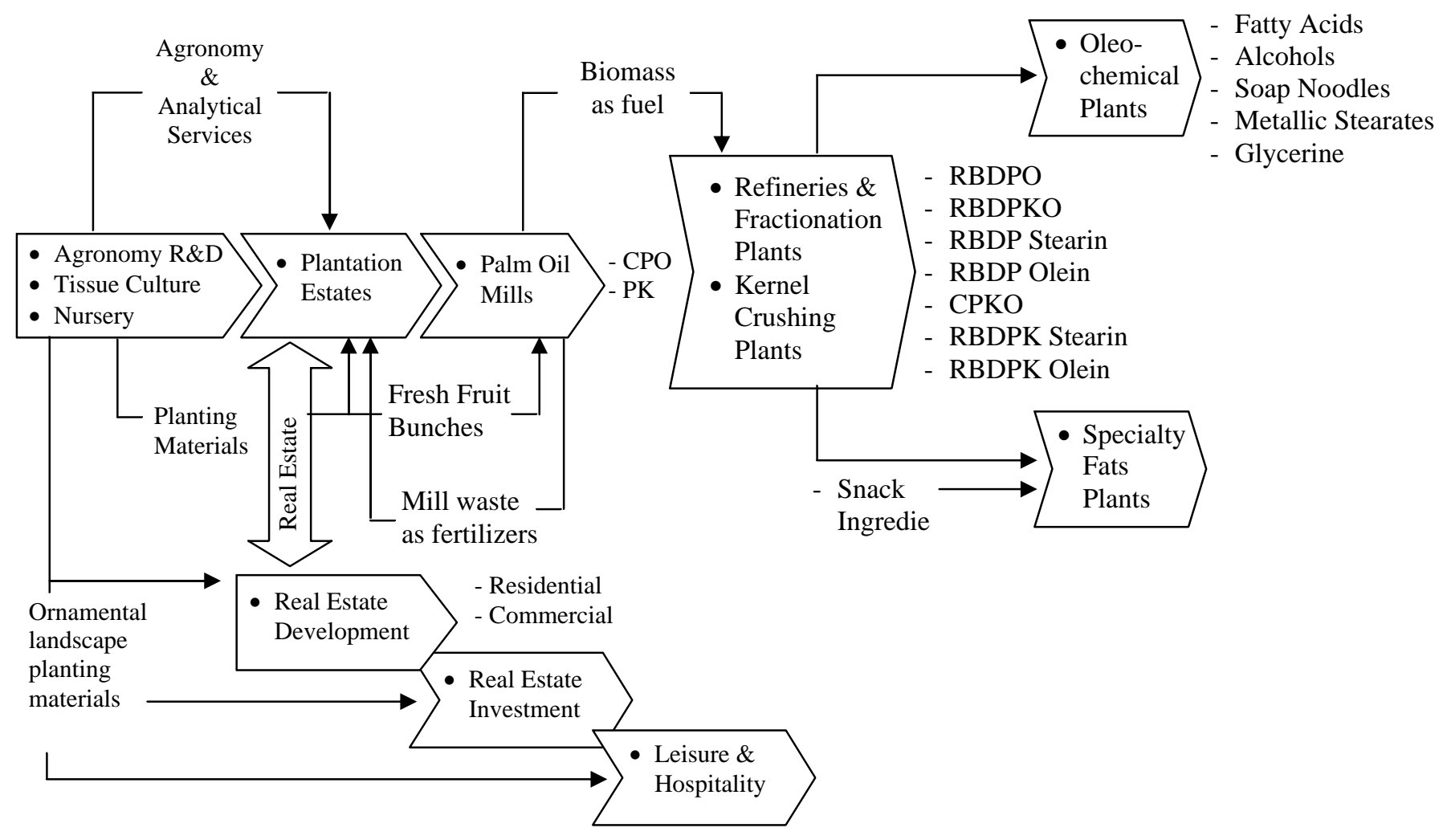

Figure 5: Business Processes and Valued Added Activities

(IOI, 2008a)

\subsubsection{Plantation}

Plantation comprises of two components, Agronomy and Estates \& Mills. Agronomy is the science of soil management and the production of field crops (Dictionary, 2008). IOI relies and invests heavily on research and development in agronomy sciences with two centre of excellence on developing agronomy best practices and introduction of high yielding planting materials. This has allowed IOI to develop its own hybrid oil-palm seed that yields high oil content for harvesting to meet increasing global demands and is available for commercial sale (IOI Group, 2008c). IOI's policies on Estates and Mills are on agri-sustainability and non-encroachment of natural forests in future expansions of plantation areas (IOI Group, 2008d). IOI currently has 12 oil-palm mills in Malaysia with a total milling capacity of 4, 100, $000 \mathrm{MT} / Y e a r$. In recent years, the demand for oil-palm 
in biofuels have increased which resulted in higher demand and high prices for crude palm; thus IOI has ventured into Indonesia to establish more plantations and mills. IOI was also awarded a license to build a biodiesel plant in Johor, Malaysia in 2007 at 200,000 litres per annum.

\subsubsection{Resource Based Manufacturing}

This business arm is the downstream of IOI's oil-palm value chain. The raw oil-palm can be processed and refined by IOI and channelled internally for further value-added processing or be sold to industrial consumers like other destination refineries for more specific refining (IOI Group, 2008e). IOI is also involved in oleo-chemicals and is currently Asia's largest vegetable oil base manufacture. Oleo-chemicals are derived from renewable resources (vegetable oil) and are unlike petro-chemicals which have proven unsustainable in the long-term. IOI's plants are ISO 9002 and 140001 certified to produce a very wide range of oleo-chemical products like fatty acids and esters, glycerine, fatty alcohols that have various industrial applications in food production, pharmaceutical, cosmetics and other industrial lubricants and products (IOI Group, 2008f). Lastly, speciality fats are a unique category of fats that have nutrition/ health supplement applications. IOI's speciality fats businesses are operated under the IOI Loders Croklaan Group of companies which is the global business leader in this field (IOI Group, 2008g).

\section{$\underline{\text { 1.2.3 Property }}$}

The Property business arm consists of three segments: development, investment, and leisure and hospitality. IOI has around 162,000 square metres of net lettable areas in its investment portfolio comprising of commercial, office buildings and shoping malls in prime locations. These properties were developed by IOI's property development wing and turned into long-term investment businesses for the company (IOI Group, 2008h). Leisure and hospitality is a natural extension of IOI's property investment segment, 
comprising of resort based golf courses, hotels and convention centres (IOI Group, 2008i).

\subsection{Founders:}

The founder, Tan Sri Dato Lee Shin Cheng was first appointed to the Board on $21^{\text {st }}$ July 1981 (IOI Group, 2008j). He is an entrepreneur with experience in the plantation and property development industries and provides advisory guidance to a large number of industry groupings and organisations. Together with his brother, Lee Cheng Leang, executive director since $21^{\text {st }}$ July 1981, who has considerable experience in the hardware, chemical and industrial gas industry (IOI Group, 2008k), IOI has thrived and grown into a dominant global player in its individual businesses and in Malaysia.

\subsection{Corporate Social Responsibility}

IOI's approach to Corporate Social Responsibility (CSR) is to strike a sustainable balance between the conflicting demands of internal and external stakeholders in the company's pursuit of profits and growth (IOI Group, 20081). IOI promotes environmental sustainability through its plantation, downstream processing (i.e. oleo-chemicals and crude palm refining) and property development. IOI also undergoes a number of sustainability audits by regional and international bodies and seeks for all their plantation estates to be Roundtable on Sustainable Palm Oil (RSPO) - certified. With profits derived from its businesses, IOI uses it for social responsibility like education, community and employee benefits.

\subsection{Case Study Reflection}

As we can see from the short case study of IOI Group, their primary produce of palm oil is responsible for two of their business segments, Plantation and Resource Based Manufacturing. The interest in the renewable and biofuel industry has grown tremendously with environmental issues like global warming and reducing of carbon emissions and the need to find renewable energy resources to replace fossil fuels. This 
has led to $R \& D$ for renewable fuels. The oil palm has emerged as the favoured biofuel crop as it is aggressively cultivated by Asian nations who are able to produce at lowcosts. The IOI Group has to mitigate between Corporate Social Responsibility (CSR) for its palm oil operations and their wider business objectives. Environmental lobby groups have increasingly pressured their respective governments to monitor how palm-oil producers expand their plantations and acquire available lands. Sustainability audits are one of the ways of certifying the company's CSR. IOI can purchase existing plantations instead of acquiring land for new plantations. IOI Group has shown diversification with sustainable short-term or other types of businesses supporting long-term palm oil operations. Stakes in property development, rentals and investments are useful to sustain their biofuel business and distribute business risks amongst their different operations. 


\section{Chemical Company of Malaysia (CCM) Berhad}

\section{$\underline{1.1 \text { Company Background }}$}

Chemical Company of Malaysia (CCM) Berhad established a presence in Malaysia since 1930 as a subsidiary of Imperial Chemicals Industries PLC (UK). In August, 1963, CCM became a fully Malaysian-owned corporation. CCM achieved significant corporate presence since it became publicly-listed in 1966 on the Malaysia Exchange (MYX) and is considered a 'blue-chip' company in the Malaysia Exchange with good returns to shareholders (CCM, 2008a).

\subsection{Company Major Products/Technology}

CCM is presently involved in 4 types of businesses, from chemicals, fertilisers, pharmaceuticals and duopharma biotech. However CCM started out as an industrial and speciality chemicals company in Malaysia in the 1930s (CCM, 2008b) It has now grown in the South-East Asian region with full-fledged offices in Singapore and Indonesia. CCM is involved and deals primarily in the manufacturing and marketing of industrial and speciality chemicals. CCM currently represents over 50 world renowned principals in the region with a strong export business market presence in Malaysia, Singapore and Indonesia (CCM, 2008c). CCM started diversifying in September, 1966 to establish the fertiliser business and built a manufacturing plant (CCM, 2008d). In March, 1995, CCM first delved into the life sciences after acquiring a pharmaceutical company and thus established their pharmaceuticals division.

\subsubsection{Chemicals}

CCM Chemicals is the first business wing of CCM Bhd. This business wing has progressed from being an industrial and speciality chemicals plant to a manufacturing and trading company; and is also currently involved in water engineering and services. CCM 
Chemicals provides its industrial chemicals and acids to a diverse variety of industries like pharmaceuticals, glass and food.

\section{$\underline{1.2 .2 \text { Fertilisers }}$}

CCM Fertilisers manufactures compound fertilisers especially for commercial customers. Research and development for this business segment is heavily pursued to formulate the best fertilisers for both plantation and cash crops. This is essential as Malaysia is an agricultural country and CCM Fertilisers stand to benefit from a domestic market of farmers and corporations. The Malaysian government agricultural research institutions also collaborate closely with CCM Fertilisers to produce fertilisers suitable for crops in Malaysia.

\subsubsection{Pharmaceuticals}

CCM Pharmaceuticals has the reputation of being the largest domestic producer of generic drugs with over 280 products like antihistamines and antibiotics divided distinctively into ethical and over-the counter medication (CCM, 2008e). CCM Pharmaceuticals have close working relations with other laboratories in the United States of America and Canada which allows them to share new capabilities and enhance research and development progress. This multi-lateral network is an example of how CCM Pharmaceuticals keep abreast of global developments and ensure their products meet international standards. CCM Pharmaceuticals sells and distributes its wide range of products to customers like doctors, private/general practitioners, Chinese Medical Halls, pharmacies and hypermarkets. They export to more than 20 countries worldwide which includes Asia-Pacific and Asean and 20\% of overall sales to Muslim countries.

\subsubsection{DuoPharma Biotech}

CCM acquired this latest business segment in 2005. The plant produces solutions for oral preparation, sterile injectables, haemodialysis and sterile irrigation. It has managed to 
establish a niche market as a leading local manufacturer of sophisticated and specialised small volume injectable solutions in Malaysia (CCM, 2008f). DuoPharma works extremely closely with Pharmaceuticals as both segments require extensive and substantial investments either through research and development or the hiring and training of current and new personnel.

\section{$\underline{1.3 \text { Corporate Governance }}$}

CCM follows and adopts the Malaysian code on corporate governance which sets out the principles and best practices on structures and processes used to direct and manage the company's activities towards enhancing corporate accountability (refer to http://www.sc.com.my/eng/html/cg/cg2007.pdf for more information on the Malaysian Corporate Governance). The objective is to realise long-term shareholder value and taking into account the interests of other stakeholders (CCM, 2008g)

\subsubsection{Board of Directors}

The Board reviews and approves short-term budgets and long-term strategies for CCM. The Board also approves all acquisitions, major capital expenditure and disposal of investments. Internal control and risk management systems within the organisation are done with the Board and the Audit Committee. This allows the effective utilisation of CCM assets and reduces malpractices (CCM, 2008h). Appointments and re-election of the Board goes through a formal procedure. The existing Board can appoint new directors and re-elect current directors which is also subjected to shareholders' vote of approval during the company's Annual General Meetings.

\section{$\underline{1.4 \text { Case Study Reflection }}$}

As we can see from this short-case study, CCM started out as an industrial and speciality chemicals company in the 1930s and later diversified into the biopharmaceuticals from 1995 onwards. This is an interesting prospect since the life sciences industry has been 
growing rapidly in the last decade and especially the biopharmaceutical sector. Biopharmaceuticals has been used to push the frontier of pharmaceutical products with the use of living cells. This has led to more discoveries and newer drugs to treat various ailments and diseases. As mentioned earlier, CCM Bhd is involved in the production of generic medicines. This is a useful advantage as Malaysia can target consumers that have lesser purchasing power in developing countries like Laos and Cambodia that are close in proximity. Another note, CCM Bhd has a focus on producing Halal medicines for export into Muslim countries and consumers. The global Halal market has increased in revenue and export potential has increased tremendously. Focusing on low-cost and halal medicines will be advantageous for CCM to establish a position in niche markets. 


\section{BioFact Life Sdn Bhd}

\subsection{Company Background}

BioFact Life Sdn Bhd, is a Malaysian biotechnology private limited company incorporated in February 2005 to cultivate cordyceps in a specially designed clean room environment. This new start-up was formed to align with the Malaysian government's biotechnology policy, global biotechnology trends and is part of the BioNexus Network (Biofactlife, 2008a). BioFact Life is a seed-to-shelf approach company with extensive research and development. Seed-to-shelf approach is synonymous with farm-to-fork and seed-to-supper. This means that the paper trail of fully-documented traceability like audits and inspection is never interrupted from seed supplier all the way to the grower, storage, shipping and product distribution (CertID, 2008). It allows full accountability and total background information of how the product was grown and manufactured and sold to the consumer. The company produces cordyceps, manufactures and market the end-products in domestic and international markets. This has led the company to become one of the largest herbal healthcare product distributors in Malaysia, with an outstanding track record in offering OEM services (Biofactlife, 2008a).

\subsection{Company Major Products/ Technologies}

Cordyceps, well-known to traditional Chinese medicines and found primarily in China and Nepal is an expensive herb worth in excess of US\$14,000 per kilogram at wholesale prices (Biofactlife, 2008b). BioFact Life's method of cultivating cordyceps is unique as it is grown by regulating the temperature, humidity, oxygen, light and the acidity conditions. With such a controlled environment, the medicinal properties in the cordyceps are pharmacologically ten times more active than wild-grown ones. This has enabled them to be a pioneer in this field. With the farming of a single crop, the company has developed six products for sale. These products contain the main ingredient of cordyceps to provide health benefits in forms of capsules and powdered drinks. The 
products are targeted and available to both genders and all age groups. There are also specific products that target men and possible sex-health issues; and other particular ailments like liver and respiratory allergies. The company consists of two major divisions; one being research and development and the other being standard manufacturing division.

\subsubsection{Research and Development}

This business division is led by Chartered Scientist Dato Chang and is responsible for research into good cultivation practices of cordyceps and other herbs through the use of advanced biotechnology (Biofactlife, 2008a). Other responsibilities include technological innovation to improve the quality of product, new product development, product innovation, quality analysis and improvement (Biofactlife, 2008c). This division also has a Memorandum-Of-Understanding (MOU) with Usains Holding Sdn Bhd, a commercial arm of Universiti Sains Malaysia to collaborate in research and development studies for biotechnology.

\subsubsection{Standard Manufacturing}

This business division is responsible for the manufacturing of all types of herbals products by transforming raw materials into finished goods. Adopting a simple philosophy of continuous excellent product quality, products are manufactured according to the GMP standard of Good Manufacturing Practice with scientific and total quality management systems in place (Biofactlife, 2008d). To achieve this target, a quality department was set-up from the beginning to ensure total quality in all its manufacturing processes. The quality department includes QA (Quality Assurance), QC (Quality Control) and IPQC (In Process Quality Control). The QA team is responsible for developing a standard process and structured system for all production lines. The QC team performs inspections on the raw materials and finished products to ensure the products are within quality control limits. Lastly IPQC conducts sampling tests on products during the production process to ensure any material which does not meet the 
required standards will not be processed in the next working stage (Biofactlife, 2008d). The quality department is also under the direct supervision of a professional management team to ensure total quality is not compromised and every process is strictly under control and complete with an audit system to ensure traceability.

\subsection{Key Personnel}

Dato Chang Eng Thuan, technical director of Biofactlife has thirty-seven years of experience in analytical chemistry. He holds a Bachelor of Science (Hons) in Chemistry from the University of Malaya (1969). He has attended advanced training programs in analytical chemistry and microbiology at the Laboratory of the Government Chemist, London; Mycotoxins analysis in the Tropical Product Institute and forensic science training at New Scotland Yard, London (Biofactlife, 2008e). He was also bestowed Chartered Scientist of the British Science Council and also has affiliations with the Royal Society of Chemistry, United Kingdom and Malaysian Institute of Chemistry. Besides his current tenure in BioFact Life, he is chairman of the Industrial Standards Committee on Chemicals and Materials and a member of several statutory boards in Malaysia. He has published journal articles on toxicology and traditional Chinese medicines in both local and international publications and chemical conferences.

Dato Dr. Gan Ee Kiang holds the position as a pharmacology consultant in the company. He obtained his degree as a Doctor of Philosophy from the University of Western Australia in 1972. He has a strong background in academia from being a lecturer at the Universiti Sains Malaysia (USM) and later serving as Dean of School of Pharmaceutical Sciences at USM from 1979-1995. He was instrumental in setting up three new departments at USM; Drug Research Centre, National Poison Centre and National Doping Control Centre. He has published two books and over one hundred scientific/professional articles and is co-inventor of two patents (Biofactlife, 2008d). He was previously appointed and served as a temporary advisor to the World Health Organisation, member in the International Health Advisory Panel of the United States Pharmacopoeia Convention and at various international conferences. Other than his 
current tenure at BioFact Life, he is active in community services and sits on the Board of Directors of several private limited companies and is also a consultant to venture capital companies (Biofactlife, 2008e).

\subsection{Case Study Reflection}

From this short case study, it is known that BioFact Life is a biotechnology company which cultivates and manufacture cordyceps into health-supplements for sale and export. However what is interesting is that the company has transformed the cultivation of a traditional Chinese herb using modern biotechnology to develop a line of nutraceuticals to address health issues. The idea of nutraceuticals originated in Japan in the 1980s when 'physiologically functional foods' appeared on the market and were defined as having a positive health impact on the consumer apart from the basic nutritive value (Hardy, 2000).

Three important lessons are drawn from this case; protecting their R\&D innovation through IP, strategic alliances with partner-universities and commercialising a product with easy access to customer-markets. BioFact Life's innovative process of cultivating cordyceps and patenting the entire process with Intellectual Property protection, demonstrates how a R\&D discovery can be protected, commercialised and derived profits from. The implementation of IP protection has proven useful and outlines how a company can protect their own R\&D and IP. A strategic alliance with Universiti Sains Malaysia allows sharing of capabilities, networks and R\&D knowledge to develop new products with cordyceps as the main ingredient. The relevance of this herb has importance in the Asia region and in traditional medicines. A major part of the nutraceutical and medicines industry in Asia carries a strong herbal and traditional medicine component. BioFact Life's products infuses western technology with an Asian herb to derive products which can be targeted at nearby Asian markets 


\section{Malaysian Bio-Diagnostics Research (MBDR) Sdn Bhd}

\section{$\underline{1.1 \text { Company Background }}$}

Malaysian Bio-Diagnostics Research Sdn Bhd (MBDR) was incorporated in 1994 and began operations in September 1995. It is 100\% Malaysian-owned and was initially established as a company to commercialise research on the diagnosis of typhoid fever. MBDR has expanded into producing other various medical diagnostics products like pregnancy test kits, drugs of abuse and brugian filariasis (MBDR, 2008a). MBDR has also established strategic partnerships with various universities and research institutes to develop new medical diagnostic products for the detection of various diseases like tuberculosis, malaria, paratyphoid, HIV, Nipah Virus and Dengue (MBDR, 2008a). With cutting edge technology and extensive research, MBDR aims to position itself as global competitor in developing and marketing diagnostic tests. MBDR has managed to capture export markets in various countries like Indonesia, Philippines, Thailand, Vietnam, India, Pakistan and Australia. MBDR is also part of Malaysia's BioNexus Network of companies which allows the company access to a creative cluster of biotechnology companies and cooperates to develop new products and services.

\subsection{Company Major Products/Technologies}

By utilising technology platforms such as protein-based immunochromatograpy tests (ICT), polymerase chain reaction method (PCR) and enzyme linked immunosorbent assay method (ELISA); MBDR is a pioneer company in Malaysia to incorporate three technology platforms into its medical diagnostic products which serve the in-vitro diagnostic (IVD) market (Biotechcorp, 2008a). MBDR's products have a wide-variety of applications across all industries and can be seen in later analysis. 


\subsubsection{Drugs of Abuse}

These are rapid tests for drugs in detecting levels of opiate, commonly found in morphine and codeine; terahydrocannabinol (THC), found in marijuana; and other drugs like amphethamine and Methamphetamine (MBDR, 2008b). Detection of these drugs are done by urine testing which uses immunochromatography which is immersing a dip-stick into the urine and waiting for five minutes when a colour band will appear to show positive signs of drugs or two colour bands to show a negative presence of drugs MBDR has allocated a variety of applications for this sort of testing to pre-employment testing, scheduled drug-user testing, random testing or post-accident testing. This product by MBDR is rated as highly reliable, quick and easy to use and does not need any scientific surroundings and can be done at anytime and anywhere.

\subsubsection{Filariasis}

Lymphatic Filariasis is caused by three species of blood/ tissue worms. One hundred and twenty million people in 83 countries worldwide are infected and estimates of one billion people are at risk of acquiring infection of this disease. It is spread from an infected human to an uninfected human by mosquitoes. The danger of this infection is recurrent fever, lymphatic damage, renal damage and pulmonary disease (MBDR, 2008c). MBDR's has a product test-kit which gives rapid results in 15 minutes and requires a small amount of specimen like blood, serum or plasma. Like all its products, MBDR manufactured diagnostic kits are capable of being used in any type of environment.

\subsubsection{Tuberculosis}

Tuberculosis (TB) is an infection which commonly affects the lungs and can also affect the central nervous system like meningitis, lymphatic system and circulatory system. TB is one of the most deadly and common major infectious diseases today and roughly affects two billion people worldwide. TB increases at a steady annual rate of nine million new cases globally which results in two million deaths, mainly in developing countries 
(MBDR, 2008d). MBDR uses a thermo-stabilised PCR mix which is ideal for private or hospital laboratories to conduct testing. Results are available within three hours and specimens of body fluids can range from sputum, gastric lavage, blood and others.

\subsubsection{HIV/Aids}

Acquired Immunodeficiency Syndrome (AIDS), is a chronic, life-threatening condition caused by the human immunodeficiency virus (HIV). It damages and destroys the cells in the immune system and interferes with the body's ability to effectively fight viruses, bacteria and fungi. This makes an individual extremely susceptible to certain types of cancers and other opportunistic infections. This condition is usually spread through sexual contact with an infected partner and also through infected blood and shared needles contaminated with the virus. AIDS is currently a global epidemic with an estimated 38 million people living with HIV. This is an increasing problem in developing countries. MBDR's diagnostic product uses an immunochromatographic test to detect antibodies of HIV in body fluids (MBDR, 2008e). By using a small volume of blood, serum or plasma, a laboratory worker needs to drip the sample into the receiver of the test-kit and results can be obtained in ten minutes. With such rapid diagnosis of HIV infections, MBDR has targeted this product at clinics, hospitals, private laboratories and for pre-marital screening.

\subsubsection{Typhoid}

Typhoid fever is an infectious disease caused by Salmonella. The disease lives in the faeces of human carriers and is transmitted through the consumption of food and water contaminated with typhoid. Symptoms vary from patients, ranging from headaches, diarrhoea, fever to delirium and shock. Typhoid is prevalent in the Asia Pacific region due to the tropical climate and in Africa and South America or places where poor sanitation and sewerage treatment systems are non-existent. The World Health Organisation estimates there are millions affected with typhoid annually and deaths average about 600,000 (MBDR, 2008f). MBDR's has a diagnostic test-kit that utilises 
only four drops of blood to obtain a serum for testing. The total test time is between 1-3 hours to obtain a confirmed result and can be done outside a laboratory and no special equipment is needed.

\section{$\underline{1.3 \text { Bio Science Team }}$}

MBDR's research and development initiatives are conducted by its own in-house team of scientists which includes its chairman, Professor Dr Ong Kok Hai who has academic links to International Medical University of Malaysia as a Dean and Professor in Pathology. He received his Doctorate of Philosophy from Manchester University (IMU, 2008) and is also actively involved in community service. MBDR also has a team of collaborating scientists from external institutions especially from Universiti Sains Malaysia (USM). Professor Asma Binti Ismail, deputy vice chancellor of Research and Innovation from USM received her formal education in the United States of America. She has a Doctorate of Philosophy from the University of Nevada specialising in the field of Cellular and Molecular Biology. She also serves on MBDR's board of directors (USM, 2008). Professor Asma is credited with the translation of scientific discovery of typhoid into 4 rapid diagnostic kits that has been successfully commercialised globally. She is currently actively involved in the World Health Organisation as a temporary advisor since 2002 in the Vaccine and Diarrhoeal Diseases and serves on several expert and national panels for the evaluation of National grants into research and development areas and biotechnology clusters.

\section{$\underline{1.4 \text { Case Study Reflection }}$}

As we can see from this case study, MBDR is involved in the medical diagnostic sector of the biotechnology sector. MBDR's products are manufactured with the idea of ease in usage with most products not requiring any special equipment or a laboratory environment. This allows medical practitioners or personnel to carry such test-kits into epidemic areas and to carry out initial analysis and diagnosis to ascertain the levels of infections. Furthermore the interesting part of medical diagnostics is that with improved 
technologies, different medical equipments are becoming increasingly common and can be found in households. An interesting thing to note, MBDR has only resolved to manufacture and be involved in diagnostic kits that are applicable to diseases prevalent in countries near Malaysia like Typhoid and Tuberculosis. Though this can be viewed as peripheral participation in the global diagnostics market, it can also be judged as MBDR's resource-based-view of overall-growth process. It means building and developing newer capabilities and products with easily-available resources. MBDR has focused on building capabilities and products in diseases that are prevalent in tropical environments. This is beneficial since R\&D testing of their diagnostic products can be conducted onsite where MBDR is situated. 


\section{StemLife Malaysia Sdn Bhd}

\section{$\underline{1.1 \text { Company Background }}$}

StemLife Sdn Bhd is Malaysia's first stem cell banking and therapeutics company. Established in 2001, StemLife was awarded the prestigious MSC status in 2002 which is formerly known as Multimedia Super Corridor, a government initiative to aid promising companies as they enter the knowledge and information technology era (StemLife, 2008a). On 17 October 2006, the company went for listing on the Malaysia Exchange of Securities Dealing \& Automated Quotation (MESDAQ). In 2007, StemLife was awarded BioNexus status which gives the company access to clusters of other promising biotechnology companies. StemLife has also been successfully involved in 19 transplants, between both related and unrelated donor-patient cases for the treatment of leukaemia, heart disease, thalassaemia major and lymphoma (StemLife, 2008b). The company is also currently in collaboration with the Kuala Lumpur Sports Medicine Centre (KLSMC) to offer therapies for patients with joint cartilage injuries. StemLife is also a founding member of the Asia Pacific Cord Blood Bank Consortium (APCBBC) with active participation in R\&D projects with over 150 leading hospitals and 450 renowned specialists. This forum gives participants the opportunity to congregate and deliberate over current issues in stem cells like medical breakthroughs and industry or public perspectives in the Asia region. StemLife is ranked as one of the largest and reputable stem cell companies in South East Asia (StemLife, 2008a).

\subsection{Company Major Products/ Technologies}

StemLife provides cord blood banking services which stores umbilical cord blood for bone marrow transplants in paediatric leukaemia and adult stem cells for use in treatment of blood-related disorders, heart disease and sports and trauma injuries. Storage and cryopreservation of stem cells is an important criterion to maintain the quality. StemLife offers two different systems of storage; cryobags and cryovials. Clients get to choose their preferred method of storage. Umbilical Cord blood is harvested from the blood that 
remains in the cord and placenta after birth. StemLife offers their stem cell banking services to collect the cord blood immediately after delivery and cryogenically stores it for future use (StemLife, 2008c). Collections are done after normal or caesarean births and delivery procedures will not be affected. The collection occurs after the cord has been clamped and cut and the process takes less than 5 minutes. Parents who have made their decisions are able to enrol and take the collection kit to their hospital of choice. Shipping and handling of their baby's cord blood will be taken care of by the company's logistics representative (StemLife, 2008d). StemLife will process the incoming cord blood for storage, test for diseases and contamination and lastly, store it away in the bank (StemLife, 2008e). A preliminary report will be sent to confirm receiving of the cord blood and a complete report will be issued three to four weeks later.

StemLife also provides stem cell banking for adults where the stem cells can be collected from the blood stream and stored under cryogenic conditions. Stems cells collected in this manner are termed as peripheral blood stem cells (StemLife, 2008f). Customers who wish to store their stem cells will have to come into the clinic to undergo a process called apheresis and the extraction process will begin. It will take roughly 4-5 hours and the patient is able to watch a movie, listen to their favourite songs or enjoy a foot reflexology massage (StemLife, 2008g).

The storage of all stem cells is in StemLife's own cryopreservation facility in central Kuala Lumpur, Malaysia. StemLife only uses the American Food \& Drug Administration-approved storage systems to store the stem cells. With approved facilities, StemLife also participates in external quality assurance and accreditation programs to ensure quality assurance in their products, services and facilities to ease the minds of customers (StemLife, 2008a). In addition to the storing of stem cells, StemLife provides stem cell consultancy and therapeutic services in close cooperation with medical specialists to provide cost-efficient and personalised treatment. StemLife's current stem cell therapy applications are in oncology, haematology, heart disease and diabetic foot ulcers (StemLife, 2008a). 


\subsection{Company Key Personnel}

StemLife is led its own management team coupled with an overriding Board of Directors and an advisory panel of medical specialists. StemLife was started by three founders; Sharon Low, Christina Lim and Professor Dr Aw Tar Choon.

Sharon Low, managing director since 2001, was a scientific researcher at a private research institute for the National University of Singapore and held a managing position for a South-East Asian internet company (StemLife, 2008h). She also holds an honours degree in Biochemistry from the University of Bristol, United Kingdom. Christina Lim, deputy managing director since 2002, was a director and general manager of a securities firm. Since her joining of StemLife, she has contributed tremendously with her experience of over 25 years in financial and management experience and oversees all operations and financial planning of the company (StemLife, 2008h).

Professor Dr Aw Tar Choon, Chief Medical Officer since 2001, was a group medical advisor to the Health Management International Group. He also co-founded two medical science companies in Thailand and Singapore. Dr Aw graduated from the University of Malaya Medical School and trained in internal medicine at the Singapore General Hospital and King College Hospital Medical School, United Kingdom (StemLife, 2008h). Dr Aw has been the Chrief of Laboratory Medicine at the National University Hospital from 1988-2002 and the Vice-Dean of the National University of Singapore Medical School from 1994-2002.

\section{$\underline{\text { 1.3.1 Company Advisory Panel }}$}

StemLife's advisory panel consists of the international and medical board. Members are recruited and invited to join from a wide variety of institutions and they provide medical input on a voluntary basis which will assist in policy making and analysis. This will allow StemLife to grow as Malaysia's top stem cell company and be a global player. The panel members will also assist in establishing relations between Malaysian and international 
scientists in order to improve the company's services and quality provided (StemLife, 2008i).

\subsection{Case Study Reflection}

In this case-study of StemLife, insight is shown on their business operating activities which involves cord blood banking and how the company has two panels of international advisors to grow the company in terms of new initiatives and provide itself with a ready pool of knowledge. With close mentoring provided by advisory panels, StemLife is able to keep abreast of new medical technologies and other outstanding issues surrounding the industry. The establishment of StemLife demonstrates the entrepreneurship of the three founders who capitalised on their scientific expertise and various connections to commercialise the company. StemLife's participation and being a founding member of the Asia Pacific Cord Blood Bank Consortium provides the company a close insight into developments of stem cell banking in the Asia region. Additionally this forum provides a formal platform for StemLife to source potential collaborative partners in medical research and new technologies. Alternatively this forum can be viewed as a cluster of companies situated across geographical borders, with the potential of cross-border product-innovation and research, multi-layered networking and provide easier access to overseas markets and patients. 


\section{$\underline{\text { Results }}$}

\section{Survey Demographics}

This study surveyed approximately 80 affiliated companies of Malaysia's Bionexus network and received 34 responses (43\% participation-rate) during the September November 2008 time period. Participants were allowed to select multiple roles in the biotech industry (i.e. scientific founder maybe a board member, academic researcher, or a service provider such as an attorney maybe also be an investor). In Figure 6, management (76\%) and board member (32\%) were the leading roles, with additional roles such as scientists (24\%), service providers (9\%), academics (6\%), investors (6\%) and government officials $(6 \%)$. There were also several other types of roles found, such as the chief executive officer, entrepreneur and vice-presidents. The study also found that $41 \%$ of participants have more than 10 years of experience in the biotechnology industry (refer to Figure 7).

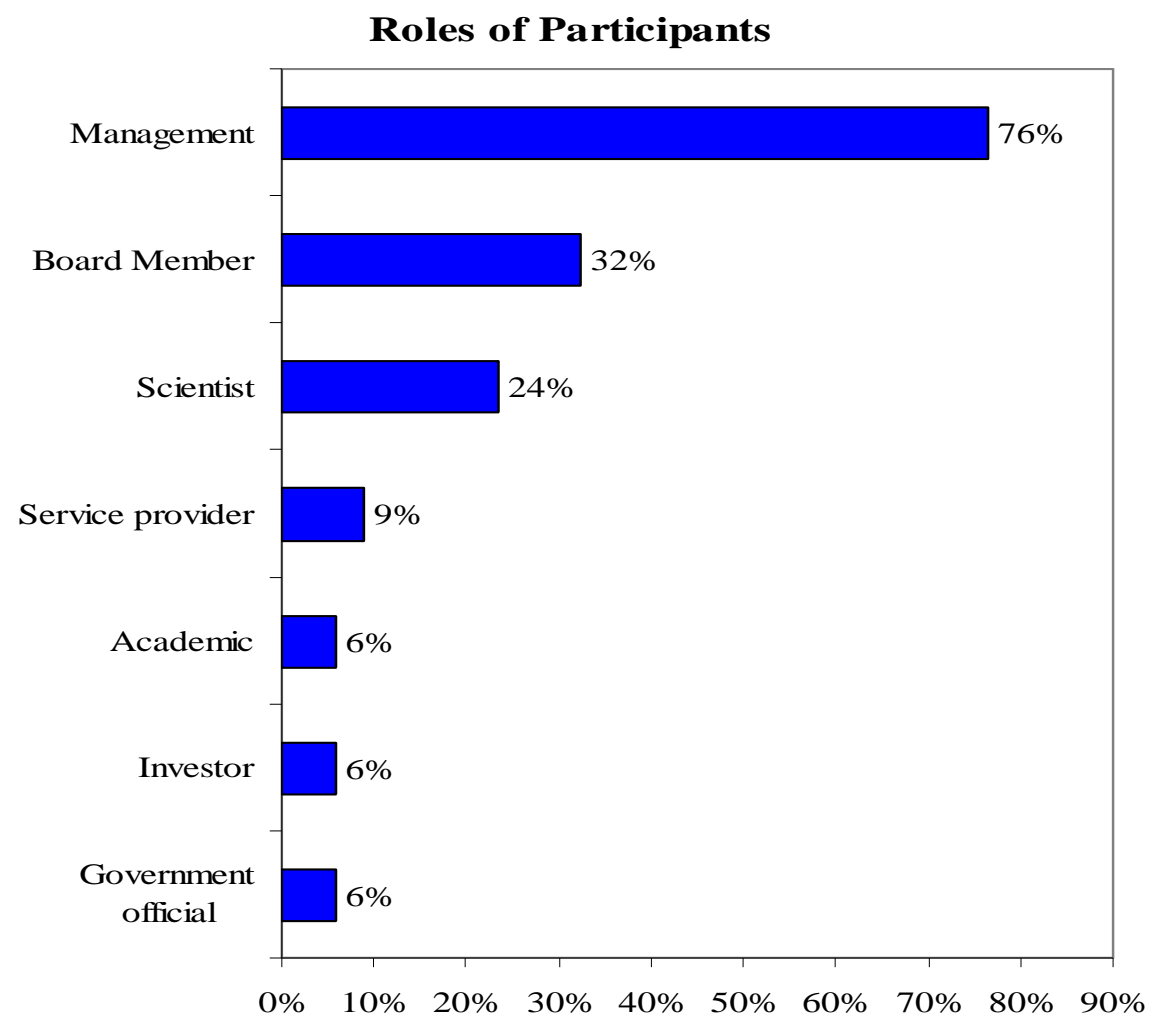

Figure 6: Roles of Participants 


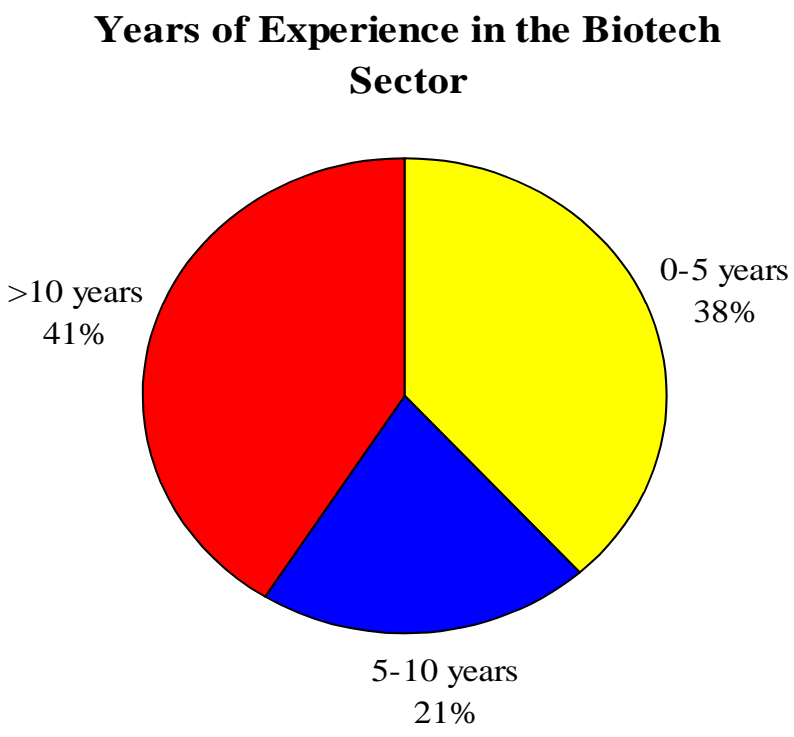

Figure 7: Years of Experience

\section{Priority Sectors and Competiveness}

The next stage of the study was to find out the priorities among the biotechnology sector. This was assessed by force ranking each area in the industry - agriculture and foods, biofuels, environment, and medical devices. For this study (refer to Figure 8), participants indicated strongly that Malaysia needs to build on one of its traditional strengths, agriculture and food sector; with biofuels as a distant second priority. Respondents noted that the Malaysian biotechnology industry is just starting to take flight and companies are venturing to establish their own research operations, therefore its imperative for the government to make sure these research ventures are well supported for the next three years of infancy and retain the intellectual property to enable further development of the value-chain. After identifying the priority sectors, participants were asked to assess Malaysia's current global competitiveness in each biotech sector. The results mirrored the sector focus as agriculture and food was identified as the only area with overarching global competitiveness, with biofuels as a second but distant area of competitiveness. Comments by a survey participant noted: "Healthcare biotechnology will definitely help Malaysia in the long run. But since palm oil is 
abundantly available, focusing on biofuels will help Malaysia to achieve a leadership position in that sector."

An example of consideration is Industrial Oxygen Incorporated (IOI), Malaysia's leading integrated palm-oil company. IOI has core capabilities in palm-oil production from seedlings to plantations, crop extraction; palm-oil and biofuel production. Also, IOI operates in more than 65 different countries and employing more than 30,000 employees. IOI has an annual production capacity of 4 million metric tonnes from 12 palm-oil mills in Malaysia, which produces oils for consumption and as well as biodiesel after being awarded a license in 2007 to build a biodiesel plant in Malaysia. The oil palm has the highest oil yield per unit area compared to other types of crops like rapeseed, soybean or sunflower. This has led to the oil palm being credited as the favoured crop for production. Furthermore the oil palm tree has a life-span of 25-30 years and with consistently highyields, this makes the oil palm a sustainable and renewable energy source. Secondly, the global production of biofuels increased from 4.8 billion to 16.0 billion gallons. Production levels should increase if petroleum prices prove too costly or unsustainable and non-oil producing countries switch to alternative fuel sources. The importance of biofuels should grow with improvement of current technology and a growing global sentiment supporting renewable-energy. 


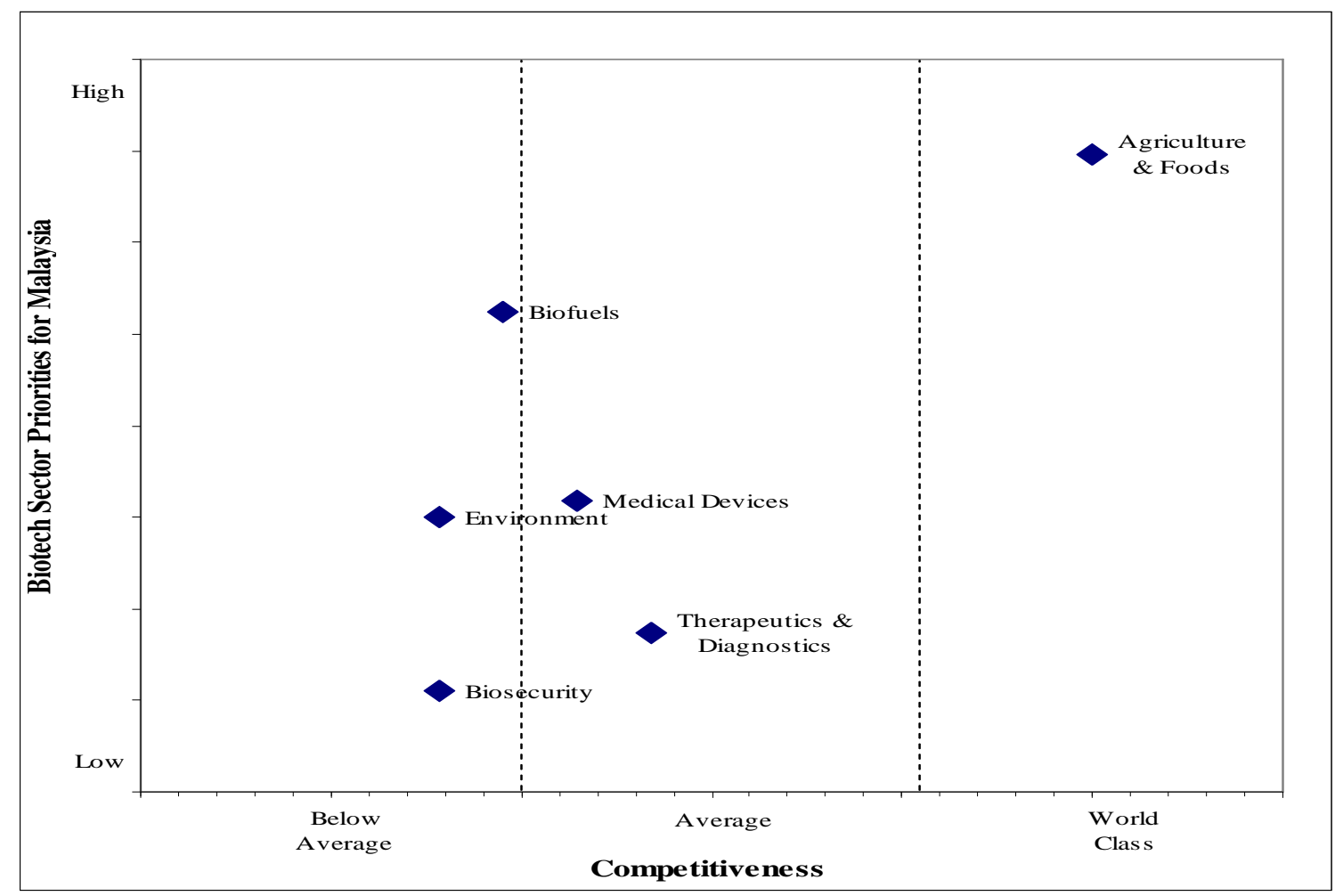

Figure 8: Malaysian Bioeconomy - Priority Sectors vs. Competitiveness

\section{Capabilities and Competiveness}

With the priority sectors established, the next critical issue was in identifying the capabilities required to enhance Malaysia's relative global competitiveness. In Figure 9, participants expressed strongly on two necessary critical capabilities - access to funding and talent. These two capabilities were ranked significantly higher than all other potential capabilities required to establish a sustainable bioeconomy and biotechnology industry in Malaysia. Coincidentally respondents rated Malaysia in these critical areas as 'average' in terms of access to funding and talent. Respondents also noted that there was a need for smoother cooperation between government departments, irrespective federal or local. Suggestions included "There should be no conflict of interest and reduction of redtape between government-related agencies...we need cooperation between all parties and stakeholders to enhance the business environment and not to further complicate it". Respondents also pushed forth new learning initiatives to educate the various government departments about business management and critical elements to gain success in the biotech industry. 


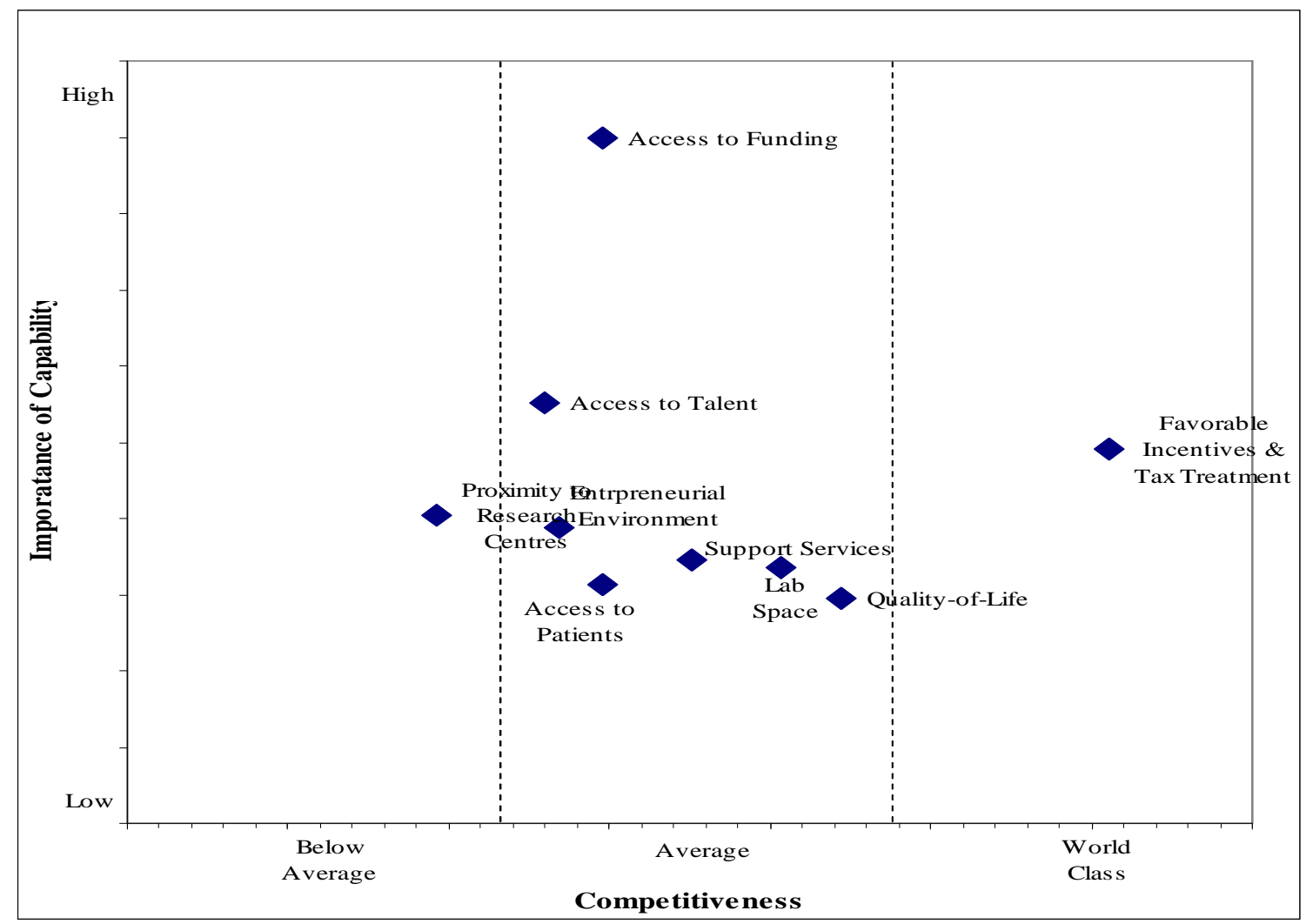

Figure 9: Malaysian Bioeconomy - Priority Capabilities vs. Competitiveness

Access to funding was identified as the highest priority amongst the other critical capabilities necessary for enabling and accelerating the Malaysian bioeconomy. Participants were asked to prioritize specific areas which could improve capability and increased competitiveness. For this study (refer to Figure 10), respondents expressed that both government (96\%) and private stakeholders (93\%) had an 'important - very important' role in building and accelerating funding for the Malaysian biotechnology industry. The government initiatives frequently highlighted were for less stringent government policies and regulations; research grants and financial incentives. Respondents called for equal access to markets, finance and assistance for all biotechnology companies without favour regardless of foreign/local status. Research in biotechnology is often long-term and developmental periods are risky, therefore there is a need to support current companies in midst of research and also encourage other companies to start their own research and development capabilities. Suggestions included: "A conducive environment for both personnel and company through tax cuts, 
rebates or exemptions; foreign companies to be made eligible for government grants base on quality of work, similar to the current way which the Info-Communication Technology sector is supported; centralization of grants and financial assistance to avoid overlapping; championing agency or ministry to regulate, and promote Malaysian biotech industry in overseas and foreign markets; identify, build, support and fund potential clusters to world standards; control inflation to prevent labour costs from rising too fast; Attracting foreign companies to start doing 'world-class' research in Malaysia is just winning half the battle, the other half lies in facilitating them to do good work".

From a private sector perspective, many participants acknowledged that the Malaysian biotechnology industry is in its developmental stages and there is an urgent need of a supportive environment. Respondents mentioned that local bankers and commercial banks were too risk-adverse and had little knowledge of the biotechnology industry. This amounted to the lack of venture capital in view of these private investors being unable to make an informed decision or evaluation and this has hampered the growth of Malaysia's biotechnology industry to move onto the next level. Respondents also cited - " $a$ supportive environment for entrepreneurial activity is crucial and not just going through the motions; government policies and initiatives need to encourage growth rather than moderate growth at this stage; government venture companies should be consistent, transparent, accountable and corrupt free in their dealings and activities; friendly investment environment to enhance foreign investment." 


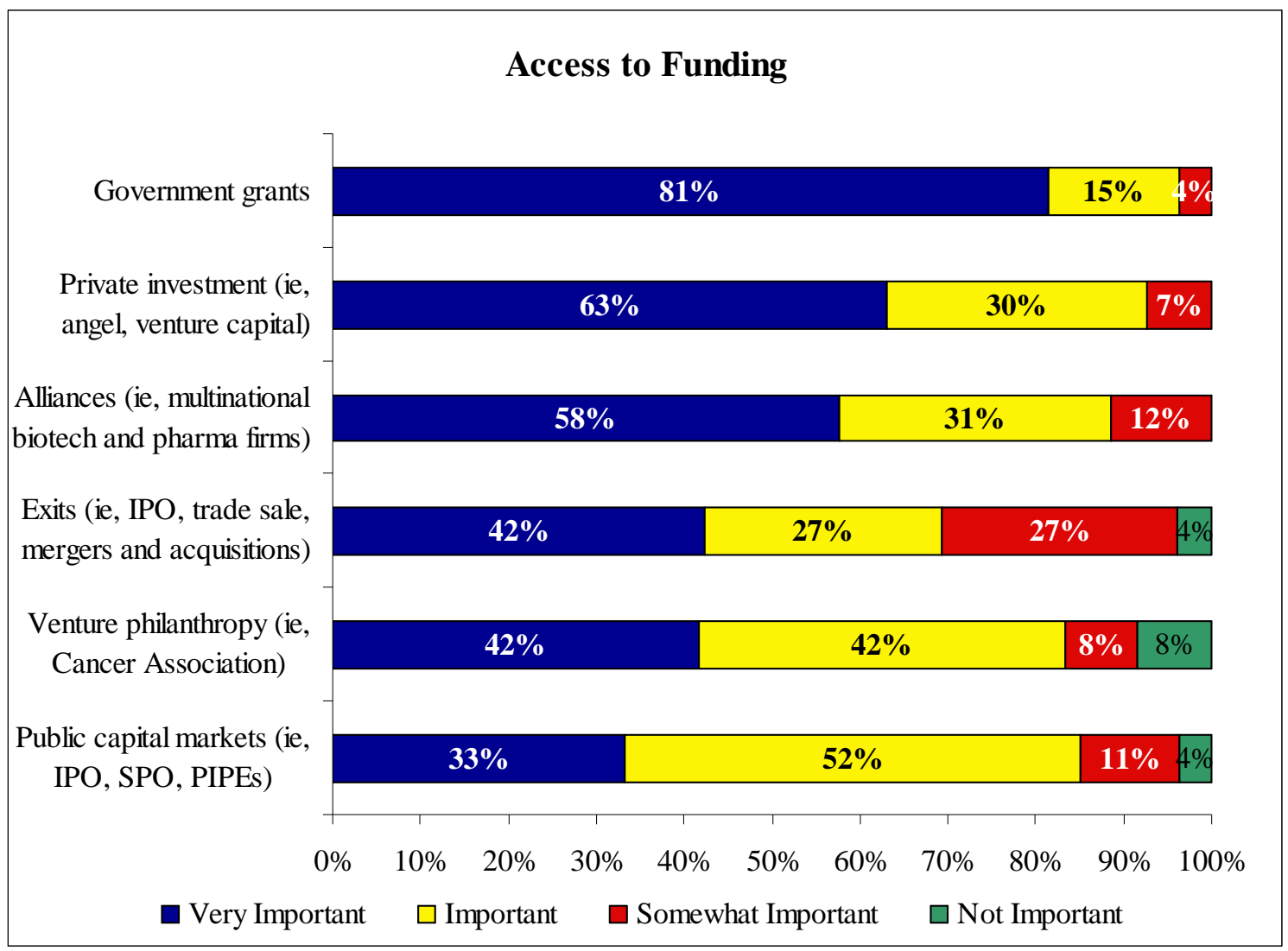

Figure 10: Access to Funding

A Cronbach's Alpha test (refer to Figure 11) was conducted to ascertain the level of reliability in this finding. The closer the reliability coefficient gets to 1.0 , the better. Therefore in general reliabilities less than 0.6 are considered to be poor and those over 0.8 are considered very reliable. Therefore with a value of 0.916 , the reliability of this result is extremely good.

Reliability Statistics

\begin{tabular}{|c|c|c|}
\hline & $\begin{array}{c}\text { Cronbach's Alpha } \\
\text { Based on } \\
\text { Cronbach's Alpha }\end{array}$ & N of Items \\
\hline 0.916 & 0.930 & 6 \\
\hline
\end{tabular}

Figure 11: Cronbach's Alpha on Access to Funding 
An example of consideration is StemLife Sdn Bhd, Malaysia's first stem cell banking and therapeutics company. Cord blood, was first identified as a source of human stem cells when the first cord blood transplant between siblings resulted in a successful outcome. StemLife started as a greenfield investment in 2001 by a technology entrepreneur and internationally trained clinical scientists. StemLife offers banking services for infant cord blood and adult stem cells; which are stored to treat paediatric leukaemia, blood-related disorders, heart-disease and trauma injuries. This is a unique form of service and StemLife has grown to be one of the largest and reputable stem cell companies in South East Asia. To date, StemLife is also involved in the Asia Pacific Cord Blood Bank Consortium as a founding member and R\&D partner. Interest in cord blood and stem cell development has grown in the premise of regenerative medicine. Private cord blood banks have emerged since 2005 and achieved steady growth. These private banks charge a one-time fee to collect and an annual fee to store the blood in the bank. Funding these cord blood banks are capital-intensive and require large amounts of venture capital or seed funding. To highlight growth on this biotechnology segment, Viacell was acquired by PerkinElmer in 2007 for US\$300 million. Viacell is well-known for developing new drug therapies from stem cells. Prior to acquisition, Viacell's annual turnover was US\$70 million per annum and the stem-cell/cord-blood market is project to grow in the next few years.

\section{Access to talent was seen as the second highest priority amongst industry}

participants. Respondents rated the undertaking of education, research and commercialization to build a world class biotechnology community as 'important - very important'. Figure 12 results indicate that $100 \%$ of respondents rated 'skilled graduates with world class training” as 'important - most important' factors. Skilled graduates with world-class training were rated at $90 \%$ as the most important. Respondents noted the need for a 'specially-tailored' education-program for local biotechnology graduates and Bionexus companies should be able to provide advice on the education through their recommendations and knowledge. Suggestions include "The government needs to utilize the skills available and encourage rolling out of training initiatives by Bionexus companies in their areas of expertise; inculcate biotechnology into the education system; 
a need to groom local graduates to ensure they can meet the demands of top biotechnology companies who decide to establish themselves in Malaysia.

From a government perspective, immigration policies can be enhanced to attract foreign students to study biotechnology degrees in Malaysia. When these foreign students graduate, biotechnology firms in Malaysia can hire them immediately. These foreign students are a useful source of foreign talent that are already trained and require lesser time to settle in since they would have been in Malaysia for a while.

Next in importance was a wide range of necessary factors to develop a talented workforce which included a pool of experienced entrepreneurs, top executives from biotechnology companies and experienced investors. Participants noted - "the focus needs to be building of specialized skills and experience in Malaysia, and developing the labour force on a senior level to compete on the global stage."

Amongst all these different ideas, maintaining momentum was a key priority. "As scientists and business heads move to live in Malaysia, the government must induce these talented people to stay as long as possible to focus on their research or commercial work. If there is no continuity, then the industry will undoubtedly be affected...; there is a long way to go and there will always be a need to revise and strategise the initial plan from time to time...but stay focused on own strengths and capitalize on fundamental resources like local brains and talents. The biotech industry must be market-driven...and success for Malaysian companies should always be measured through sales and sustainability." 


\section{Access to Talent}

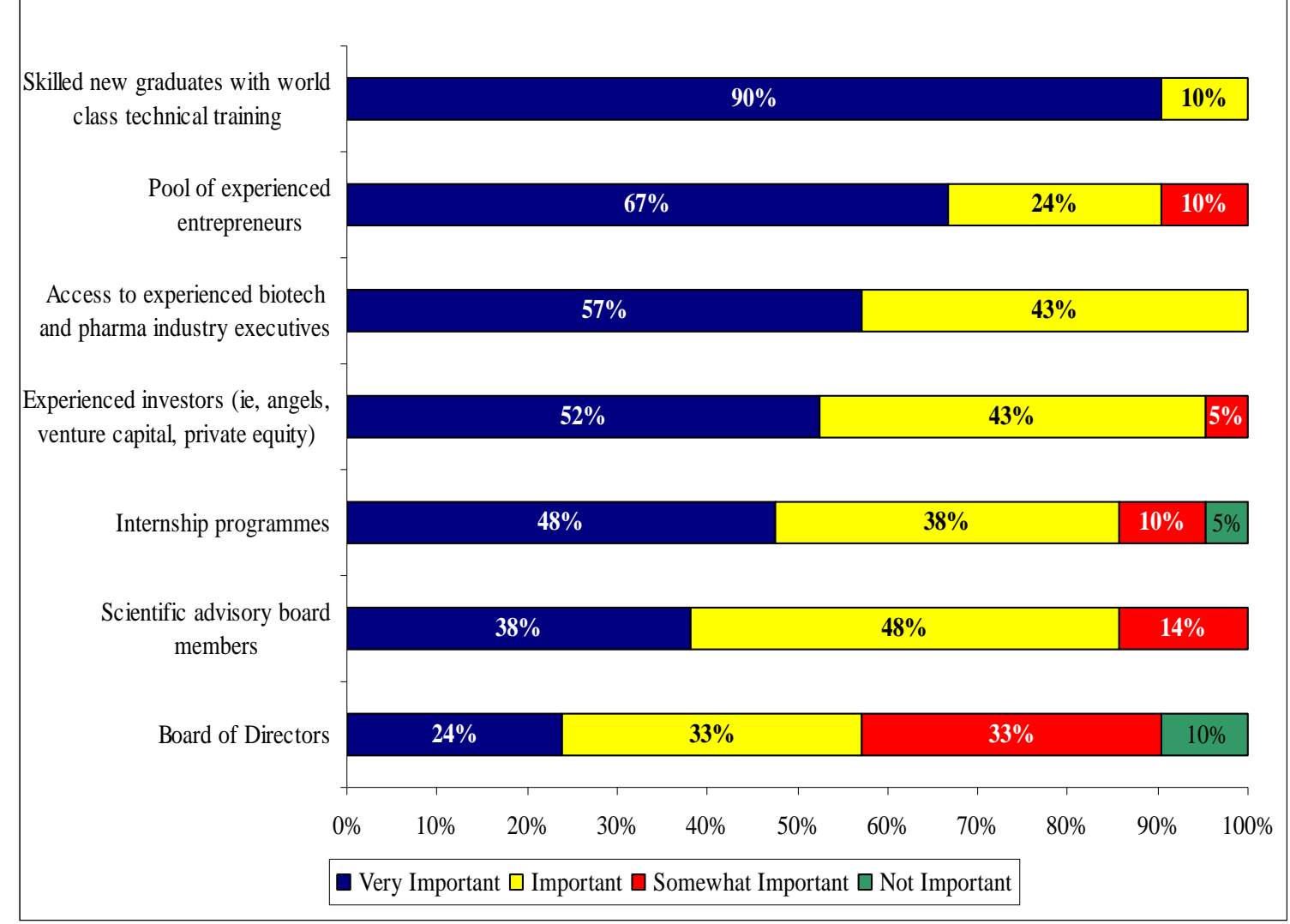

Figure 12: Access to Talent

A Cronbach's Alpha test (refer to Figure 13) was conducted to ascertain the level of reliability in this finding. The closer the reliability coefficient gets to 1.0 , the better. Therefore in general reliabilities less than 0.6 are considered to be poor and those over 0.8 are considered very reliable. Therefore with a value of 0.946 , the reliability of this result is extremely good.

\section{Reliability Statistics}

\begin{tabular}{|c|c|c|}
\hline Cronbach's Alpha & $\begin{array}{c}\text { Cronbach's Alpha } \\
\text { Based on } \\
\text { Standardized Items }\end{array}$ & N of Items \\
\hline 0.946 & 0.956 & 7 \\
\hline
\end{tabular}

Figure 13: Cronbach's Alpha on Access to Talent 
A prominent theme mentioned which addresses both access to funding and talent is the need to establish international alliances and strategic partnerships between Malaysia and other biotechnologically-advanced countries to cooperate on joint research and development. Comments by respondents were "Getting things done in Malaysia is difficult as most of what we are doing is being done for the first time...To move forward we should focus on smart partnerships;" "We have an insufficient talent pool and local talent is unable to do 'cutting edge' research in biotechnology at this point. Therefore, we need more foreign talent and $R \& D$ alliances with other firms to breach this current deficiency...this scenario might change in years to come when Malaysia has benefited from this interchange.”

To build on the importance of talent, the availability of support services and networks were deemed as a critical element to develop a sustainable bioeconomy with the characteristics of starting and managing intellectual-property-based ventures with specialist skills. These include having people like lawyers, accountants or contract research organizations. Therefore a sustainable bioeconomy needs a robust ecosystem of dyads or networks of relationships to achieve growth. For this study (refer to Figure 14), about $70 \%$ of respondents noted that the following were 'important - very important' for building a sustainable bioeconomy in Malaysia: investors (i.e. angel investors, venture capital), manufacturing capacity (i.e. research, process), government agencies, scientific advisory board members, IP (intellectual property) firms, CROs (Contract Research Organisation), accountants, investor/public relations. 


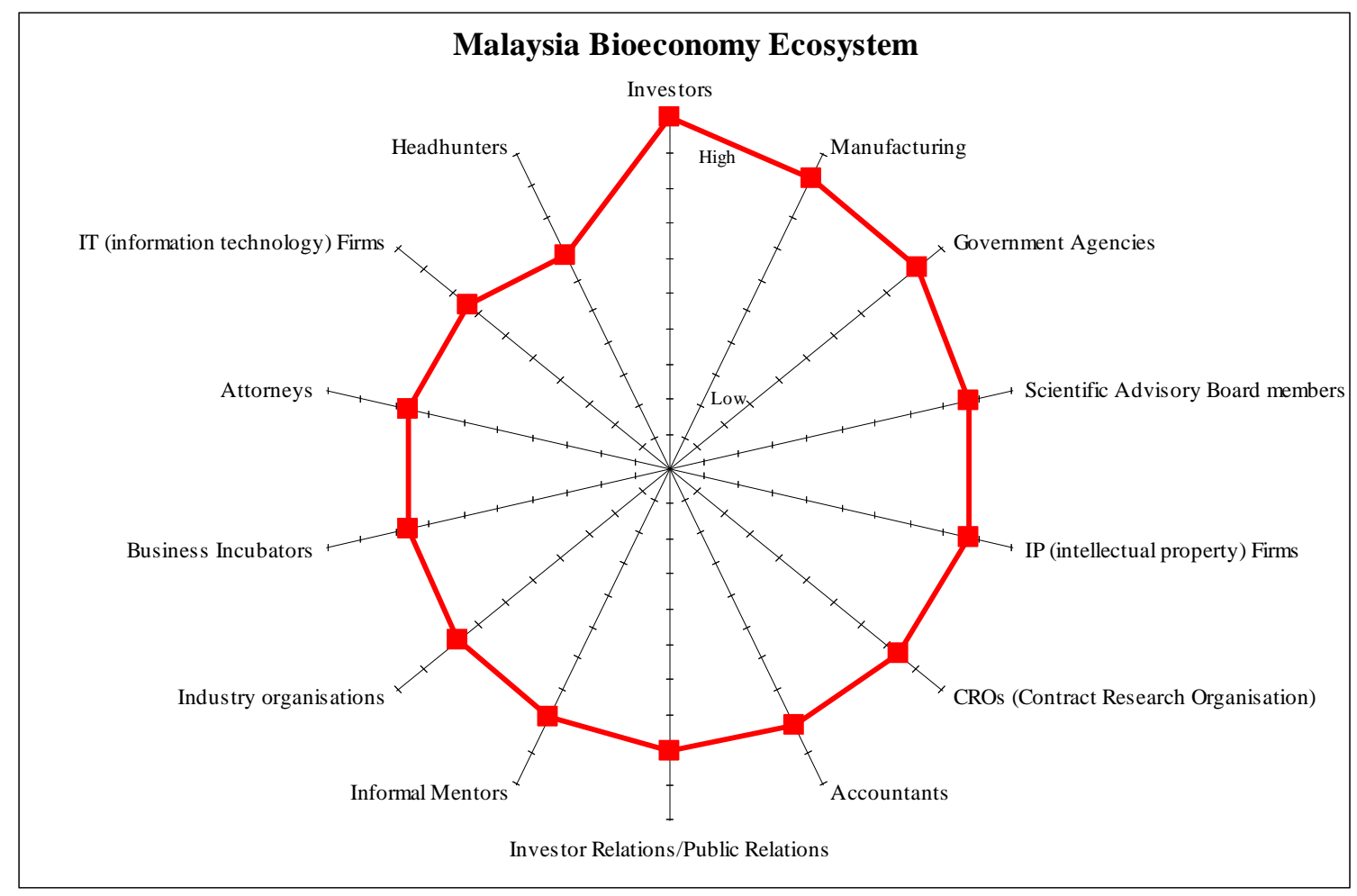

Figure 14: Malaysian Bioeconomy Ecosystem

Respondents indicated a preference to have close proximity with universities and research institutes. In Figure 15, 90\% of respondents surveyed rated having a close proximity with universities and research institutes as "important - very important". Respondents noted that academic staff in Malaysian universities should travel overseas for more research and conferences and encourage intellectual linkages. Suggestions include "We need to reduce red-tape and encourage academic staff of public universities to travel abroad to conduct scientific research and return to transfer skills to local graduates or head research departments; a platform or forum of scientists should be established to head a particular sector of Malaysia's biotechnology in order to put research, regulations and commercialization into perspective.".

From a government perspective, establishing a formal platform or forum of scientists to head a biotechnology sector, is a positive step. This encourages discourse between leading scientists and the government to work out new initiatives and future growth plans for Malaysia's developing biotechnology sector. From a private sector perspective, if the 
government establishes a formal platform or forum of scientists, this might encourage more venture capital investment into biotechnology companies. This view is based on the government playing a role in facilitating and partnering role with biotechnology companies in Malaysia. Venture capitalists will be ensured they have a unified voice through the newly-established forum to discuss any potential initiatives with the government. This is a way to protect their investments and decrease information asymmetry. Support for this viewpoint by respondents suggesting "We must have close and easy access to relevant target markets for the biotechnology venture...therefore we need access, communication and support... all these make venture creation sustainable”.

An example of consideration would be Biofact Life Sdn Bhd, a Malaysian Bionexus and nutraceutical private limited company incorporated in 2005. Biofact Life is a seed-toshelf approach company with extensive research and development. Seed-to-shelf means that the paper trail of fully-documented traceability like audits and inspection is traceable right from seed producer to production-distribution. Biofact Life produces cordyceps, a type of medicinal herb with advanced biotechnology and manufactures a variety of products with the herb as the main ingredient. Cordyceps is well-known to traditional Chinese medicines and found primarily in China and Nepal, worth in excess of $\$ 14,000$ at wholesale prices. Biofact Life utilises a unique method of farming the herb in a controlled environment that the medicinal properties of the herb are pharmacologically ten-times more active than wild-grown types. Biofact Life has a beneficial relationship through a Memorandum-Of-Understanding with Usians Holding Sdn Bhd, a commercial arm of Universiti Sains Malaysia to collaborate in research and development studies in biotechnology. This relationship seeks to improve on technological innovation to improve product quality, innovation, new product development, quality analysis and improvement. The Bionexus network consists of various institutes to support R\&D in biotechnology. There are three key centres of excellence and biotech clusters which consist of higher learning institutes like local universities, private research institutes and government-linked research boards. 


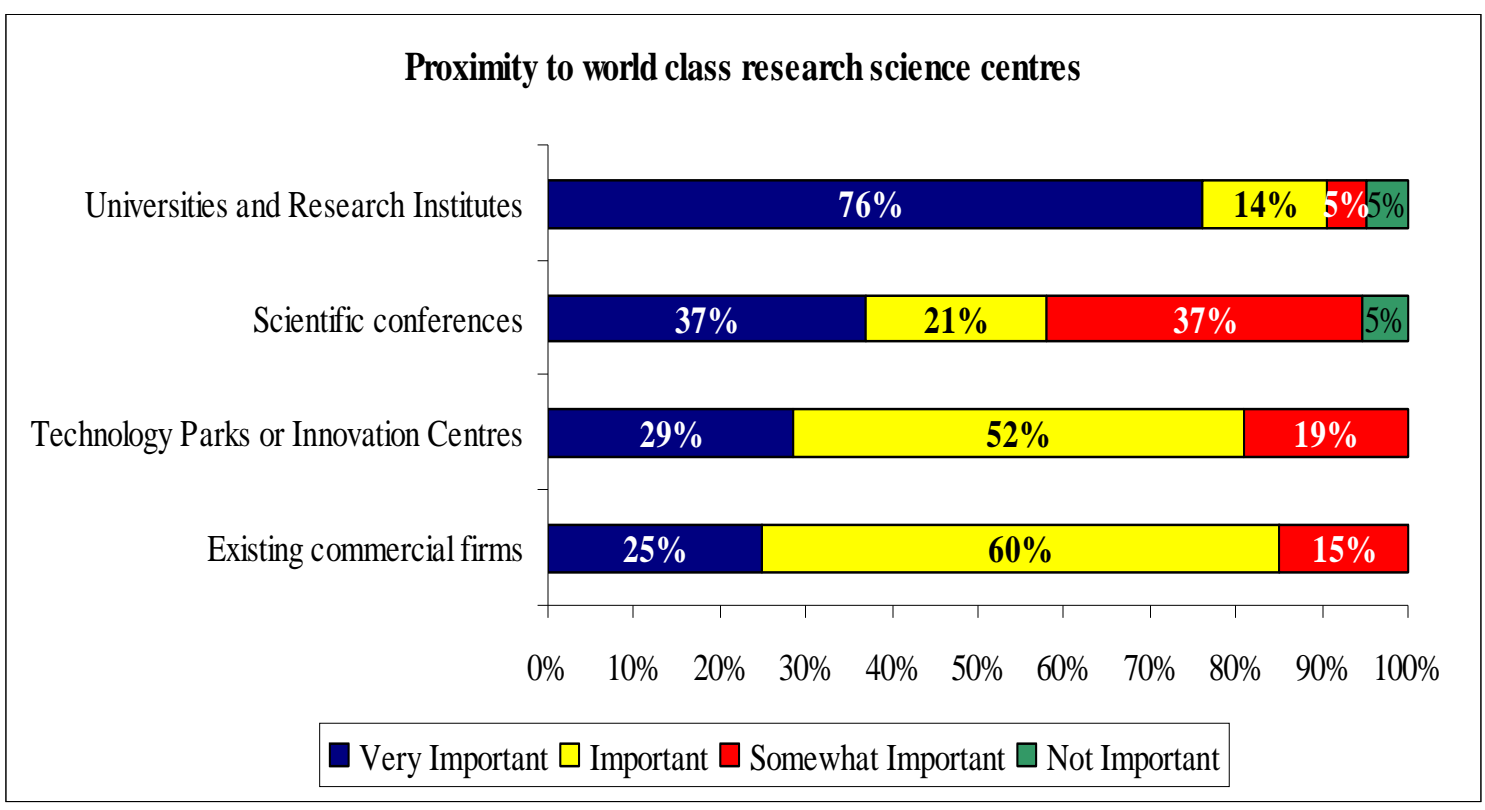

Figure 15: Proximity to Research centres

\section{High quality education was chosen as the most important quality-of-life factor with} quality healthcare next in importance. Results of Figure 16 show that $81 \%$ of respondents chose high-quality education as "important - very important". Participants noted that foreign expats, scientists and workers need to be assured of their living standards by their employers and government prior to working in Malaysia. Respondents also suggested that personal tax cuts or exemptions be provided to key expats in the biotech sector to reward them for their pioneering efforts in starting up biotech companies. Other suggestions included were "Malaysia needs to attract top talent through scientists and business heads...one way is to benchmark current incentives by other countries and offer better terms; foreign expatriates might have spouses and families, therefore a liberalised immigration policy allowing the spouse to work whilst in Malaysia can be an enticement.

Student enrolment-allocations at international schools can be awarded first preference to foreign expatriate children as a further added incentive to settle down and work in Malaysia. Biotechnology is a global business with heavy reliance on intellectual property and strategic links with foreign companies. Nevertheless firms will seek foreign talent to supplement existing talent. 
From a government standpoint, a liberalised immigration policy for foreign expatriates will be essential to increasing the current existing talent-pool and speeding growth of the Malaysian biotechnology. However a careful and incremental immigration policy should be implemented to attract useful foreign expatriates. They can be segmented into their varying scientific occupations, years of work experience, existing job-offers and or educational background. For example an application by a foreign fresh graduate, with an existing job offer should be expedited immediately by immigration as compared to a fresh graduate with similar qualifications but without an existing job offer. The proposition is favourable terms be awarded to workers, preferably with job offers from biotechnology firms and have suitable educational backgrounds.

To develop a sustainable bioeconomy, foreign expatriates need to be attracted to stay in Malaysia for a considerable period. If they leave within the first or second year, biotechnology firms will have to seek new talent once again. Though with a liberal immigration policy, foreign expatriates might use Malaysia as an intermediary to gain valuable experience before trying to seek employment in other countries which might not have considered them initially. To note, a good way would be to retain an overall positive net-worth of foreign talent annually.

From a private sector perspective, a liberalised immigration policy will be beneficial as it will increase scope and ease for firms to hire foreign employees. Removing potential barriers will increase business potential and viability for firms to hire desired employees. Firms should also work with the relevant government departments to adjust or implement immigration and labour policies to suit current trends and improve on changes. 


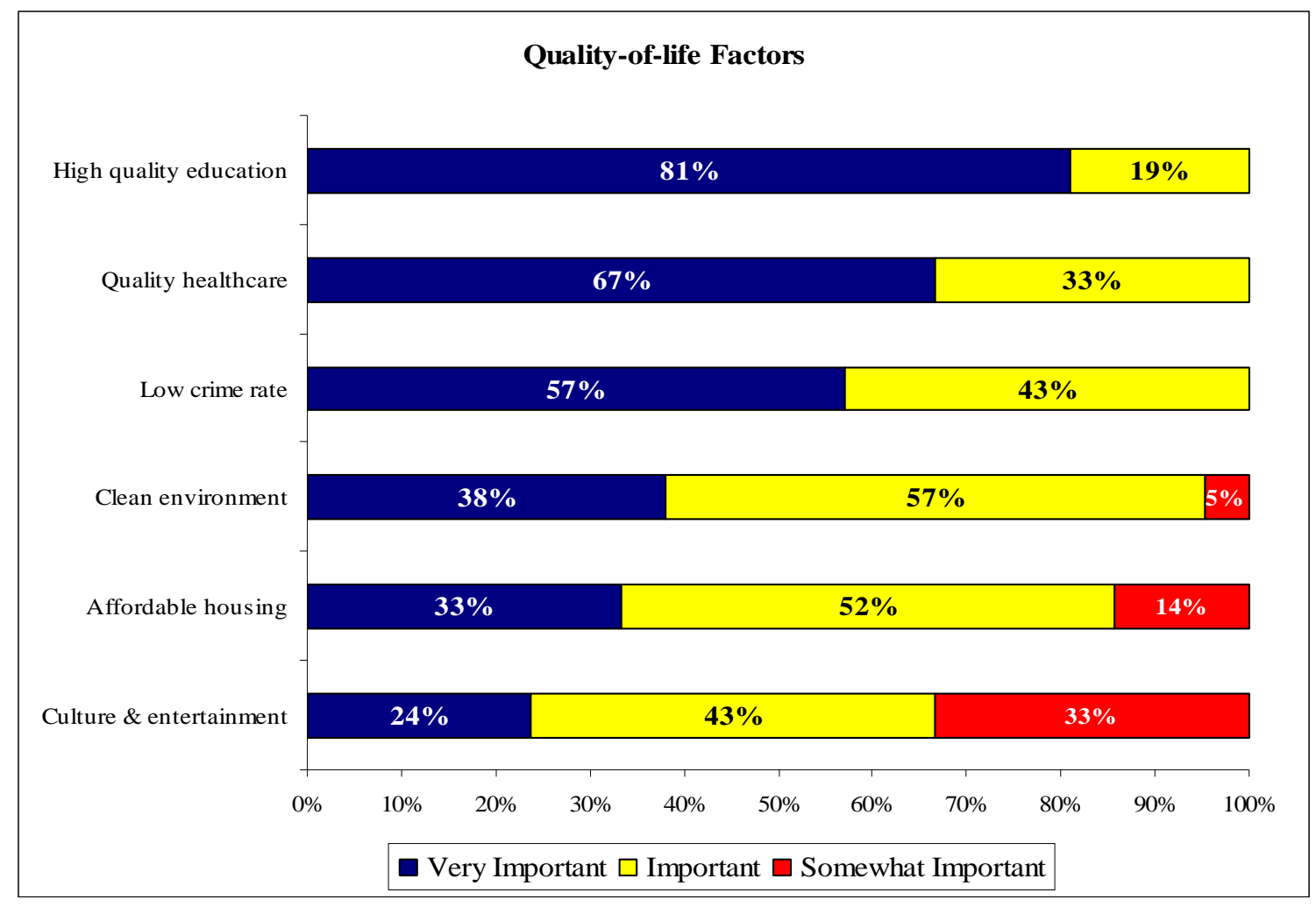

Figure 16: Quality of Life Factors

\section{Affordable commercial lab and office space was indicated as a priority amongst}

respondents. $90 \%$ of participants noted the need for affordable space as a means to decrease operating costs and increase viability (refer to Figure 17). Suggestions included "Biotechnology is risky business and help by the government to decrease costs will help businesses; more support services are necessary to renovate existing space for biotech lab needs; commercial space for laboratories need to be improved to suit international standards".

From a government perspective, provisions for new commercial lab and office space was addressed and made available in the $9^{\text {th }}$ Malaysia Plan which will put forth several billion Ringgit to develop and build creative clusters for biotechnology firms. Cluster locations are built around national research institutes in order to develop creativity and increase network linkages through bringing relevant biotechnology firms. For example, 
biopharmaceuticals, nutraceuticals and medical diagnostic companies doing research on cancer would want to be situated closer to the National Institute for Cancer Research.

From a private sector perspective, potential sites for clusters are deemed too far from commercial centres or towns. Thus several companies have approached local governments to secure favourable terms in order to establish businesses. Kuala Lumpur is the capital of Malaysia, but several other smaller cities and towns like Malaaca and Sabah have developed their own local bioeconomy through partnerships with private firms.

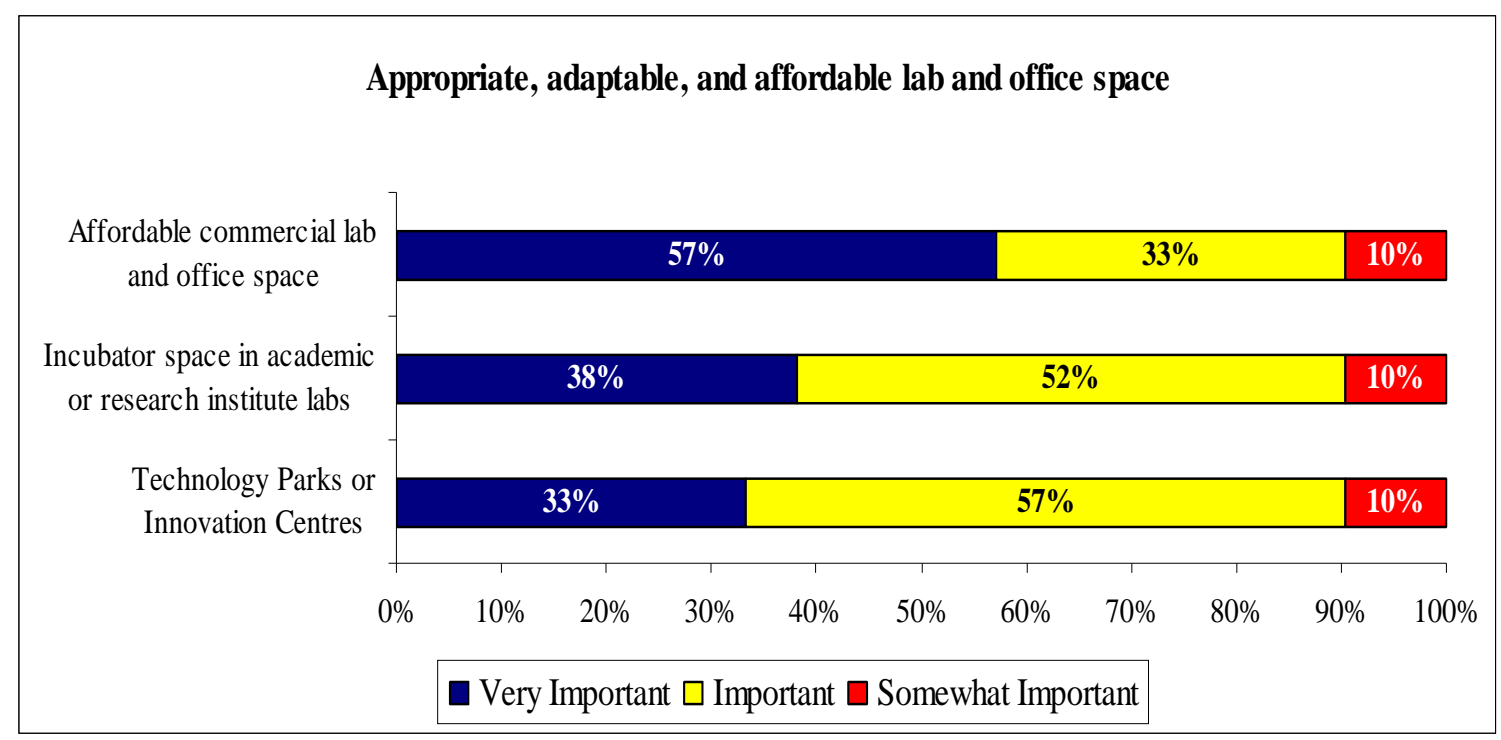

Figure 17: Lab and Office Space

Pool of serial entrepreneurs was a high priority amongst respondents. 90\% of participants rated the importance of serial entrepreneurs as "important - important" (refer to Figure 18). This reflects the trend of having entrepreneurs to engage in start-ups and raise venture capital for companies. Respondents also mentioned the difficulty of securing funding either from local bankers and government departments. This difficulty is more so when the biotechnology company is foreign. Suggestions from the survey were "make sourcing for funding easier for start-ups and foreign businesses through improving current capital markets; increase sources of funding through private and government stakeholders". 
From a government perspective, having a pool of serial entrepreneurs is positive especially when these people are part of a formal platform as suggested earlier. With a platform, potential issues and agendas can be addressed at national conferences and industry meetings to reach out to a wider audience and other stakeholders. Agendas pushed forth should be considered legitimate and representative of underlying stakeholders and members. National conferences and industry meetings were rated by $75 \%$ of respondents as "important - very important".

From a private sector standpoint, biotechnology firms should stand to benefit with serial and possibly new entrepreneurs. Entrepreneurial education and research was rated by $81 \%$ of respondents as "important - very important". Suggestions by respondents include "entrepreneurial education is essential to advancements in the bioeconomy; we need more entrepreneurs and local and federal government need to introduce more incentives; risk-taking and venture capitalists are too few...respective government agencies responsible for venture creation need to understand how the private sector operates and works to motivate local entrepreneurs and attract foreign investors".

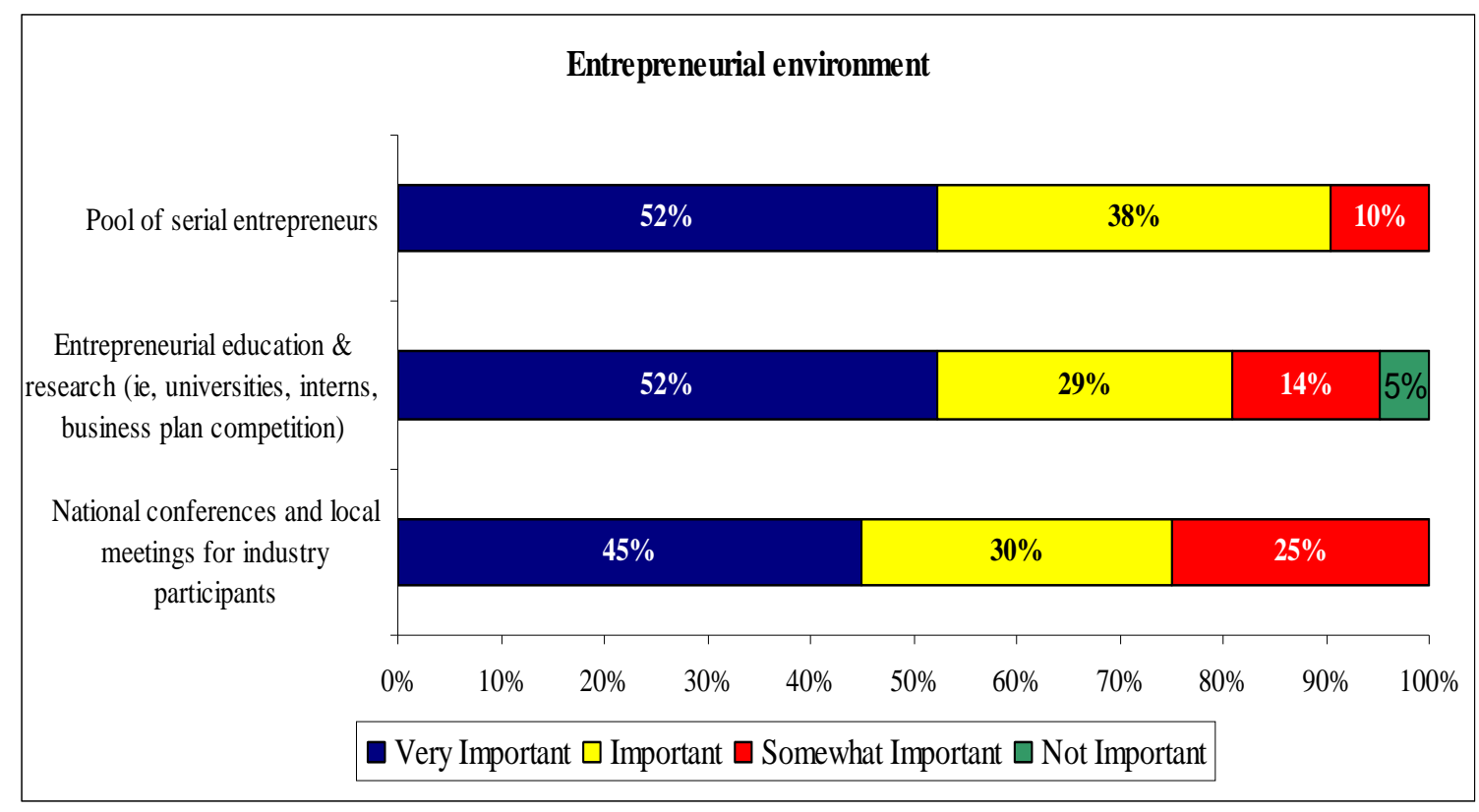

Figure 18: Entrepreneurial Environment 


\section{Prompt review of regulatory fillings was seen as a high priority amongst}

participants. In Figure 19, respondents suggested that local requirements and regulations be improved or revamped to suit international standards for example Convention on International Trade in Endangered Species (CITES), World Health Organisation (WHO) and International Organization for Standardization (ISO) that might impede the biotech industry. Suggestions include "We need a common or international standard to work towards... as it establishes credibility for our local companies and a level playing field for foreign biotechnology companies; having two different standards will turn away international biotechnology companies which Malaysia is trying to attract; government agencies should work on the same platform, rather than differing standards". Respondents highlighted the point that authorities for the various biotech areas need to be well-versed, ideally in the science itself as there are potential implications. Respondents mentioned "Authorities need to be well-versed and with a good background in the science itself in order to assess or review biotech-related policies and implement proper decisions; if the relevant authorities are unable to implement the right decisions, the industry will end up going around aimlessly”.

An example of consideration is Malaysian Bio-Diagnostics Research Sdn Bhd (MBDR), Malaysia's leading diagnostics and Bionexus company. Incorporated in 1994 as a research-based biotechnology company, MBDR has since expanded into producing and exporting products. MBDR also has established strategic relationships with various overseas universities and research institutes to develop newer medical diagnostic products and grow its own intellectual knowledge-base. MBDR's medical diagnostic products specialises in detecting diseases like malaria, dengue fever, Nipah Virus, typhoid, lymphatic filariasis and tuberculosis commonly found in tropical regions. MBDR has entered the diagnostics market in South-East Asian countries like Indonesia, Philippines, Thailand, Vietnam and others like India, Pakistan and Australia; and aspires to become a global competitor in medical diagnostics. As the healthcare biotechnology sector in Malaysia grows, access to patients for clinical trials will increase in importance. A view concerning such healthcare and medical diagnostic companies is that a large majority of drugs fail in the late and costly stages of human testing. Hence medical 
diagnostics can play a major role in establishing initial results with human DNA through indicators to ascertain the likelihood of success prior to actual human trials.

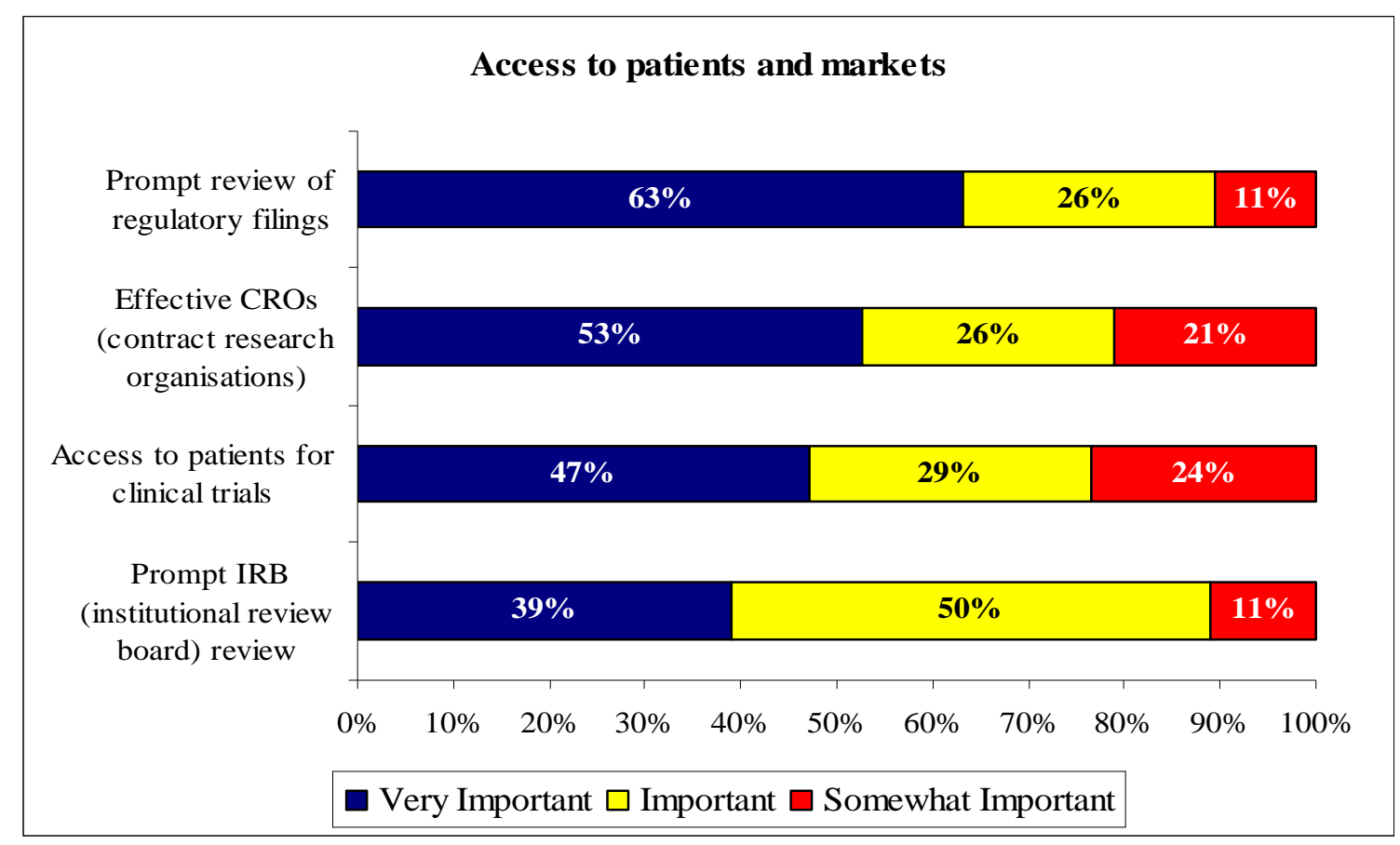

Figure 19: Access to patients and Markets

\section{A regulatory environment that supports new venture creation was seen as a high}

priority amongst respondents with a $100 \%$ response-rate indicating it as "important very important" factor (refer to Figure 20). Respondents noted that the overall business environment in Malaysia was conservative and focus was on current core strengths like manufacturing and low cost/technology services. Respondent suggestions were "the government needs to revamp their marketing campaigns and include biotechnology as one of the new pillars of revenue creation for Malaysia in the $21^{\text {st }}$ Century; public relation and marketing campaigns are useful but there must be adequate regulations in place to prevent malpractices and mis-use of funding; though the Malaysian bioeconomy is still developing, the government can derive lessons learnt from the experiences of other countries to introduce regulations to protect venture creation”.

From a government perspective, introducing regulations to moderate the business environment should assist Malaysia's aspiration to achieve biotechnology success. At this 
initial stage, the government can finance or ease regulations on certain biotechnology sectors like biofuels to capitalise on Malaysia's natural advantage of growing palm fruit. Achieving success in biofuels will be useful as mentioned in earlier sections; since it puts Malaysia in a reputable position as a new-entrant in biotechnology and there are potential spill-over effects in other biotech sectors.

From a private sector perspective, regulations on venture creation might stifle creativity and innovation especially when funding comes primarily from the government. Current venture capital funds are either solely government or mixed with private sector participation. Alternative sources of funding like public-listing, seeking angel investors or from local state governments might be useful. Respondents noted that success from funding should be substantiated from business sustainability and long-term growth and investors should be aware that biotechnology is a long-term business. Respondents further mentioned the need for transparency in funding disbursements and for sound corporate governance in companies. This was to ensure accountability to various shareholders.

An example of consideration is Chemical Company of Malaysia (CCM) Berhad, a subsidiary of Imperial Chemicals Industries PLC (UK) and now fully Malaysian-owned since August 1963. CCM has achieved significant corporate presence since 1966 when it first became public-listed on the Malaysia Exchange (MYX). CCM is currently considered a 'blue-chip' company on MYX with good returns to shareholders. CCM is a heavily-diversified biopharmaceutical company, presently involved in 4 types of businesses ranging from chemicals, fertilisers, pharmaceuticals and duopharma biotech. CCM started out as an industrial and speciality chemicals company in Malaysia and progressively diversified in 1966 to fertilisers and pharmaceuticals in 1995 respectively. CCM Pharmceuticals is Malaysia's largest domestic producer of generic drugs with over 280 products like antihistamines and antibiotics. CCM Pharmaceuticals has close working relationships with other pharmaceutical firms in the United States and Canada which allows sharing of new discoveries, capabilities and enhance R\&D programs. With a multi-lateral network in place, CCM Pharmaceuticals is able to keep abreast of global 
developments and for their exports to adhere to changing international standards. CCM adopts the Malaysian code on corporate governance which sets out the principles and best practices on structures and processes used to direct and manage the company's assets and activities towards enhancing corporate accountability. CCM also has a board of directors that reviews and approves short-term budgets and long-term strategies and goals. An Annual General Meeting (AGM) is held yearly to appoint or re-elect current directors subject to shareholders' vote of approval. The Malaysian code on corporate governance started as a private sector initiative and subsequent reviews later established a reform of standards on corporate governance on a macro and micro level. To date, the code is chaired by members from the public and private sector.

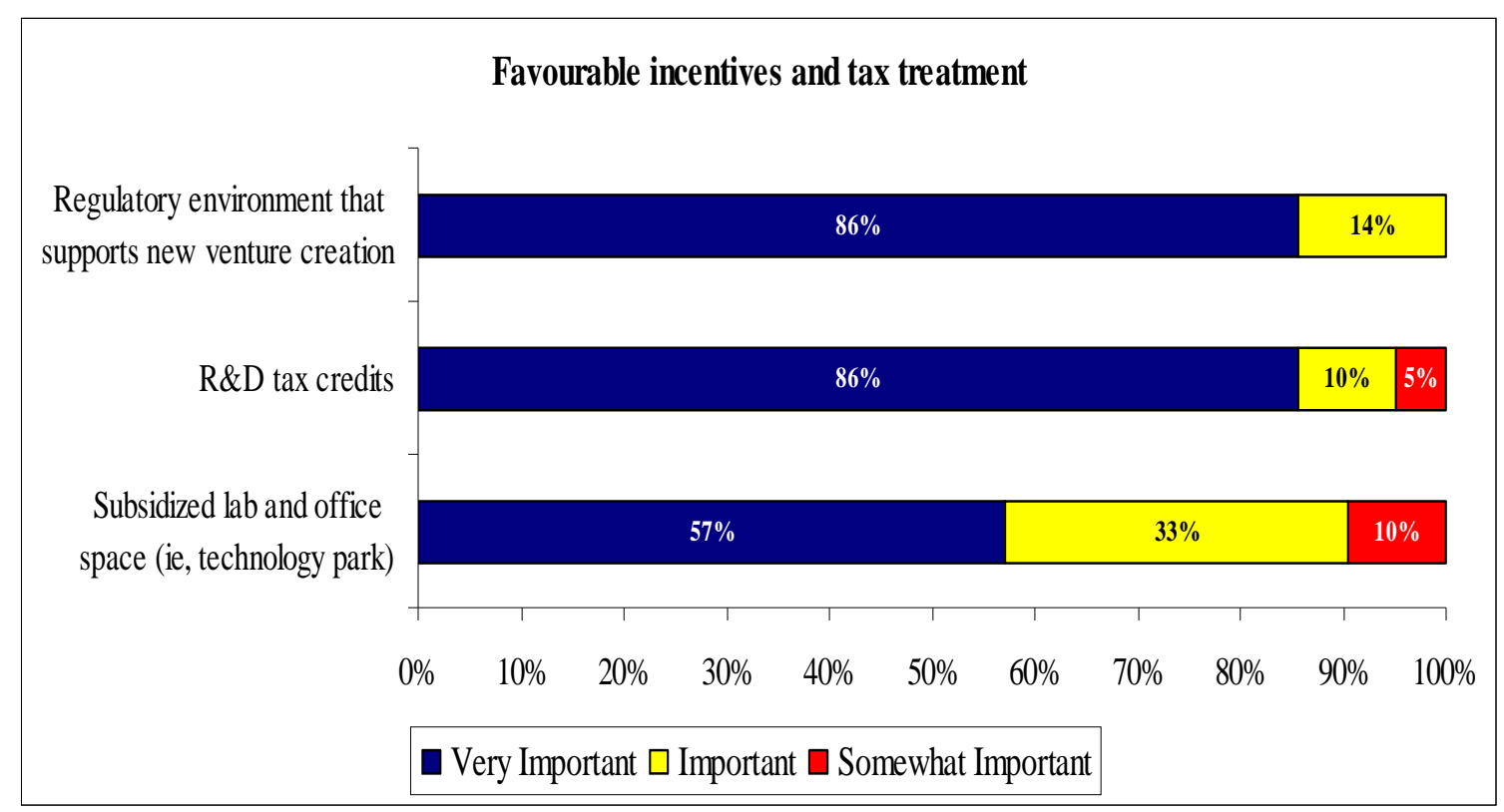

Figure 20: Favourable incentives and tax treatment 


\section{Discussion}

This paper serves to find out about the Malaysian biotechnology industry which is in its developmental stages; and survey perceptions and attitudes of industry participants regarding key attributes of developing a sustainable bioeconomy in Malaysia. Growth patterns, entrepreneurial activity, innovation, productivity, sustainability and funding were areas that formed the survey questions posed to respondents. Key questions explored were: Do initial factor endowments impact or affect the development trajectory of a biotechnology cluster in Malaysia? How should Malaysia prioritise, mobilise and coordinate scarce resources to build a competitive bioeconomy?

A mixed-methods approach of data-collection was conducted to achieve a rich data-set. In-depth case studies, confidential personal interviews and an online-survey were the techniques used to gain insights into Malaysia's developing biotechnology industry. Five case studies were undertaken and analysed, with each company representing a biotechnology sector; for example: biofuels, nutraceuticals, biopharmaceuticals and medical diagnostics. Biotechnology companies of the Bionexus network of Malaysia were surveyed with the assistance of Malaysia Biotechnology Corporation, a government-linked company established to spearhead the overall growth and development of biotechnology in Malaysia.

Confidential personal interviews were conducted on Bionexus industry participants and asked to provide their opinions on building a sustainable bioeconomy. For the first half of interviews, participants provided their opinions on open-ended questions. In the second half of interviews, participants were asked close-ended questions on concepts developed from the literature review and insights derived from earlier case-studies. Participants' insights were duly recorded and their contribution led to developing an online survey.

From the survey, 34 responses were received out of 80 companies that were contacted to participate. In terms of demographics, $76 \%$ of respondents indicated they were part of 
their company's management panel or team with at least $41 \%$ having more than 10 years of experience working in the biotechnology industry.

\section{Key findings are as follow:}

1) Malaysia should leverage on existing advantages in agriculture and food and biofuels. Developing healthcare biotechnology capabilities will be extremely useful as long-term comparative advantage.

2) Access to Funding and Talent were deemed the most important variables to developing a sustainable bioeconomy. Existing government sources of funding should be made available to foreign biotechnology companies. Education programs should have inputs by Bionexus companies to ensure relevant course materials are taught.

3) Malaysia needs to maintain current growth rates by adding new initiatives and growth strategies into the future. Continuity is necessary and capitalise on fundamental resources.

4) Development of platforms or forum of scientists to lead respective biotechnology sectors with the government to enhance cooperation and leadership.

5) Dyads and networks of relationships were essential to building a robust bioeconomy. Investors, manufacturers and government agencies ranked highest.

Priority sectors and competitiveness was an important segment of the survey as the researcher wanted to establish if respondents' viewpoints were similar to Malaysia's ambitions. Malaysia has targeted the agriculture, healthcare and industrial biotechnology sectors as future growth areas. From the results, respondents indicated Malaysia should leverage on its existing advantage in agriculture and food and biofuels as the second most important priority. This response is typical of the economic theory of ResourceBased-View where the competitive advantage of an entity lies in the application of valuable resources at the entity's disposal (Wernerfelt, 1984). Therefore if the entity is 
able to use these valuable resources and make it into a competitive advantage, this advantage should stay sustainable in the long-run.

Respondents were asked to assess Malaysia's current global competitiveness within each biotech sector. Agriculture and food were assessed to be "world-class" with biofuels seen as slightly “below-average” Respondents' opinions were for Malaysia to focus on healthcare biotechnology in the long-term, and to develop biofuel capabilities through improving technologies to convert palm oil into fuel as a short-term achievement.

Developing capabilities in biofuels in the short-term will be essential to Malaysia's bid to establish a long-term leadership position as this will enhance the country's reputation and credibility as a global producer and manufacturer of renewable fuels.

Malaysia is naturally endowed with palm oil and establishing a early leadership position in biofuels will prove lucrative when fossil-fuel sources start diminishing. The attraction of biofuels should increase when fossil-fuel prices rise beyond record prices.

Several respondents suggested that Malaysia should increase developments in healthcare biotechnology to create comparative advantages similar to agriculture biotechnology. Estimates predict that healthcare will increase in prominence especially in developed nations as poor lifestyles, hectic work-life and increased health-awareness will spearhead demand.

For capabilities and competitiveness, respondents were asked to indicate their opinions on what critical capabilities were necessary to establish a thriving bioeconomy. The results were Access to Funding was chosen as the most important; followed by Access to Talent, and both were also rated as average in competitiveness.

Respondents mentioned that Access to Funding was the most critical as biotechnology is a R\&D-intensive industry and the entire value-chain process from research to product commercialisation normally takes a few years and requires extensive capital investment. 
Initiatives suggested by respondents were for less stringent government policies and regulations; allow research grants to be based on ideas and financial incentives for startups regardless of foreign or local status. At this current stage, Malaysia has a wide variety of funding sources primarily through government agencies and several private equity firms. Introduction of new sources of funding might not have an immediate impact to ease funding difficulties; instead regulations should be relaxed with more emphasis on a 'case-by-case' scenario. At this early stage of development in a bioeconomy, having new sources of funding would require increased monitoring by the Ministry of Finance to ensure the new financial institutions are of excellent financial health. Moreover with the current economic crisis, there might be lesser sources of private funding.

The establishment of Malaysia Biotechnology Corporation (BiotechCorp) and the involvement of numerous government institutions involved in the bioeconomy, shows that the Malaysian government seeks to play a more active role other than facilitating between local and foreign biotechnology companies. Having an active government

presence establishes credibility and should attract foreign companies and investors to grow the Malaysian bioeconomy. However in most business industries, some form of self-regulation by the private sector is preferred as extensive legislation by the government is viewed as over-regulation and restrictive. In the end, respondents seem to advocate for government intervention with an institutional approach to building the bioeconomy but yet calls are made for the government to ease moderation and speed growth.

Funding has emerged to be an important capability and respondents indicate their preference for benefits like exemption of corporate tax regardless of status (i.e. pioneering company), easier foreign worker employment regulations and attracting more foreign companies into biotechnology clusters.

Respondents also mentioned that the government needs to introduce a supportive environment for entrepreneurial activity and government venture companies to be 
consistent and transparent. Malaysia needs to review its current policies and regulations and benchmark with other nations who have successfully implemented policies to attract and support entrepreneurial activity. There is much to learn especially when America and Europe have had successful biotechnology industries for the past two decades. Benchmarking and closely mimicking what others have done might stem future innovation and creativity, but it will prove as a starting point and grow the bioeconomy.

Access to Talent was critical as respondents viewed it necessary to build a world-class biotechnology community. $90 \%$ of respondents indicated 'skilled graduates with world class training' as the most important factor towards building a reputable biotechnology community. The Ministry of Education has introduced numerous educational initiatives in schools from primary to university, in order to inculcate biotechnology into the education system.

\section{Attracting international students will be an alternative to increasing the numbers of} trained workers. Study scholarships and grants should be awarded to attract international student numbers. After training and educating these students, retention of these skilled workers can be through fulfilling a minimum bond-period or by convincing these workers to immigrate to Malaysia by awarding residency status. Several respondents also called for the government to ease recruitment of global talent into Malaysia to accelerate the biotech sector development. This is due to widespread recognition that a diverse range of experienced and networked investors, serial bioentrepreneurs and top executives from multinational companies are necessary to achieve competitiveness.

Respondents mentioned the need to maintain momentum as a key priority in ensuring continuous growth in Malaysia's bioeconomy. Respondents remarked that the government needs to carry out promises advertised in the public relations campaigns and the need to revise long term plans and strategies. The Malaysian government developed the BioValley in 2001 as a creative cluster to attract foreign investors and companies. 
This has yet to yield substantial results. For the short-term, BiotechCorp should continually procure more strategic alliances with foreign biotechnology companies. For the long-term, Malaysia should incrementally adjust their long-term plans to establish a thriving bioeconomy and with achievable short-term plans to support their objectives.

The availability of support services and networks that were deemed to develop a bioeconomy were investors, manufacturing, government agencies, scientific advisory board members, IP firms and contract research organisations (CRO). Previous research showed that with creation of a new biotechnology company, four new supporting companies are created. Furthermore with each new biotechnology job, fifteen other jobs in related and supporting industries are needed (Nbbnet, 2002). Developing a sustainable bioeconomy will require an extensive support system which Malaysia currently uses government agencies. This will not be a long-term solution as current Bionexus firms have mentioned working with government agencies as either being too stringent or having differing standards. Utilising government firms as a starting point is practical, and this should filter off to new private start-ups. These new firms should be allowed to undertake or bid for sub-contracts or other minor roles in providing supporting services.

\section{Respondents noted the need to have a formal platform or forum of scientists to lead}

the biotechnology sector and establishing close proximity to universities and research institutes. Respondents want a private cum government sector movement to develop new initiatives and future growth plans. This will give biotechnology companies that are directly affected by any future plans to voice out their opinions. With the government playing a role in facilitating, supporting and partnering with biotechnology companies in Malaysia; and with an increase in discourse, venture capitalists will be encouraged to invest in Malaysia.

Biotechnology firms continually seek foreign talent as biotechnology is a global business which requires experienced employees, workers and scientists. Thus when companies hire foreign talent, social environment and welfare factors are parts of the equation which attract or discourage foreign talent. $81 \%$ of respondents rated high quality education as 
"important - most important". Allocation of student enrolments at international schools in Malaysia can be preferentially offered to foreign expatriate children to entice foreign expatriates to settle and work in Malaysia. Respondents also suggested a liberal immigration policy extended to foreign expatriates to increase the existing talent-pool in Malaysia. However a careful and incremental policy should be implemented to attract useful foreign expatriates. The proposition is favourable terms like personal income tax-rebates be offered to foreign expatriates with desirable skill-sets to commence work in Malaysia's biotechnology focus areas. The viewpoint is to expedite immigration and work-permit applications for foreign talent with the necessary skill-sets to grow Malaysia's bioeconomy. It does not mean that foreign talent without the right skill-sets are less desirable as Malaysia needs foreign talent. But ease of hiring foreign talents under targeted growth areas will create a faster inflow of talent that will positively impact and grow Malaysia's bioeconomy. 


\section{$\underline{\text { Recommendations }}$}

This is the list of recommendations for practitioners after careful consideration. This list is by no means exhaustive and is merely a guideline for future progress in developing Malaysia's bioeconomy.

\section{Short-term:}

1) Malaysia should leverage on its existing advantage in agriculture and food and biofuels to establish leadership positions in the respective sectors.

2) Existing government sources of funding should be made increasingly available to all foreign biotechnology companies on a "case-by-case" basis. This is to reward deserving companies' base on merit, rather than origin.

3) Foreign expatriates with the desired skill-sets to commence work in Malaysia's biotechnology focus areas should be awarded favourable terms.

\section{Long-term:}

1) More companies are needed to provide supporting services to biotechnology companies and new start-ups are a way to ensure dedicated support services are available.

2) Malaysia should increase developments in healthcare biotechnology to create long-term comparative advantages

3) Attracting international students to study biotechnology will be essential to training and developing skilled graduates who will be available for employment annually.

Short-term objectives are essential as its benefits can be immediately realised within 1-2 years of implementation as opposed to long-term objectives. Malaysia needs to review its long-term strategies and ensure its short-term objectives are able to guide progress towards the eventual goal. Benchmarking factors of success of other biotechnologicallyadvanced countries are essential to establishing a foot-hold in success. Malaysia needs to focus on how resources are utilised towards success. 


\section{Conclusion}
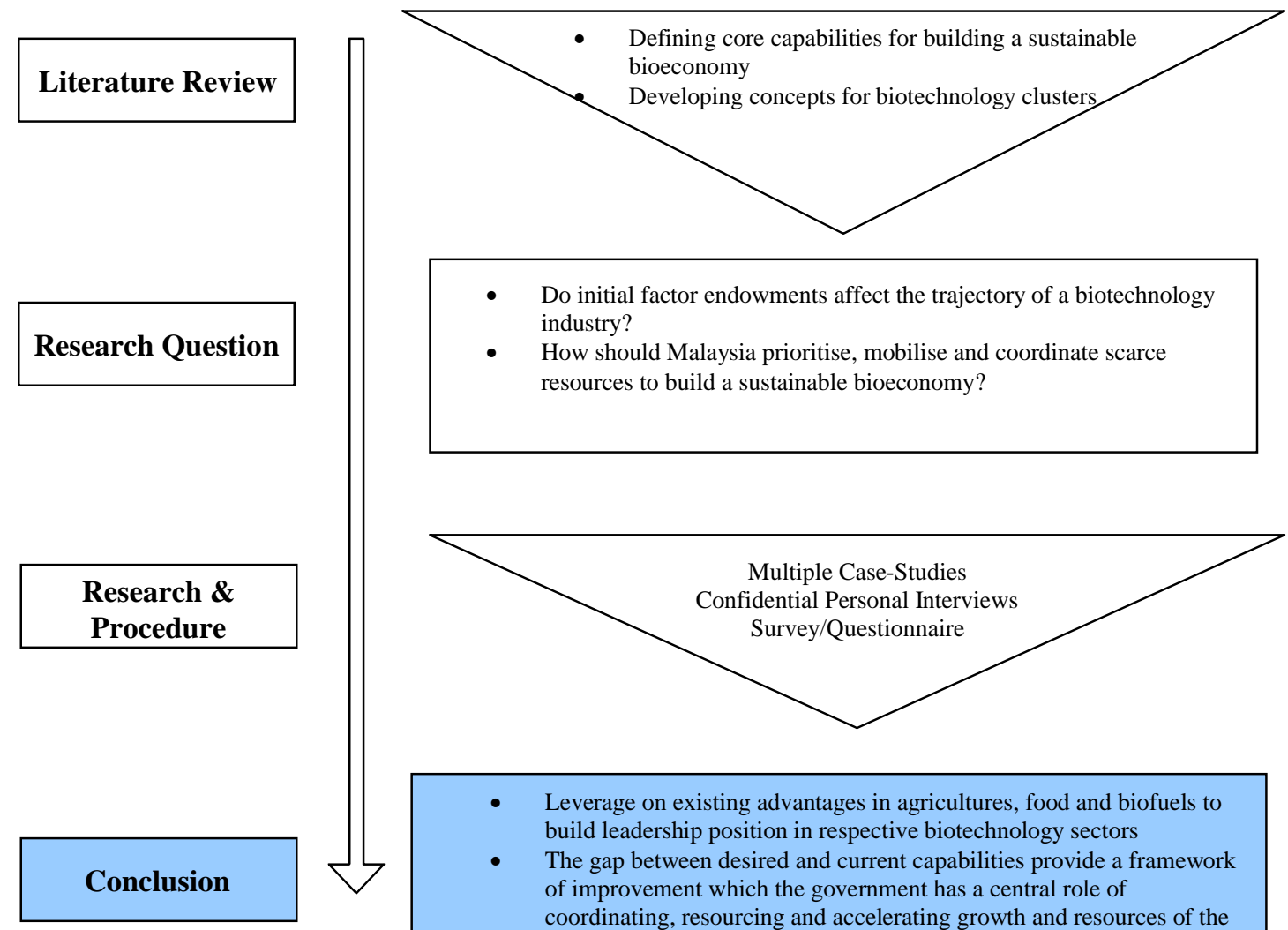

- $\quad$ Leverage on existing advantages in agricultures, food and biofuels to build leadership position in respective biotechnology sectors

- $\quad$ The gap between desired and current capabilities provide a framework of improvement which the government has a central role of coordinating, resourcing and accelerating growth and resources of the nascent Malaysia bioeconomy

Biotechnology is a global business with implications and social and economic benefits. This branch of science has evolved from a highly-specialised and regulated industry to an increasingly mainstream capability with diverse commercial applications. The researcher was guided by research objectives to assess Malaysia's emerging biotechnology industry and the necessary capabilities to develop a sustainable bioeconomy. Biotechnology companies from Malaysia's prestigious Bionexus network formed the survey sample population and all 80 were surveyed with 34 responses which gives a $43 \%$ response rate. Case studies were conducted as part of the data-collection through secondary sources to gain a richer insight into Bionexus and Malaysia's biotechnology industry. From the case studies, insights were derived on factors of success like entrepreneurial founders, scientific advisory boards, venture capital funding, and strategic alliances with research partners and talented scientists. A triangulated design involving confidential interviews 
and in-depth case studies, was later cross-validated with industry participants to construct a questionnaire. This questionnaire was administered and distributed online to all companies in the Bionexus network.

In this study, the researcher explored the priorities and capabilities necessary to establish and develop a sustainable bioeconomy. The findings add to knowledge that in developing a biotechnology industry; funding, talent and government support are essential for creating an investor cum business environment. Firstly the respondents indicated initial factor endowments do affect the trajectory of a biotechnology industry which in this case as seen earlier, respondents urged Malaysia to establish a competitive advantage in biofuels since the country has ample supplies of palm oil. Malaysia has developed a thriving industry in traditional agriculture and food, thus the impetus is to adopt biotechnology to increase growth in this segment. This coincides with the ResourceBased-View that an entity should build sustainable competitive advantage through available valuable resources. Respondents seem split or bimodal over the levels of government intervention and support. However results show that the government's role is pivotal to establishing and growing a sustainable bioeconomy. Additional findings showed that access to funding and talent were the highest priority capabilities required for biotechnology companies to exploit sector priorities and commercial opportunities.

Overall this study shows that the government has a critical role in building and coordinating infrastructure, building comparative advantages, accelerating technological and capital flows and sustaining growth levels. Malaysia is naturally endowed with vast amounts of natural resources and would prove fundamental to its bioeconomy. The questions of how these resources are applied are critical for its success.

The pitfall of this study is firstly, the questionnaire's design consisted of close-questions which limited other forms of statistical analysis and limited the responses from participants. However this also meant the responses from participants were easier to analyse and derive assumptions from. Secondly, endorsement of this research by Malaysia Biotechnology Corporation might sway Bionexus participant responses, 
however the results of this study indicates this risk to be minimal. Third, surveying biotechnology companies only from the Bionexus network might diminishe the value of the study as opinions of non-Bionexus biotechnology companies are yet to be considered. Fourth, the time-frame for this paper is only 12 months and extensive research methods would be unfeasible within this short time-frame. Fifth, there are many factors and variables that a survey is unable to totally capture in one study. Therefore it is acknowledged as a weakness in methodology.

Areas for future research include firstly, a mixed-methods approach of interviewing and surveying Malaysia biotechnology respondents needs to be undertaken once again and should include a representative sample of all biotechnology companies regardless of Bionexus status. This should give a richer and better set of data to increase generalisability of results.

Secondly, this research results coincides with previous research outlining the importance of the government in growing a biotechnology industry due to their position to offer favourable terms and conditions or incentives. However if biotechnology firms are global by nature and tend to establish strategic alliances with other overseas firms, which allows them to cooperate cross-border in terms of manufacturing and conducting R\&D; will strategic alliances or a receptive government be more important? Will these two factors differ between small or large biotechnology companies?

Thirdly, how should Malaysia coordinate resources to ensure success? Should resources be distributed according to cluster, company potential or are there other factors to be considered? Efficient distribution of resources will be a crucial element to success. Biotechnology is an industry with high risks and long profit-waiting periods; therefore there is a need for caution and prudence in allocating and distributing resources to recipients. 


\section{References}

Ahn, M., Meeks, M., (2007). Building a Conducive Environment for Life Science Based Entrepreneurship and Industry Clusters. Journal of Commercial Biotechnology $14,20-30$

Ahn, M. J., Meeks, M. D., Ross, C., Dalziel, S., \& Bednarek, R., (2008). Towards a High Performance Bioeconomy in New Zealand: Determining Cluster Priorities and Capabilities.

Ahn, M. J., York, A., Bednarek, R., \& Loh, M., (2009). Accelerating Biotechnology Industry Growth and Innovation in Malaysia: Identifying Priorities and Building Capabilities.

Albinson, R., (1987). Biosensors - from concept to commercialisation. Sensor Review, 7(1), 39-44.

Andersson, T., Serger, S., Sorvik, J., Hansson, E. W., (2004). The Cluster Policy

Whitebook: International Organization for Knowledge Economy and Enterprise Development.

Andlauer, W., \& Fürst, P., (2002). Nutraceuticals: a piece of history, present status and outlook. Food Research International, 35(2-3), 171-176.

ArthritisNZ, (2009). Rheumatoid Arthritis - Everybody - Health Information for New Zealanders. Retrieved 23 January 2009, from: http://www.everybody.co.nz/page75d2b8b9-9b93-4e99-9274-171b33e156dc.aspx

Asian Development Bank, (2001). Agricultural Biotechnology, Poverty Reduction and Food Security. Retrieved 13 October 2008, from: http://www.adb.org/Documents/Books/Agri_Biotech/agribiotech.pdf

Baker, M., (2006). New-wave diagnostics. Nature Biotechnology, 24(8), 931.

Bar Chronicle, (2000). Biotechnology: An important for sustainable agriculture. Bureau of Agricultural Research - Department of Agriculture Philippines. Vol 1 No.13 July 1-15, 2000. Retrieved 3 January 2009 from: http://www.bar.gov.ph/barchronicle/2000/jul00_1-15_biotechnology.asp

Barney, J., (1991). Firm resources and sustained competitive advantage, Journal of Management, 17(1): 99-120. 
Barney, J., (2001). Is the Resource-Based "View" a Useful Perspective for Strategic Management Research? Yes. The Academy of Management Review, Vol. 26. No. 1 (Jan, 2001), pp. 41-56.

Basiron, Y., (2007). Palm oil production through sustainable plantations (Vol. 109, pp.289-295).

Batchelder, K., \& Miller, P., (2006). A change in the market--investing in diagnostics. Nature Biotechnology, 24(8), 922.

Belem, M. A. F., (1999). Application of biotechnology in the product development of nutraceuticals in Canada. Trends in Food Science \& Technology, 10(3), 101-106.

BIO (Biotechnology Industry Organization), (2006). BIO 2005-2006: Guide to Biotechnology. Retrieved 5 July 2008 from: www.bio.org.

BIO (Biotechnology Industry Organization), (2007). Guide to Biotechnology. Retrieved 20 August 2008, from: www.bio.org.

Biobusiness Channel, (2007). Malaysian Government Fosters Biotech Growth: Country is attempting to grow the industry with investments and an $R \& D$ zone. Retrieved 11 July 2008 from: http://www.genengnews.com/articles/chitem.aspx?aid=2210\&chid=0

Biofactlife, (2008a). BioFact Life: About BIO FACT LIFE - Introduction. Retrieved 26 October 2008 from: http://www.biofactlife.com/about2.php

Biofactlife, (2008b). BioFact Life: The Origin of Cordyceps. Retrieved 26 October 2008: http://www.biofactlife.com/origin.php

Biofactlife, (2008c). BioFact Life: Biotechnology - Research and Development. Retrieved 26 October 2008 from: http://www.biofactlife.com/research.php Biofactlife, (2008d). BioFact Life: Good Manufacturing Practices - QA/QC/IPQC. Retrieved 26 October 2008 from: http://www.biofactlife.com/q.php Biofactlife, (2008e). BioFact Life: Biotechnology - Key R\&D Persons. Retrieved from 26 October 2008: http://www.biofactlife.com/key.php

Biopolis, (2007). Biopolis Biomedical Research and Development Hub Singapore Pharmaceutical Technology. Retrieved 17 February 2009: http://www.pharmaceutical-technology.com/projects/biopolis/ 
Biospectrum, (2008). Malaysia to see rise in Pharmaceutical industry in 2008: Frost \& Sullivan. Retrieved 21 October 2008 from http://www.biospectrumasia.com/content/270208MYS5627.asp

Biotechcorp, (2005). Prime Minister's speech at launch of National Biotechnology Policy. Retrieved 13 August 2008 from: http://www.biotechcorp.com.my/biotechinmalaysia/pmspeech.pdf

Biotechcorp, (2008). The Bionexus Network. Retrieved 14 August 2008 from: http://www.biotechcorp.com.my/bionexusnetwork/bionexusnetwork.htm Biotechcorp, (2008a). Bionexus Network Companies - Malaysian Bio-Diagnostic Research Sdn Bhd. Retrieved 14 August 2008 from: http://www.biotechcorp.com.my/bionexusnetwork/companies/mbdr.htm Biotechcorp, (2009). Malaysia Biotechnology Focus Areas - Malaysia Biotech Corporation. Retrieved 16 January 2009 from: http://www.biotechcorp.com.my/biz_comm_grants_focusarea_cnt.html

Biotechcorp, (2009a). Malaysian Technology and Development Corporation - Funding and Investments. Retrieved 16 January 2009 from: http://www.biotechcorp.com.my/fund_invsts.html

BIOTEK, (2009). Funds - National Biotechnology Division. Retrieved 6 February 2009 from: http://www.biotek.gov.my/fund.htm

BIOTEK, (2009a). Background BIOTEK Malaysia - Ministry of Science, Technology and Innovation. Retrieved 6 February 2009 from: http://www.biotek.gov.my/background.htm

BIOTEK, (2009b). Venture Capital - National Biotechnology Division. Retrieved 6 February 2009 from: http://www.biotek.gov.my/venture.htm

BM, (2005). BioMalaysia - What \& How - PM Explains by Koh Lay Chin (April 2005) in The New Straits Times, Malaysia. Retrieved 31 September 2008 from: http://www.biotechcorp.com.my/biotechinmalaysia/article_pminterview.html Boston Scientific, (2009). About Us: Boston Scientific - Delivering What's Next. Retrieved 5 January 2009 from: http://www.bostonscientific.com/AboutUs.bsci/,/navRelId/1000.1004/seo.serve 
Burrill, (2007). Life Sciences: A Global Transformation. Burrill Life Sciences Venture Capital Group, San Francisco, United States of America.

Burrill, (2008). Biotech 2008 - Life Sciences: A 20/20 Vision to 2020. Burrill Life

Sciences Venture Capital Group, San Francisco, United States of America.

Byrum, A.L, (2004). BioValley - A trinational biocluster. Retrieved 22 August 2008 from:

http://pubs.acs.org/subscribe/archive/mdd/v07/i12/pdf/1204feature_byrum.pdf

Casper, S., (2007). How do technology clusters emerge and become sustainable? Social network formation and inter-firm mobility within the San Diego biotechnology cluster. Research Policy 36(4), 438

Cavana, R.Y, Delahaye, B.L., Sekaran, U., (2001). Applied Business Research Qualitative and Quantitative Methods. John Wiley \& Sons Australia, Ltd.

CCM, (2008a). Chemical Company of Malaysia - Company Background. Retrieved 11 September 2008 from: http://www.ccm.com.my/aboutCCM/bground.asp

CCM, (2008b). Chemical Company of Malaysia - Business Activities. Retrieved 11 September 2008 from: http://www.ccm.com.my/businessActivities/chemicals.asp

CCM, (2008c). Chemical Company of Malaysia - Business Activities: Chemicals

Retrieved 11 September 2008 from:

http://www.ccm.com.my/businessActivities/chemicals.asp

CCM, (2008d). Chemical Company of Malaysia - About: Milestones Retrieved 11

September 2008 from: http://www.ccm.com.my/aboutCCM/milestones.asp

CCM, (2008e). Chemical Company of Malaysia - Business Activities: Pharmaceuticals

Retrieved 11 September 2008 from:

http://www.ccm.com.my/businessActivities/pharmaceuticals.asp

CCM, (2008f). Chemical Company of Malaysia - Business Activities: Duopharma.

Retrieved 11 September 2008 from:

http://www.ccm.com.my/businessActivities/duopharma.asp

CCM, (2008g). Chemical Company of Malaysia - Corporate Governance. Retrieved 11

September 2008 from: http://www.ccm.com.my/aboutCCM/corp_governance.asp.

CCM, (2008h). Chemical Company of Malaysia - Corporate Body. Retrieved 11

September 2008 from: http://www.ccm.com.my/aboutCCM/corp_bod.asp 
Cerebos, (2009). Cerebos Pacific Limited - Annual Report 2008. Retrieved 8 January, 2009 from:

http://www.cerebos.com/financial/ReportPDF/Cerebos\%20AR\%202008\%20Low \%20Res.pdf

CertID, (2008). Certification Services: Consumer Pages - FAQs for Consumers.

Retrieved 15 August 2008 from: http://www.cert-id.com/consumers-faq.htm\#8

California Healthcare Institute (CHI), (2006). California's Biomedical Industry 2006

Report, CHI/PricewaterhouseCoopers LLP. Retrieved 14 November 2008 from: www.chi.org.

CIA World Fact Book, (2008). CIA - The World Factbook - Malaysia: Economy.

Retrieved from https://www.cia.gov/library/publications/the-worldfactbook/geos/my.html

Cooper, D. R., \& Schindler, P. S., (2008). Business Research Methods. McGraw-Hill Irwin, 10th Edition. United States of America, New York.

Coyle, W., (2007). The Future of Biofuels: A Global Perspective. Amber Waves, 5(5), 24.

Creswell, J. W., \& Clark, V. L.P., (2007). Designing and Conducting Mixed Methods Research. Sage Publications Inc, United States of America.

DeFelice, S. L., (1995). The nutraceutical revolution: its impact on food industry R\&D. Trends in Food Science \& Technology, 6(2), 59-61.

Delporte, C., (2006). Asia Still Prime for Device Sector Growth: Countries remain hotbeds for product sales and outsourcing opportunities. Retrieved at: http://www.mpo-mag.com/articles/2006/10/asia-still-prime-for-device-sectorgrowth

Demirbas, A., (2007). Progress and recent trends in biofuels. Progress in Energy and Combustion Science, 33(1), 1-18.

Dictionary, (2008). Retrieved from http://dictionary.reference.com/browse/agronomy

Ekta, K. K., (2003). Nutraceutical-definition and introduction. The AAPS Journal, 5(3), 27-28.

Ellet, W., (2007). The Case Study HandBook - How to Read, Discuss, and Write Persuasively About Cases. Harvard Business School Press. United States of America. 
EPU, (2006). Official Website of Economic Planning Unit: Prime Minister's Department

Malaysia. Speech by the Prime Minister. Retrieved 9 August 2008 from:

http://www.epu.jpm.my/rm9/RMK9\%20speech.pdf

EPU, (2008). Economic Planning Unit. $9^{\text {th }}$ Malaysia Plan Speech Presentation - Versi

Berhasa Inggeris. Retrieved from http://www.epu.jpm.my/rm9/RMKe9.htm

Ernst \& Young, (2004). E\&Y report backs Asia-Pacific biotech. EYGM Limited.

Ernst \& Young, (2008). Strategic Business Risk: Biotechnology 2008, EYGM Limited.

Retrieved 1 June 2008 from: www.ey.com.

Eselius, L., Nimmagadda, M., Kambil, A., Hisey, R. T. T., \& Rhodes, J., (2008).

Managing pathways to convergence in the life sciences industry. Journal of

Business Strategy, 29(2), 31-42.

Espicom, (2008). A new critical strategic report from Espicom Business Intelligence -

Biopharmaceuticals in South East Asia: Setting sights on global leadership.

Retrieved 17 January 2009:

https://www.espicom.com/prodcat.nsf/Product_ID_Lookup/00002169?OpenDocu ment

Furman, J.L., Porter, M.E., Stern, S., (2002). The determinants of national innovative capacity. Research Policy, 31(6): 899.

Food \& Drink, (2006). Asia Pacific leads world in nutraceutical sales. Retrieved

11August 2008 from: http://www.foodanddrinkeurope.com/Consumer-

Trends/Asia-Pacific-leads-world-in-nutraceutical-sales

Frost \& Sullivan, (2001). Southeast Asia: Gearing up for the Bio-Economy Wave.

Retrieved 5 July 2008 from: http://www.frost.com/prod/servlet/market-insighttop.pag?docid=BNNN-5377MG

Frost \& Sullivan, (2003). Agriculture Biotechnology: Engineering Nature for qualitative and Quantitative Production. Retrieved 10 July 2008 from:

http://www.frost.com/prod/servlet/market-insight-

top.pag?docid=7473587\&ctxixpLink=FcmCtx15\&ctxixpLabel=FcmCtx 16

Frost \& Sullivan, (2004). Food and Agriculture Biotechnology - Transgenic Crops.

Retrieved 24 July 2008 from: http://www.frost.com/prod/servlet/market-insighttop.pag?docid=22070308 
Frost \& Sullivan, (2006). Debuts the Paradigm Shift. Retrieved 19 July 2008from:

http://www.frost.com/prod/servlet/press-release.pag?docid=69828755

Frost \& Sullivan, (2007). Strategic Analysis of the Asia Pacific Biodiesel Industry. San

Antonio, Texas.

Frost \& Sullivan, (2007a). South African Biofuels Market 2007. San Antonio, Texas.

Frost \& Sullivan, (2007b). Indian Biofuels Market 2007. San Antonio, Texas.

Frost \& Sullivan, (2007c). A Medical Device Indusry Emerging Across Asia-Pacific's

Horizons. Retrieved 19 December 2008 from: http://www.frost.com/prod/servlet/marketinsight-top.pag?docid=103246045

Frost \& Sullivan, (2008). Medical Device Market: Mega Trends in Asia - Asian Hospital and Healthcare Management. Retrieved 14 January 2009 from:

http://www.asianhhm.com/equipment_devices/medical_device_market.htm

Frost \& Sullivan, (2008a). Frost \& Sullivan: Rising Presence of Asian Medical

Equipment Companies in Latin America. Retrieved 14 January 2009:

http://www.articlearchives.com/marketing-advertising/marketing-advertising-

measures/1898879-1.html

Frost \& Sullivan, (2009). China's biofuel industry to maintain moderate growth - Frost \& Sullivan. Retrieved 18 January 2009 from:

http://www.redorbit.com/news/business/1636542/chinas_biofuel_industry_to_maintain_ moderate_growth_says_frost_/

GENO, (2009). Mission, Objectives \& Essential Features - GENOMalaysia, Malaysia

Genome Institute. Retrieved 21 January 2009 from:

http://genome.ukm.my/content/about_us_main.html

Gerring, J., (2007). Case Study Research - Principles and Practices. Cambridge

University Press. United States of America.

Ghauri, P., \& Gronhaug, K., (2005). Research Methods in Business Studies - A Practical Guide. Third Edition. Prentice Hall, Financial Times. Great Britain.

GreenFacts, (2004). Scientific Facts on Genetically Modified Crops. Retrieved 22 August 2008 from: http://www.greenfacts.org/en/gmo/3-genetically-engineered-food/1agricultural-biotechnology.htm 
Gross, A., (2007). Medical Device Regulatory Update: The Asian Market. Retrieved 19 September 2008 from: http://www.devicelink.com/mddi/archive/07/01/008.html

Gurau, C., (2004). Positioning strategies in the value-added chain of the biopharmaceutical sector: the case of UK SMEs. Journal of Consumer Marketing, 21(7), 10.

Gushan, (2008). Gushan Environmental Energy Limited - Annual Report for the Fiscal Year Ended December 31, 2007. Retrieved 18 November 2008 from: http://library.corporateir.net/library/20/201/201174/items/304731/AnnualReport2007.pdf

Gwynne, P., (2004). International Careers Report: Global Biotech and Pharma. Science, 306(5693), 143.

Hardy, G., (2000). Nutraceuticals and functional foods: introduction and meaning. Nutrition, 16(7-8), 688-689.

Hart, S. L., (1995). A Natural Resource Based View of the Firm. The Academy of Management Review, Vol.20, No.4 (Oct. 1995), pp. 986-1014.

HKSTP, (2009). Hong Kong Science Technology Park - Introduction. Retrieved 2 February 2009 from: http://www.hkstp.org/HKSTPC/en_html/en_corporation1_1.jsp

HokkaidoBIO, (2008). Hokkaido Biotechnology Industrial Cluster Forum Characteristics of Cluster. Retrieved 16 September 2008 from: http://www.noastec.jp/biocluster/english/presentstate.html

Iammarino, S., McCann, P., (2006). The structure and evolution of industrial clusters:

Transactions, technology and knowledge spillovers. Research Policy 35(7), 1018.

IMU, (2008). International Medical University Malaysia - Faculty Member. Retrieved from 29 August 2008 from: http://www.imu.edu.my/faculty_member.asp?pageid=1\&browsefacultyid=174

IOI Group, (2008a). Corporate Information - Milestones. Retrieved 27 August 2008 from http://www.ioigroup.com/corporateInfo/corp_milestone.cfm?id=EF456F2113D3-0253-BA5FB5394352AF09

IOI Group, (2008b). Corporate Information - About Us. Retrieved 27 August 2008 from http://www.ioigroup.com/corporateinfo/corp_aboutus.cfm 
IOI Group, (2008c). Business - Agri-technology and Agronomy. Retrieved 27 August 2008 from http://www.ioigroup.com/business/busi_agritech.cfm

IOI Group, (2008d). Business - Estate \& Mills. Retrieved 27 August 2008 from http://www.ioigroup.com/business/busi_millsestates.cfm

IOI Group, (2008e). Business: Resource-Based Manufacturing. Retrieved 27 August 2008 from http://www.ioigroup.com/business/busi_resource.cfm

IOI Group, (2008f). Business: Oleo Chemicals. Retrieved 27 August 2008 from http://www.ioigroup.com/business/busi_oleo.cfm

IOI Group, (2008g). Business: Speciality Fats. Retrieved 27 August 2008 from http://www.ioigroup.com/business/busi_specialty.cfm

IOI Group, (2008h). Business: Property Investment. Retrieved 27 August 2008 from http://www.ioigroup.com/business/busi_property_investment.cfm

IOI Group, (2008i). Business: Leisure Property Investments. Retrieved 27 August 2008 from http://www.ioigroup.com/business/busi_property_leisure.cfm

IOI Group, (2008j). Corporate Information - Executive Chairman Profile. Retrieved 27 August 2008 from http://www.ioigroup.com/CorporateInfo/corp_directorsprofile.cfm?id=36F08FFF8C50-41D2-B7BB9C6758450FC0

IOI Group, (2008k). Corporate Information - Director Lee Cheng Leang Profile. Retrieved 27 August 2008 from http://www.ioigroup.com/CorporateInfo/corp_directorsprofile.cfm?id=6D3D1369 -FFD9-4C97-89487C46280945BD

IOI Group, (20081). Corporate Information - Corporate Responsibility. Retrieved 27 August 2008 from http://www.ioigroup.com/corporateresponsibility/corporate_responsibility.cfm ITC, (2009). Innovation and Technology Commission, The Government of the Hong Kong Special Administrative Region - Technology Areas: Biotechnology. Retrieved 5 February 2009 from: http://www.itc.gov.hk/en/area/bio.htm IPHARM, (2009). Vision and Mission - Malaysian Institute of Pharmaceuticals and Nutraceuticals. Retrieved 27 January 2009 from: http://www.ipharm.gov.my/v4/vision.php 
Jaeger, K., (2006). America's generic pharmaceutical industry: Opportunities and challenges in 2006 and beyond. Journal of Generic Medicines, 4(1), 15.

Kraft, (2009). 2008 - Kraft Investor Fact Sheet. Retrieved 11 January 2009 from: http://www.kraftfoodscompany.com/assets/pdf/2008_Kraft_Fact_Sheet.pdf

Lancaster, G., (2005). Research Methods in Management: A concise introduction to research in management and business consultancy. Elsevier. Pg. 133.

Makadok, R., (2001). Towards a synthesis of resource-based and dynamic capability views of rent creation. Strategic Management Journal, 22(5): 387-402

MBBNet, (2009). Global Biotechnology Clusters Map. Retrieved 6 January 2009 from: http://www.mbbnet.umn.edu/scmap/biotechmap.html

MBDR, (2008a). Malaysian Bio-Diagnostic Research: Corporate Overview. Retrieved 3 September 2008 from: http://www.mbdr.net/overview.html

MBDR, (2008b). Malaysian Bio-Diagnostic Research: Drugs of Abuse Tests. Retrieved 3 September 2008 from: http://www.mbdr.net/drugsofabuse.html

MBDR, (2008c). Malaysian Bio-Diagnostic Research: Filariasis Tests. Retrieved 3 September 2008 from: http://www.mbdr.net/filariasis.html MBDR, (2008d). Malaysian Bio-Diagnostic Research: Tuberculosis Test. Retrieved 3 September 2008 from: http://www.mbdr.net/tuberculosis.html MBDR, (2008e). Malaysian Bio-Diagnostic Research: Human Immunodeficiency Virus (HIV) Test. Retrieved 3 September 2008 from: http://www.mbdr.net/hvrapid.html MBDR, (2008f). Malaysian Bio-Diagnostic Research: Typhoid Tests. Retrieved 3 September 2008 from: http://www.mbdr.net/typhoid.html Medicon, (2009). Medicon Valley - Business Opportunities. Retrieved 17 September 2008 from: http://www.mediconvalley.com/BusinessOpportunities

MDV, (2009). Our Company - Malaysia Debt Ventures Berhad. Retrieved 10 February 2009 from:

http://www.mdv.com.my/cms/content.jsp?id=com.tms.cms.section.Section_27a5c b28-c0a8c879-185c59c0-75098c58

MIDA, (2006). Malaysian Industrial Development Authority. Publication - Make Malaysia Your Biotechnology Hub. Retrieved 9 July 2008 from: http://www.mida.gov.my/en_v2/index.php?mact=Products,cntnt01,details,0\&cntn 
t01 category=MIDA\%20Publication \&cntnt01 detailpage=publicationitem \&cntnt01cd_origpage $=133 \&$ cntnt 01 productid=25\&cntnt 01 returnid=324

MIDA, (2008). Malaysian Industrial Development Authority - Why Malaysia: Economic Strength. Retrieved 10 July 2008 from http://www.mida.gov.my/

MIDA, (2009). Intellectual Property Protection in Malaysia - Malaysian Industrial Development Authority. Retrieved 12 January 2009 from: http://www.mida.gov.my/en_v2/index.php?page=IP-protection

Miller, D., (2003). An Asymmetry Based View of Advantage: Towards an Attainable Sustainability. Strategic Management Journal, Vol 24. No. 10. (Oct. 2003), pp. 961-976.

Monsanto, (2009). Who We Are - Monsanto overview. Retrieved 21 January 2009 from: http://www.monsanto.com/who_we_are/default.asp

MTDC, (2008). Malaysian Technology Development Corporation - Venture Capital \& Investment: Introduction. Retrieved 19 July 2008 from: http://www.mtdc.com.my/index.php?page=vci/index \& $\bmod =2$

MyIPO, (2007). Annual Report 2007 - Intellectual Property Corporation of Malaysia. Retrieved 27 July 2008 from: http://www.mipc.gov.my/images/stories/AR/2007/ar2007.pdf

MyIPO, (2009). Application and Registration of Patent and Utility Innovations from 1986 to 2008 - Intellectual Property Corporation of Malaysia. Retrieved 1 February 2009 from: http://www.mipc.gov.my/index.php?option=com_content\&task=view\&id=3\&Ite $\operatorname{mid}=10$

Nbbnet, (2002). Future Plans - Biotechnology in Malaysia. Retrieved 17 November 2008 from: http://www.nbbnet.gov.my/plan.htm

NBP, (2005). Speech by Prime Minister of Malaysia at the launch of BioMalaysia 2005. National Biotechnology Policy. Retrieved 12 July 2008 from: http://www.biotechcorp.com.my/biotechinmalaysia/pmspeech.pdf

Newman, J. D., Tigwell, L. J., Warner, P. J., \& Turner, A. P. F., (2001). Biosensors: boldly going into the new millennium. Sensor Review, 21(4), 268-271. 
NesteOil, (2009). In Brief - Neste Oil Com. Retrieved 31 January 2009 from: http://www.nesteoil.com/default.asp?path=1,41,537,2455

Olympus, (2008). Annual Report 2008 - Olympus. Retrieved 15 January 2009 from: http://www.olympus-global.com/en/corc/ir/annualreport/2008/pdf/ar2008.pdf

Owen, V. M., (1985). Biosensors. Sensor Review, 5(1), $20-24$.

Peteraf, M. A., (1993). The Cornerstones of Competitive Advantage: A Resource-Based View. Strategic Management Journal, Vol. 14, No. 3 (Mar. 1993), pp. 179-191.

Rinaldi, A., (2006). More than the sum of their parts. European Molecular Biology Organisation, 7(2), 4.

Rowley, W. R., (2002). Biotechnology overview: Applications and forecasts. Foresight, 4(4), 4-13.

Smith, J. P., (2005). Medical and biological sensors: a technical and commercial review. Sensor Review, 25(4), 241-245.

StemLife, (2008a). StemLife International - Company Overview. Retrieved 1 November 2008 from: http://www.stemlife.com/international/corporate_information/overview.html

StemLife, (2008b). StemLife International - History. Retrieved 1 November 2008 from: http://www.stemlife.com/international/corporate_information/history.html

StemLife, (2008c). StemLife International - StemLife Baby Collection. Retrieved 1 November 2008 from: http://www.stemlife.com/international/stemlife_services/stemlife_baby.html StemLife, (2008d). StemLife International - StemLife Baby - Shipping and Handlng of Cord Blood. Retrieved 1 November 2008 from: http://www.stemlife.com/international/stemlife_services/baby_shipping.html StemLife, (2008e). StemLife International - StemLife Baby - Processing, Testing \& Storage. Retrieved 1 November 2008 from: http://www.stemlife.com/international/stemlife_services/baby_processing.html StemLife, (2008f). StemLife International - Adult StemLife Overview. Retrieved 1 November 2008 from: http://www.stemlife.com/international/stemlife_services/stemlife_adult.html 
StemLife, (2008g). StemLife International - StemLife Adult Collection. Retrieved 1 November 2008 from:

http://www.stemlife.com/international/stemlife_services/adult_collection.html

StemLife, (2008h). StemLife International - Management Team. Retrieved 1 November 2008 from:

http://www.stemlife.com/international/corporate_information/management.html

StemLife, (2008i). StemLife International - Advisory Panel. Retrieved 1 November 2008 from: http://www.stemlife.com/international/corporate_information/advisory.html

Stuart, T., \& Sorenson, O., (2003). The geography of opportunity: Spatial heterogeneity in founding rates and the performance of biotechnology firms. Research Policy, 32(2): 229.

Takeda, (2008). Annual Report 2008 - Takeda Pharmaceutical Company Limited.

Retrieved 29 January 2009 from:

http://www.takeda.com/pdf/usr/default/ar2008e_31898_1.pdf

Takeda, (2009). Company Overview - Takeda Pharmaceutical Company Limited.

Retrieved 29 January 2009 from: http://www.takeda.com/abouttakeda/overview/article_56.html

Teng, P., (2008). An Asian Perspective on GMO and biotechnology issues. Asia Pacific Journal of Clinical Nutrition 2008;17 (S1): 237-240. Retrieved 19 December 2008 from: http://apjen.nhri.org.tw/server/APJCN/Volume17/vol17suppl.1/237240S13-4.pdf

The Star Online, (2007). Transforming Education by Karen Chapman. Retrieved 22 July 2008 from:

http://thestar.com.my/news/story.asp?file=/2008/10/5/education/2147383\&sec=ed ucation

The Star Online, (2008). Biotech boost for Malacca. Retrieved 10 November 2008 from: http://thestar.com.my/news/story.asp?file=/2008/6/20/nation/21602331\&sec=nati on

Thompson, A. K., \& Moughan, P. J., (2008). Innovation in the foods industry: Functional foods. Innovation : Management, Policy \& Practice, 10(1), 61. 
US FDA, (2009). United States Food and Drug Administration - Department of Health and Human Services. Diabetes Information - Complication of diabetes. Retrieved 14 February 2009 from: http://www.fda.gov/Diabetes/related.html

USINFO, (2007). Asia Seen as Next Focus of Agricultural Biotech Production - Bureau of International Information Programs, United States Department of State. Retrieved 22 October 2008: http://www.america.gov/st/washfileenglish/2007/February/20070216144428AKllennoCcM6.266421e-02.html

USM, (2008). Universiti Sains Malaysia: Profile - Professor Asma Ismail. Retrieved 26 October 2008 from: http://www.usm.my/r\&i/cv_asma.htm

Wernerfelt, B., (1984). "A resource-based view of the firm". Strategic Management Journal, Vol.5, pp.171-180.

World Bank, (2009). Data \& Statistics - By Income: World Bank. Retrieved 31 January 2009 from: http://web.worldbank.org/WBSITE/EXTERNAL/DATASTATISTICS/0,,content MDK:20421402 pagePK:64133150 piPK:64133175 theSitePK:239419,00.html \#High_income

Yasheng, (2009). Yasheng Group - Company Overview. Retrieved 2 February 2009 from: http://www.yashenggroup.com/about.htm 


\section{Appendix}

\section{Questionnaire}

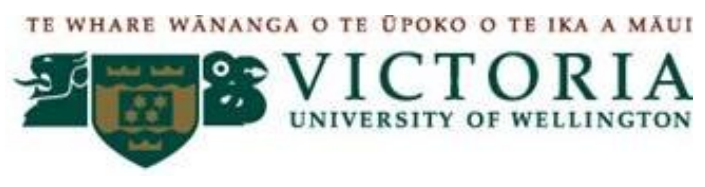

\section{Building Malaysian Biotech Capabilities and Competitiveness 1. Welcome!}

Dear Friend of the Malaysian Biotech Industry:

My name is Melvyn Loh and I am currently undertaking a Master degree in Victoria University of Wellington. This study is a partnership effort between Victoria University of Wellington and Malaysia's Biotech Corporation where I serve as a research partner and I am here to invite you to participate in this study of exploring how to build Malaysia's biotechnology industry. Identifying areas of focus, required capabilities, competitiveness for the Malaysian biotech industry are critical to economic development and wealth creation. Please help us identify key priorities for building a world class biotech sector in Malaysia, by completing this brief and anonymous survey.

The private and public sectors in Malaysia have already mobilised to create business opportunities in areas such as human healthcare, diagnostics, medical devices, agriculture, biofuels, environment, and nutraceuticals. Recognising the growing importance and potential of biotechnology to broadly impact Malaysian economic development, several government initiatives and agencies are engaged in building capacity for accelerating sector growth. To build on early successes and momentum, we need to identify specific priorities, areas of focus, and opportunities for preferential investment in building a thriving bioeconomy to achieve top tier global competitiveness.

Victoria University of Wellington requires approval for research involving human participants through an ethics review process. This project has received the necessary approval to proceed. Please note that your information will be completely anonymous and shown only in aggregated form. You don't have to provide your name. A report of the findings will be made available for public download on Malaysia Biotechnology Corporation's website. This survey should not take more than 10-12 minutes of your time.

Thank you very much for your time in completing this survey which we hope will enhance Malaysia's biotechnology industry competitiveness. We appreciate your participation and leadership! 
Sincerely yours,

Melvyn Loh, Masters of Commerce \& Administration Student, Victoria University

Mark J. Ahn, Professor \& Chair, Science \& Technology Entrepreneurship, Victoria University

Please direct any questions about the survey to:

Melvyn Loh

Masters of Commerce \& Administration Student

Faculty of Commerce \& Administration

Victoria University of Wellington

Email: melvyn.loh@vuw.ac.nz

Mark J. Ahn, PhD

Professor and Chair, Science \& Technology Entrepreneurship

Faculties of Commerce \& Administration and Science

Victoria University of Wellington

E-mail: mark.ahn@vuw.ac.nz 


\section{Demographics}

Please tell us about yourself:

1. What is your Role (please check all that apply)?

$\square$ Scientist

$\square$ Government official

$\square$ Management

$\square$ Board Member

$\square$ Service provider (ie, consultant, accountant, headhunter, attorney, et al)

$\square$ Investor (ie, angel, venture capital, private equity, individual)

$\square$ Academic

Other (please specify)

\section{Years of experience in the biotechnology sector?}

O $0-5$ years

S-10 years

D $>10$ years

\section{Where is your principal residence?}
Malaysia
Other Asia-Pacific (outside Malaysia)
North America
South America
EU (European Union)
Middle East/Africa
Other (please specify)
| 


\section{Biotechnology Priorities for Malaysia}

4. Please RANK the following priorities for building a thriving biotechnology industry in Malaysia from 1(highest priority) to 9 (Lowest priority). Please note each number can only be used once.

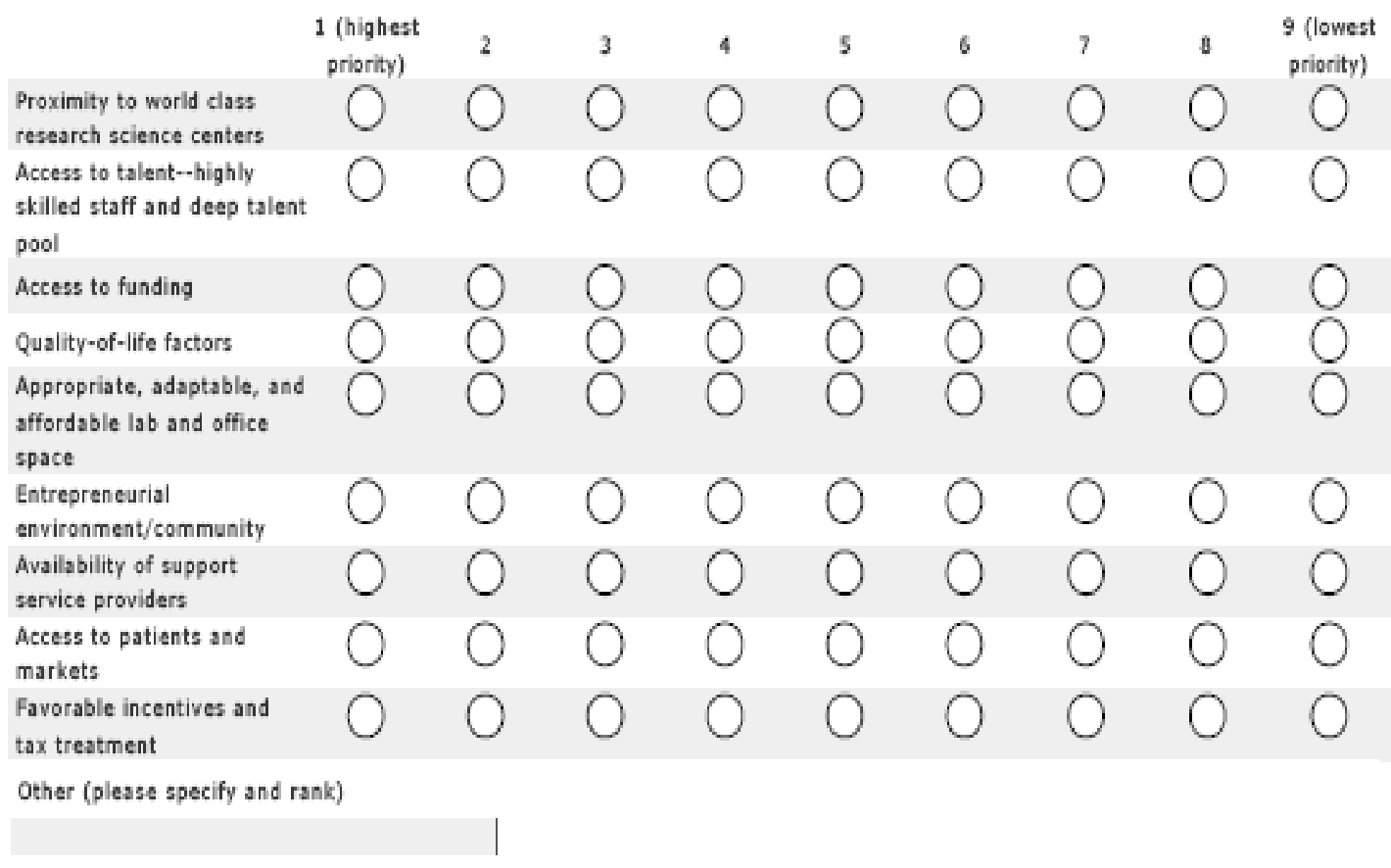

\section{How are we doing? Is Malaysia globally competitive in the following priorities?}

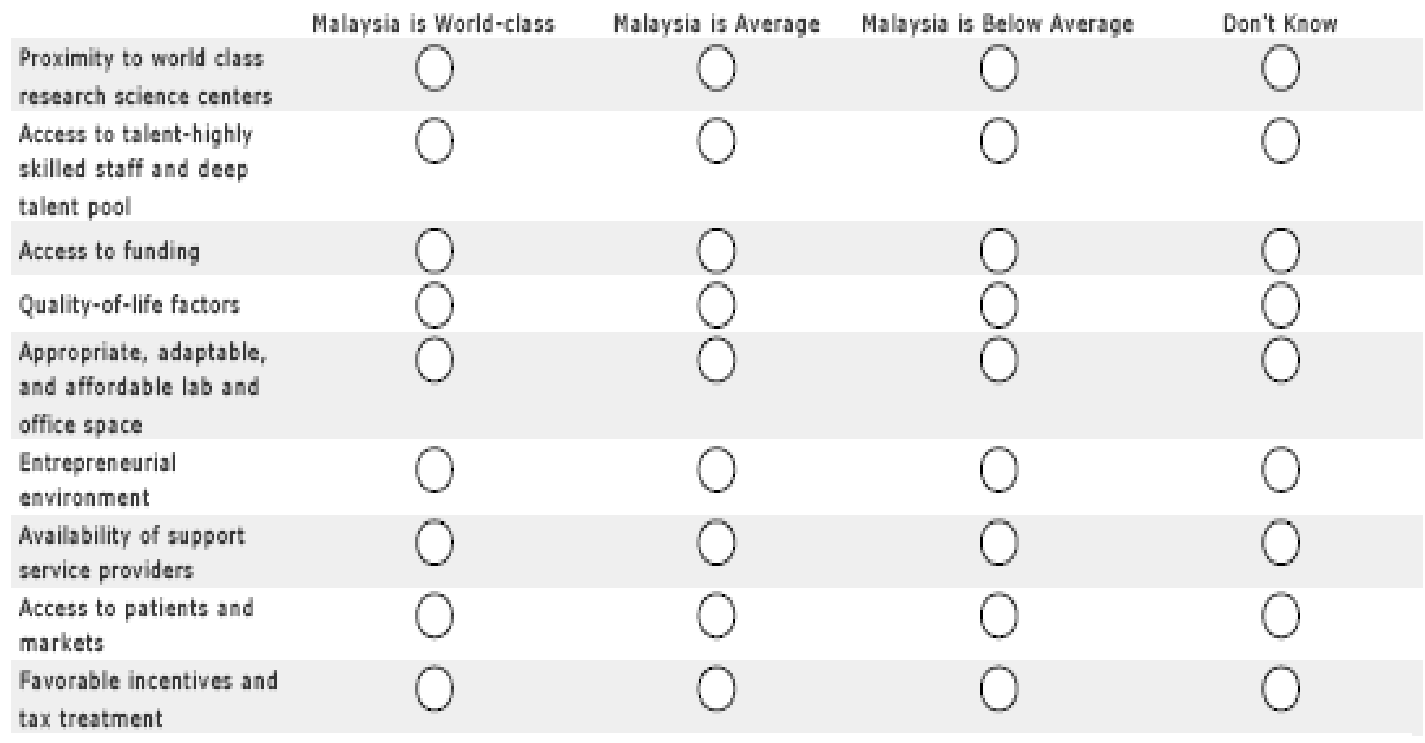

Other (please specify and rate how we're doing) 


\section{Biotechnology Priorities for Malaysia}

Please rate the following attributes in terms of importance to building a thriving biotech industry in Malaysia.

\section{Proximity to world class research science centres}

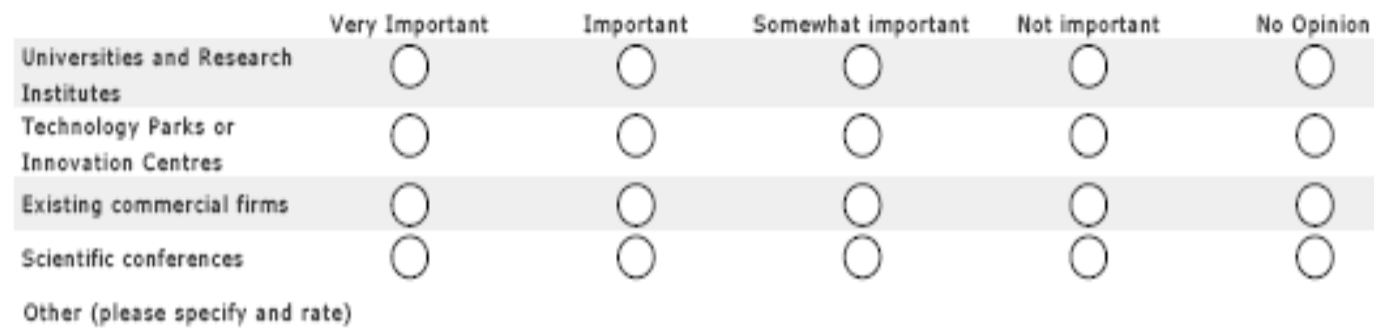

\section{Access to talent-highly skilled staff and deep talent pool}

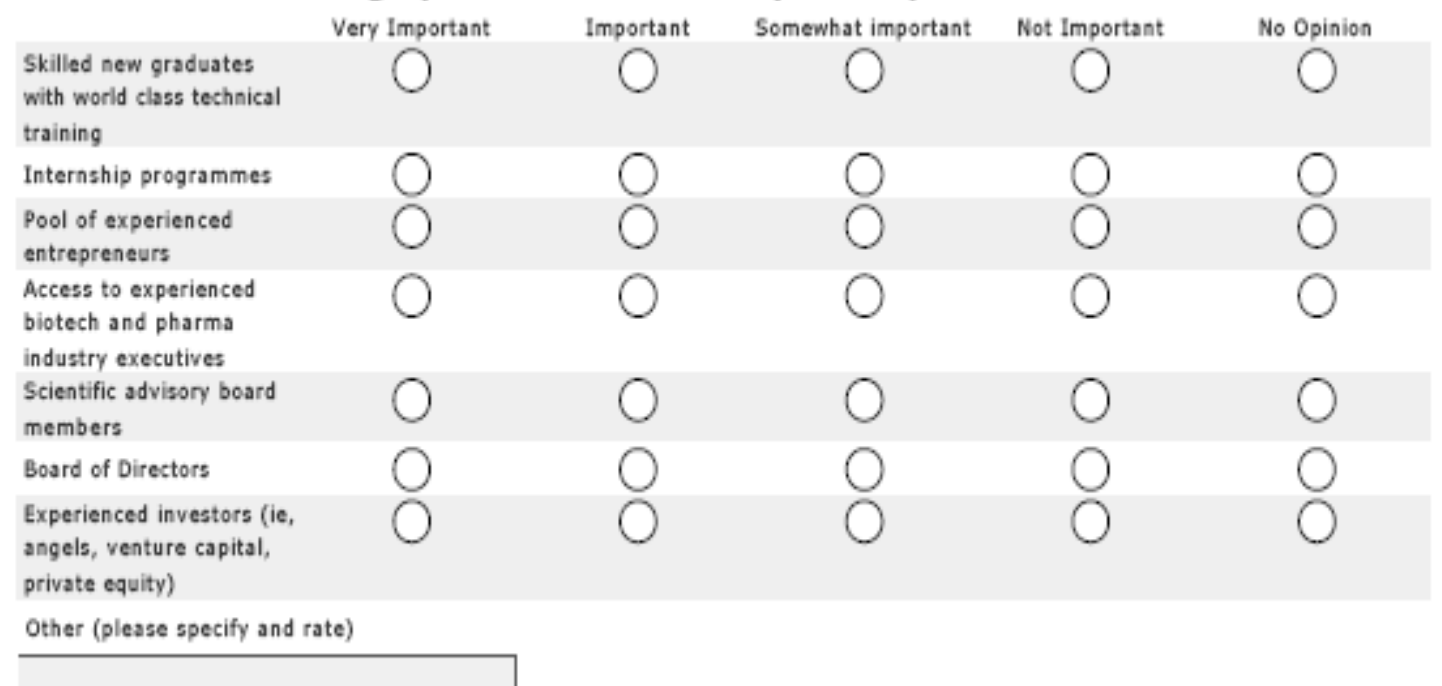

\section{Access to funding}

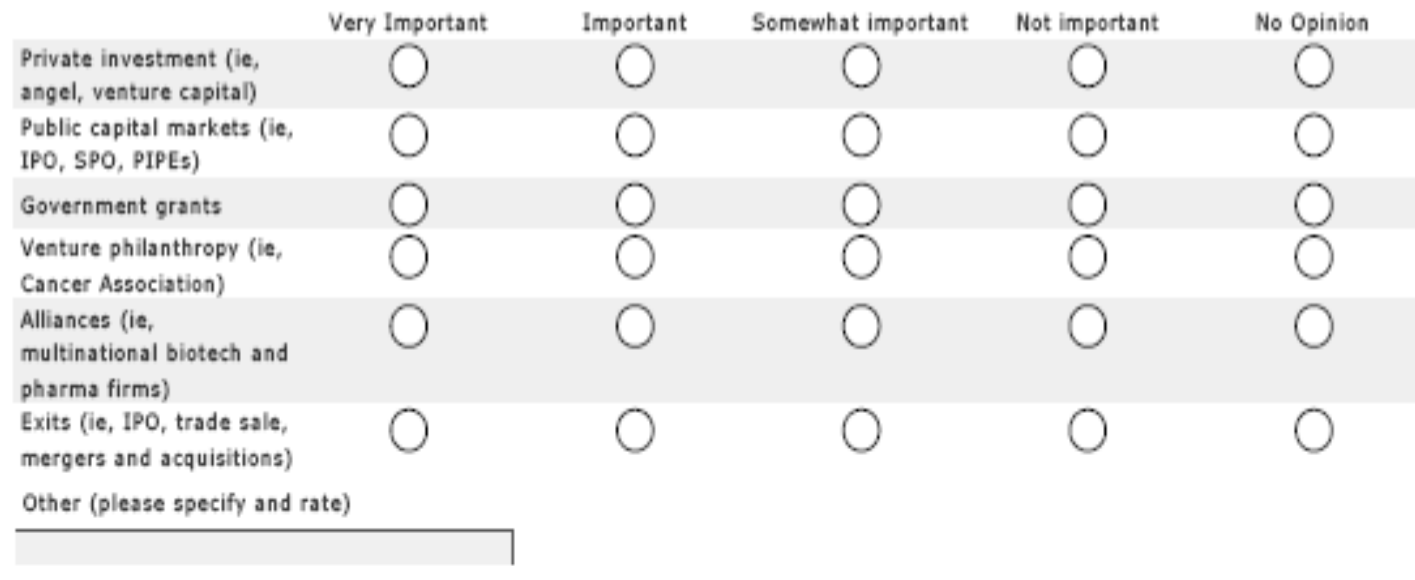




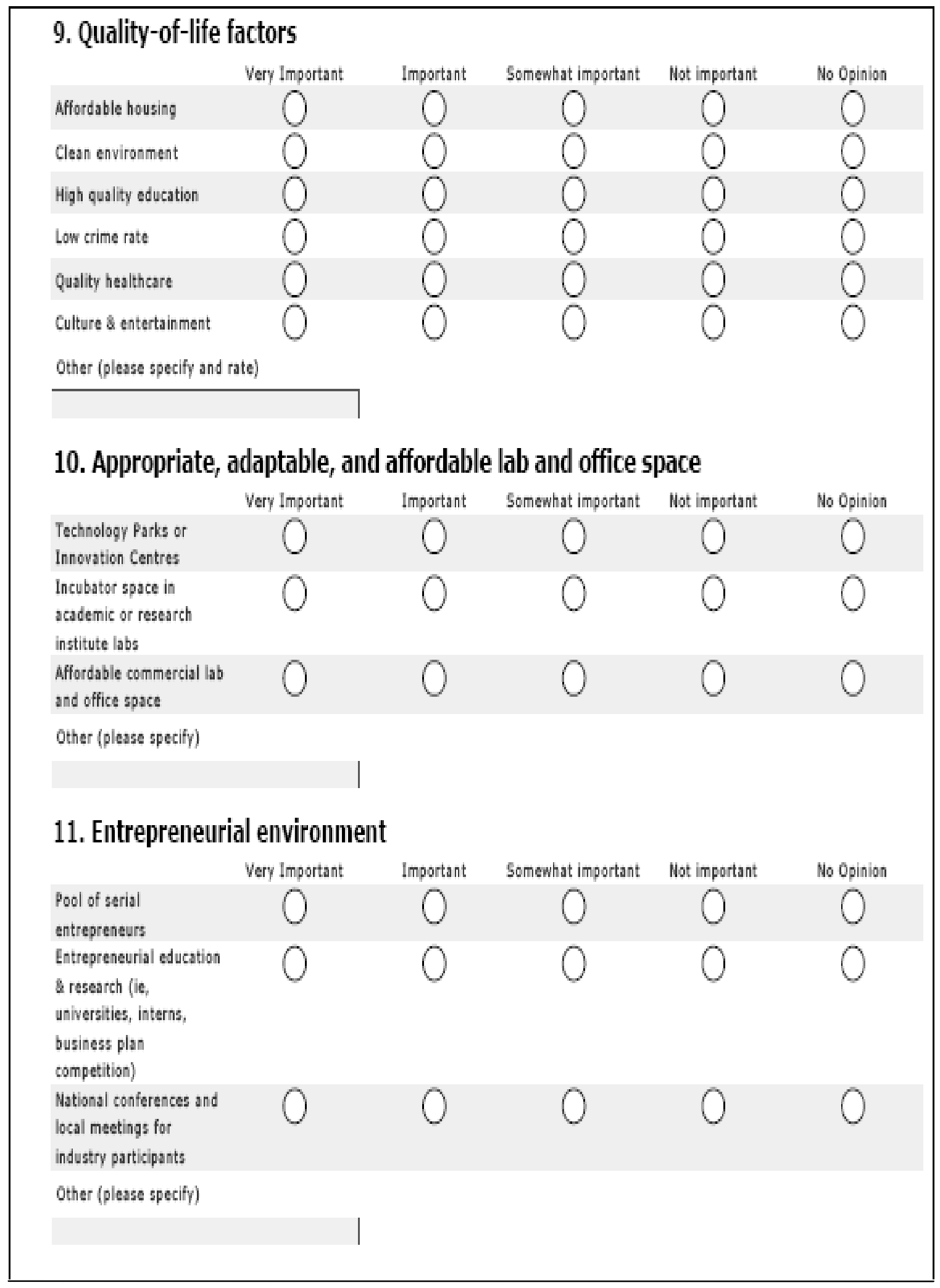




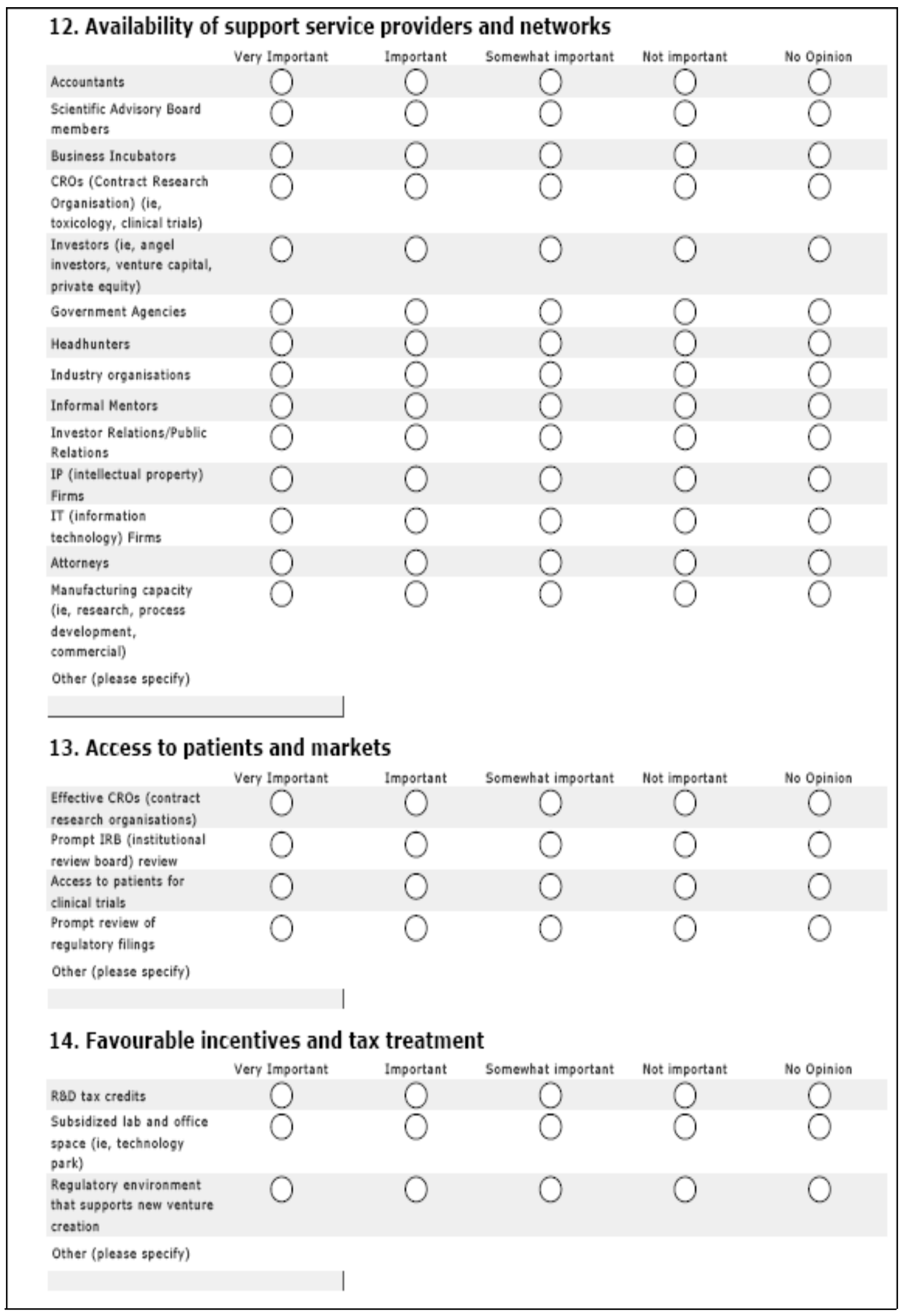




\section{Areas of focus for value creation and economic development in Malaysia}

Please rank the following areas of focus for promoting value creation and economic development for Malaysia

\section{Please RANK the following biotechnology industry AREAS OF FOCUS for value} creation and economic development in Malaysia from 1(highest priority) to 7 (lowest priority). Please note each number can only be used once.

$\begin{aligned} & \text { Agriculture (ie, vaccines) } 8 \\ & \text { food (ie, functional food, } \\ & \text { pesticide reduction) } \\ & \text { Biofuels (ie, ethanol) }\end{aligned}$
$\begin{aligned} & \text { Biosecurity } \\ & \text { Environment (ie, } \\ & \text { bioremediation) } \\ & \text { Human therapeutics \& } \\ & \text { diagnostics } \\ & \text { Medical devices }\end{aligned}$

Other (please specify)

16. How are we doing? Is Malaysia GLOBALLY COMPETITIVE in the following areas of focus?

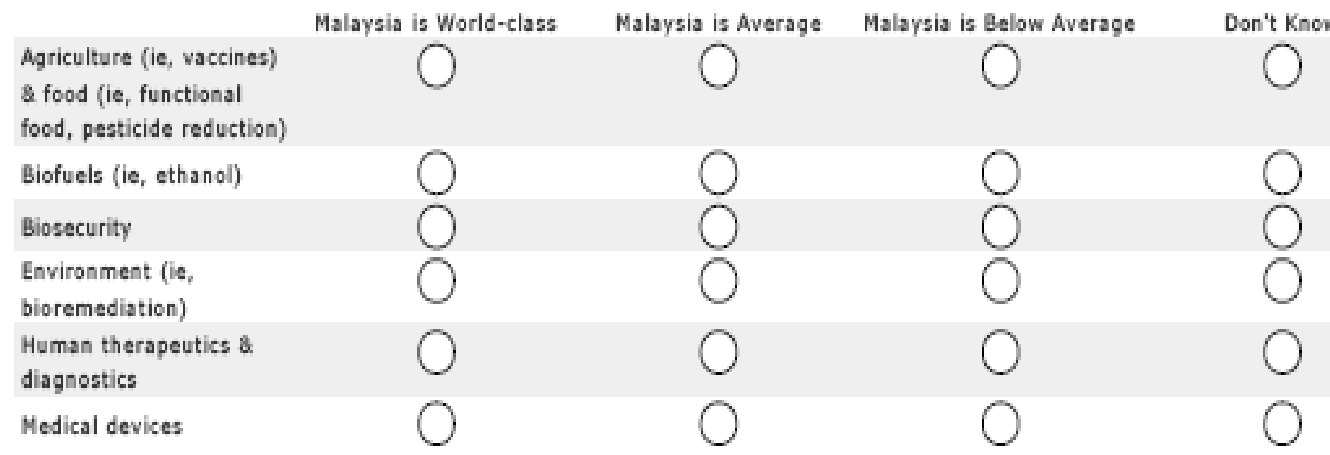

Other (please specify)

\section{Building Biotech Capabilities in Malaysia}

17. Any other advice for building biotech capabilities in Malaysia? Do you think there is anything different or unique about building biotechnology companies in/from Malaysia? 


\section{Thank you!}

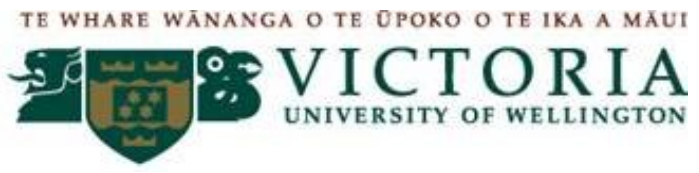

Thank you very much for your time in completing this survey which we hope will enhance biotech industry competitiveness in Malaysia. We appreciate your participation and leadership!

Please note that your information will be completely anonymous and shown only in aggregated form. For your participation we will send you a report of the combined results and

findings.

Sincerely yours,

Melvyn Loh, Masters of Commerce \& Administration Student, Victoria University

Mark J. Ahn, Professor \& Chair, Science \& Technology Entrepreneurship, Victoria University

Please direct any questions about the survey to:

Melvyn Loh

Masters of Commerce \& Administration Student

Faculty of Commerce \& Administration

Victoria University of Wellington

Email: melvyn.loh@vuw.ac.nz

Mark J. Ahn, PhD

Professor and Chair, Science \& Technology Entrepreneurship

Faculties of Commerce \& Administration and Science

Victoria University of Wellington

Email: mark.ahn@vuw.ac.nz 